No. 34

\title{
Ensayos sobre
}

ECONOMÍA CAFETERA

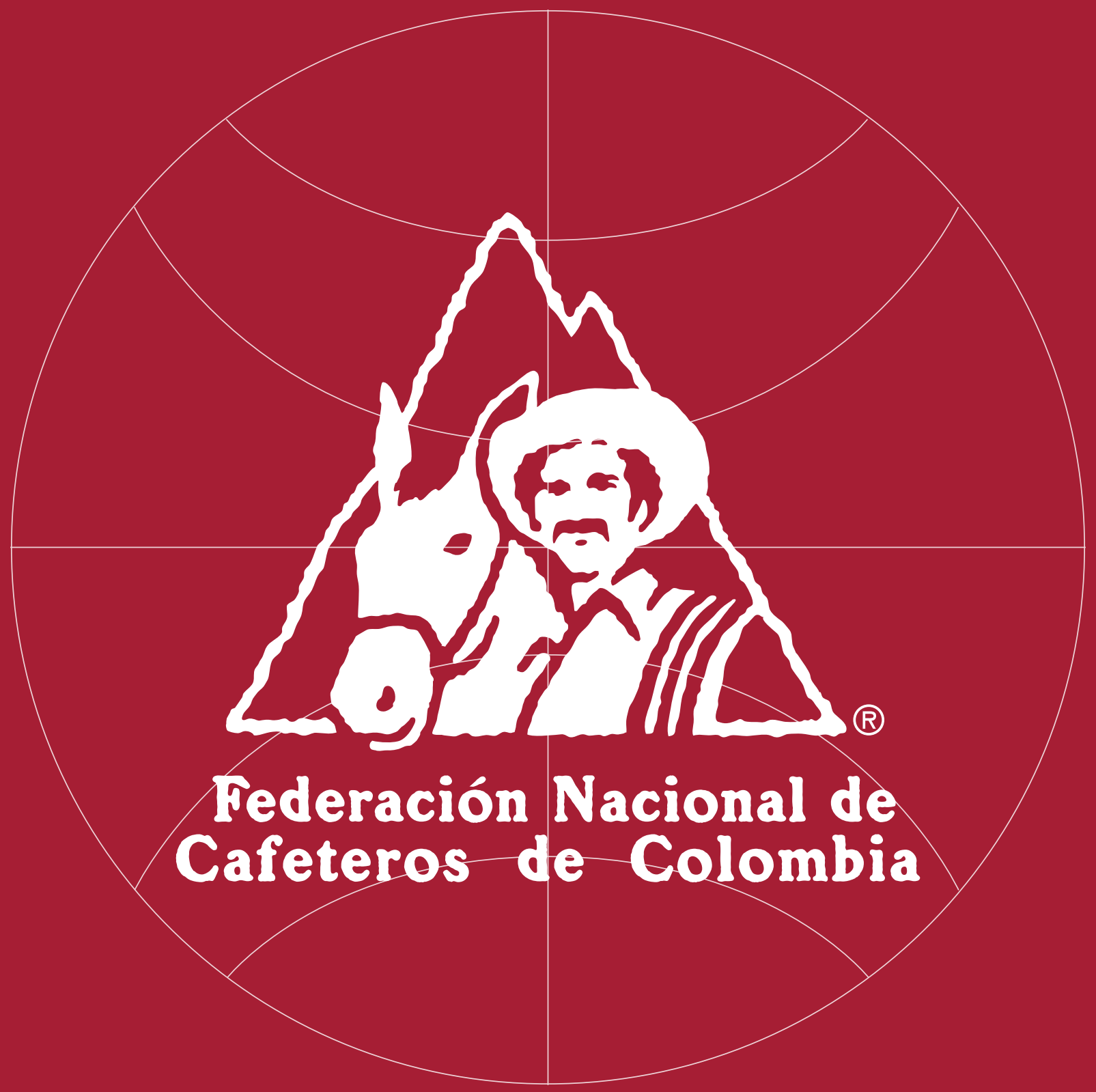




\section{Ensayos sobre ECONOMÍA CAFETERA}

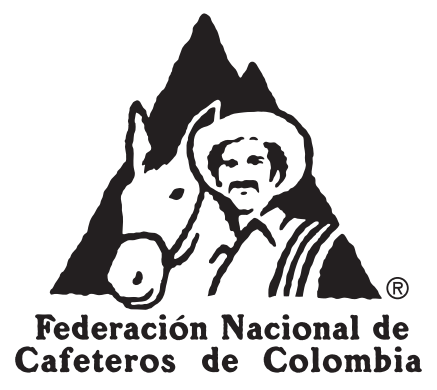





\section{Ensayos sobre ECONOMÍA CAFETERA}

DIRECCIÓN

Gerencia General Federación

CONSEJO EDITORIAL

Roberto Vélez Vallejo

Juan Camilo Becerra

Juan Camilo Ramos

Hernando Duque Orrego

Javier Mantilla Sánchez

COORDINACIÓN EDITORIAL

José Leibovich Goldenberg

Claudia Carolina Córdoba Currea

Mario Alberto Villamil Polo

José David Méndez Buitrago

Juan Manuel Izquierdo

Andrea Cárdenas Fernández

German Esteban Gutiérrez Poveda

Nancy González Sanguino

DIAGRAMACIÓN Y FOTOCOMPOSICIÓN

Formas Finales Ltda. consuelo.lozano@formas finales.com

Año 33 No. 34 2020-2021

La opinión de los colaboradores no compromete el pensamiento de la Federación Nacional de Cafeteros y es de su exclusiva responsabilidad
Presentación

Federación Nacional de Cafeteros de Colombia

Demografía, inclusión social y pobreza de los

hogares cafeteros (1993-2020)

Dirección de Investigaciones Económicas - FNC 7

La Cosecha asistida de café y su impacto en la economía de la recolección en finca

Juan Rodrigo Sanz Uribe

Hernando Duque Orrego

Álvaro León Gaitán Bustamante

Caracterización ambiental del sector cafetero en Colombia

Dirección de Investigaciones Económicas - FNC

Caracterización socioeconómica de los cafeteros que participaron en las elecciones gremiales del 2018

Dirección de Investigaciones Económicas - FNC 75 



\title{
PRESENTACIÓN
}

\author{
Federación Nacional de Cafeteros \\ Para citar este artículo: Federación Nacional de Cafeteros de Colombia. (2021). Editorial. \\ Ensayos sobre Economía Cafetera, 34(1), 5-6.
}

El presente número de la revista de Ensayos de Economía Cafetera llega a su edición no.34 con cuatro artículos de interés para los estudiosos e interesados en la economía cafetera colombiana

El primero titulado "Demografía, inclusión social y pobreza de los hogares cafeteros (19932020)" de Claudia Carolina Córdoba, José Leibovich y José David Méndez, miembros del equipo de la Dirección de Investigaciones Económicas de la Federación Nacional de Cafeteros hace un análisis exhaustivo de la estructura demográfica de los hogares cafeteros, analiza los principales indicadores de inclusión social de los mismos y se aproxima a la situación de pobreza de los caficultores y sus familias gracias a contar con el Sistema de Información de Hogares Cafeteros (SIHC) que se estructuró en el último año, gracias al convenio establecido entre la Federación Nacional de Cafeteros y el Departamento Nacional de Planeación que ha permitido el cruce información del Sistema de Información Cafetera (SICA) y el Sistema de Identificación y Clasificación de Potenciales Beneficiarios para Programas Sociales (SISBEN). Es la primera vez que se tiene una panorámica en es- tas materias de las últimas tres décadas donde se pueden ver los avances importantes, estancamiento relativo y retroceso en algunos indicadores sociales. Sin duda, este artículo sirve para poner en perspectiva los retos en materia social que la institucionalidad cafetera tiene que adelantar en los próximos años en conjunto con las entidades gubernamentales y la cooperación internacional.

El segundo artículo titulado "La cosecha asistida de café y su impacto en la economía de la recolección en finca" de Juan Rodrigo Sanz, Investigador de Cenicafé; Hernando Duque, Gerente Técnico de la Federación Nacional de Cafeteros y Alvaro Gaitán, Director de Cenicafé, explica cómo ante la escasez relativa de mano de obra para la recolección de café en una perspectiva futura, gracias al trabajo investigativo de Cenicafé se ha podido desarrollar un paquete tecnológico compuesto por la derribadora de granos de café DSC 18 y las lonas para la recolección que al utilizarlo en vez de la recolección tradicional con el "coco", se logran ganancias importantes en la eficiencia de la recolección del café y por lo tanto una reducción en los costos de producción que permiten aumentar la renta- 
bilidad del cultivo y remunerar mejor a los recolectores capacitados en esta tecnología. La adopción por parte de los caficultores de estas nuevas técnicas, en la medida que muestre sus beneficios se irá dando gradualmente.

El tercer artículo titulado "Caracterización socioeconómica de los cafeteros que participaron en las elecciones gremiales de 2028" de José David Méndez, Juan Manuel Izquierdo y Andrea Cárdenas, miembros del equipo de la Dirección de Investigaciones Económicas de la Federación Nacional de Cafeteros hace un análisis del perfil sociodemográfico de los caficultores que participaron y los que no lo hicieron en las elecciones gremiales de 2018. Igualmente se analiza el perfil de los cafeteros elegidos a los cuerpos colegiados en esas elecciones. El análisis incluye variables de contexto como son la participación electoral en elecciones para elegir alcaldes y concejales. También se analiza el impacto que tiene la mayor competencia electoral de listas de candidatos en la participación electoral y la inversión de la institucionalidad a nivel departamental. Del análisis realizado se concluyen las principales acciones que la institucionalidad cafetera debe adelantar en preparación de las próximas elecciones que se llevarán a cabo en 2022.

El cuarto artículo titulado "Caracterización ambiental del sector cafetero en Colombia" de José David Méndez, José Leibovich y Germán Gutiérrez de la Dirección de Investigaciones económicas de la Federación Nacional de Cafeteros analiza los principales indicadores en materia ambiental que presenta la caficultura colombiana y los hogares cafeteros a partir de información recogida en la encuesta de hogares cafeteros realizada en 2018'. Allí están recogidos indicadores sobre uso y contaminación del agua, conservación y uso del suelo, y protección de la biodiversidad. Sin duda, estos indicadores sirven para la construcción de la línea de base para avanzar en la estrategia ambiental de la Federación Nacional de Cafeteros.

La recolección de información de la Encuesta Nacional de Hogares Cafeteros fue realizada con recursos del Fondo Nacional de Café (FoNC). 


\title{
Demografía, inclusión social y pobreza de los hogares cafeteros (1993-2020)
}

\author{
Dirección de Investigaciones Económicas - Federación Nacional de Cafeteros de Colombia
}

\section{RESUMEN}

Este documento presenta la evolución de la demografía, la inclusión social y la pobreza de los hogares cafeteros, entre (1993-1997) y 2020. El artículo compara las estimaciones realizadas con datos del Censo Nacional Cafetero (1993-1997) con información para 2020, calculada a partir de los registros administrativos que forman parte del Sistema de Información de los Hogares Cafeteros (SIHC).

Los resultados de este estudio confirman, por una parte, los logros en inclusión social alcanzados por los hogares cafeteros desde la última década del siglo XX hasta las dos primeras del siglo XXI. Por otra parte, los resultados también ratifican las dificultades que hoy enfrentan los cafeteros para alcanzar un mayor bienestar y reducir los niveles de pobreza. Adicionalmente, el artículo confirma los riesgos que enfrenta el futuro de la caficultura, dadas las tendencias demográficas de largo plazo que dificultan el relevo generacional.

\section{ABSTRACT}

This paper focus on demographic, social inclusion and poverty evolution of colombian coffee households between (1993-1997) and 2020. The authors compare social and demographic indicators according to Colombian Coffee Census (1993-1997) statistics and 2020 administrative registers that constitute the Household Coffee Information System (SIHC).

Results confirm, on the one hand, social inclusion achievements of the last coffee household generation and, on the other hand, some difficulties coffee households face to improve their well-being and reduce poverty. Furthermore, the article shows that long-term demographic tendencies can thread coffee crops future, given the difficulties for generational succession that they face.

Palabras clave: Vulnerabilidad, Demografía, Inclusión Social, Hogares cafeteros, Condiciones de vida, Necesidades Básicas Insatisfechas (NBI), Pobreza Multidimensional, Bienestar

Códigos JEL: 132, O18, Q12

Key words: Vulnerability, Demography, Social Inclusion, Coffee Household, Quality of life, Unsatisfied Basic Needs (UBN), Multidimensional Poverty, Well-Being

JEL Codes: 132, O18, Q12 



\title{
Demografía, inclusión social y pobreza de los hogares cafeteros (1993-2020)
}

\author{
Dirección de Investigaciones Económicas - Federación Nacional de Cafeteros de Colombia' \\ Para citar este artículo: Federación Nacional de Cafeteros de Colombia. (2021). Demografía, inclusión social y \\ pobreza de los hogares cafeteros (1993-2020). Ensayos sobre Economía Cafetera, 34(1), 7-34.
}

\section{INTRODUCCIÓN}

En un documento publicado por la Cepal, (Rodríguez, 2001, pág. 18) definió la vulnerabilidad como "el conjunto de características no idiosincráticas que generan debilidad, desventajas o problemas para el desempeño y la movilidad social de las personas, hogares y comunidades". Estas características se pueden agrupar en un complejo de desventajas demográficas y sociales que, en conjunto, limitan el desarrollo humano.

Según (Rodríguez, 2000, pág. 15) la vulnerabilidad demográfica se define como un "conjunto de características demográficas de las unidades domésticas que, en el contexto de una sociedad moderna, limitan la acumulación de recursos" como la disminución del tamaño de la población y de los hogares, las altas tasas de dependencia demográficas, el envejecimiento de la población o las migraciones masivas.

Por su parte, PNUD (2015) definió las vulnerabilidades sociales, como las limitaciones $\mathrm{O}$ barreras al logro del bienestar. Desde la perspectiva de Sen (1999), el bienestar y la libertad se amplían cuando se logra acceder a un conjunto de bienes y servicios que les permiten a los individuos tener las capacidades para funcionar en la sociedad, para que puedan defenderse adecuadamente ante las adversidades, es decir, ser menos vulnerables y al mismo tiempo lograr definir y llevar a cabo sus proyectos de vida.

La definición de este conjunto mínimo de bienes depende de cada sociedad. Inspirados en los postulados de Sen, la Cepal (2017) pro-

Equipo de Investigación: Córdoba, C. (Claudia.Cordoba@cafedecolombia.com); Leibovich, J. (jose.leibovich@cafedecolombia.com); Méndez, J. D. (jose.mendez@cafedecolombia.com). 
puso como canasta mínima de bienestar un conjunto de bienes y servicios para la inclusión social. Esta canasta se compone del acceso a los servicios sociales de educación, protección social e infraestructura básica. Los servicios de protección social incluyen el acceso a la seguridad social en salud, la protección económica y social en la vejez, la garantía de un ingreso básico universal y el aseguramiento frente al desempleo. Por su parte, la infraestructura básica la conforma el acceso a viviendas adecuadas y a entornos saludables. Por esta razón, según DPS (2018) la superación del umbral de inclusión social puede entenderse como consistente con la superación de la pobreza.

Durante décadas, los avances en el bienestar y la reducción de la vulnerabilidad de los colombianos han estado ligados con el cultivo del Café. De acuerdo con Caballero (2016, pág. 130) el cultivo del café, desde sus inicios en la segunda mitad del siglo XIX, permitió rentabilidades aceptables en predios de tamaño menor a 2 hectáreas, lo que hizo posible la democratización de los recursos del Café y el acceso creciente a servicios sociales para poblaciones que antes eran excluidas y que son en su gran mayoría rurales.

Asimismo, la institucionalidad cafetera ha tenido un rol protagónico en el desarrollo rural en más de la mitad de los municipios del país. Su contribución se ha materializado a través de la construcción de obras de infraestructura comunitaria, domiciliaria y productiva. De acuer- do con los registros históricos de la Federación Nacional de Cafeteros (FNC), entre 1944 y 2015, la FNC gestionó recursos de inversión en infraestructura por cerca de $\$ 7,6$ billones de pesos, de los cuales el $61 \%$ se destinó principalmente al desarrollo de obras relacionadas con vivienda y servicios públicos; un 25\% a la construcción de vías y obras conexas, un $12 \%$ al desarrollo de instalaciones educativas, de salud y comunitarias y un $2 \%$ en infraestructura productiva (FNC, 2017, pág. 28).

Por esta razón, es importante tener diagnósticos actualizados que den cuenta, por un lado, de los avances en inclusión social y superación de la pobreza de los hogares cafeteros y, por otro lado, que visibilicen las vulnerabilidades demográficas y sociales que limitan el logro de un mayor bienestar para la población cafetera.

La FNC, entre 1993 y 1997, levantó el Gran Censo Cafetero con inclusión de variables sociodemográficas ${ }^{2}$. Este censo se convirtió en la línea base para el seguimiento de las dimensiones sociales de los hogares cafeteros. Para su actualización se han usado las encuestas a hogares y agropecuarias oficiales del gobierno nacional, más el uso de encuestas con seguimiento exclusivo en la población cafetera.

Esta investigación tiene como objetivo presentar un diagnóstico actualizado de las vulnerabilidades demográficas y de inclusión social de los hogares cafeteros, a partir de la 
combinación de cuatro fuentes administrativas que forman parte del Sistema de Información de los Hogares Cafeteros (SIHC) y que hasta el momento no han sido explotadas simultáneamente en una sola investigación: 1) El Sistema de Información Cafetera (SICA) de la FNC, 2) El Sistema de Identificación y Clasificación de Potenciales Beneficiarios para Programas Sociales (Sisbén III homologado a la versión IV-DNP) ${ }^{3}$, 3) El Registro Social de Hogares (RSH-DNP) y 4) El registro de cafeteros con cotización a BEPS de Colpensiones ${ }^{4}$.

El análisis de esta información y su comparación con la línea base del Censo de 1993 1997, permitió conocer que los hogares cafeteros son cada vez más pequeños, menos rurales, con mayor presencia de población adulta, con mejor educación y condiciones habitacionales. En ellos, sigue siendo muy importante la figura masculina que predomina ampliamente, tanto en la jefatura de la producción como en la jefatura del hogar. Asimismo, el estudio puso en evidencia el acceso exitoso que ha tenido la población cafetera a los mecanismos de protección social de Colombia por el aseguramiento en salud y el acceso a la Red de transferencias monetarias del gobierno nacional.

No obstante, la evolución de los indicadores revela que, debido al menor tamaño de la po- blación cafetera, la atracción de los jóvenes hacia las ciudades y la disminución de niños en los hogares, el relevo generacional puede estarse viendo comprometido en las próximas décadas. Además, continúan existiendo barreras para acelerar las mejoras en el logro educativo, especialmente, las orientadas al acceso en educación superior y las que pueden impulsar el mejoramiento de algunos aspectos críticos en las condiciones habitacionales.

En términos globales, y de acuerdo con la información del Sisbén y el Registro Social de Hogares, en 2020, el 54,4\% de los productores cafeteros se encontraba en la pobreza 0 era vulnerable y el $65,2 \%$ pertenecía a un hogar beneficiario de Transferencias Monetarias del Gobierno Nacional, lo que evidencia, de nuevo, el reto de seguir trabajando por lograr un mejor bienestar del caficultor al tiempo que se consolidan los avances alcanzados.

A continuación, se presenta el balance de los estudios más relevantes que han dado cuenta de los indicadores demográficos, de inclusión social y pobreza para la población cafetera. En la tercera sección, se resume la situación demográfica, de inclusión social y pobreza de los hogares cafeteros con desagregación departamental para el año 2020; en la cuarta sección se muestra la evolución de los indicadores, tomando como línea base el Censo Nacional

3 El DNP inició el barrido del Sisbén IV en el año 2018, no obstante, la base fue publicada el 5 de marzo de 2021. Para aprovechar la información actualizada durante los años 2018-2020, el DNP compartió con la FNC, el Sisbén III en su versión homologada al Sisbén IV, es decir actualizó todas las variables de Sisbén con la última información suministrada en el Sisbén IV.

4 La combinación de estos registros administrativos fue posible gracias a la celebración de dos Convenios de Intercambio de información confidencial. El CN-2019-1627, realizado entre el Departamento Nacional de Planeación y la Federación Nacional de Cafeteros y el CN 2019-0006 entre Colpensiones y la Federación Nacional de Cafeteros. 
Cafetero 1993-1997; y en el quinto apartado, se presentan las conclusiones del estudio.

\section{LOS ESTUDIOS SOBRE DEMOGRAFÍA E INCLUSIÓN SOCIAL DE LA POBLACIÓN CAFETERA}

La FNC realizó el primer Censo Nacional Cafetero, con inclusión de variables sociodemográficas entre 1993 y 1997. Esta primera línea base se incorporó al Sistema de Información Cafetera SICA que sigue manteniéndose. Para ese entonces, se registraron 566.230 unidades de producción con 423.368 hogares y 1.972.736 habitantes de estos hogares cafeteros. En ellos predominaban los hombres (53\%) y habitaban en promedio 5 personas.

Los menores de edad en los hogares cafeteros representaban el $45,0 \%$, los adultos entre 18 y 60 años participaban con el $47,5 \%$ y los adultos mayores de 60 años conformaban el 7,5\% de la población cafetera. Los departamentos con mayor proporción de adultos mayores eran: Cundinamarca (13,4\%), Boyacá $(10,9 \%)$ y Nariño $(9,7 \%)$.

El nivel educativo de la población cafetera era bajo, el 23,3\% de la población cafetera no sabía leer ni escribir, el 21,0\% no tenía educación y el $69,5 \%$ sólo había logrado cursar algún nivel de primaria, 8,9\% algún nivel de secundaria y sólo el 0,4\% tenía educación superior. La inasistencia escolar también era alta, el 18,7\% de los niños entre 7 y 11 años y el $58,1 \%$ de los niños entre 12 y 17 años no asistían a ningún centro educativo.

El Censo (93-97) también evidenció importantes privaciones en las condiciones habitacionales de los hogares cafeteros. El 31,2\% de las viviendas no tenía acceso a conexión eléctrica, el 63,8\% no tenían acueducto, $39,4 \%$ no tenía ninguna solución de saneamiento básico, 94,1\% carecían de alcantarillado y $97,7 \%$ no disponían de conectividad, entendida como la tenencia de teléfono fijo.

Con esta información se lograron conocer importantes brechas en los niveles de calidad de vida entre los departamentos cafeteros, por ejemplo, mientras los hogares cafeteros de Antioquia, Caldas, Cundinamarca y Quindío ya habían alcanzado tasas de acceso a energía eléctrica superiores al 90\%, los hogares cafeteros en departamentos como La Guajira y Cesar no alcanzaban el 5\%.

En línea con lo anterior, según los resultados del Censo (93-97), los departamentos con mejor estándar de vida, medido por el $\mathrm{NBI}^{5}$, eran: Quindío, Caldas, Risaralda y Valle. Por el contrario, los departamentos con mayores necesidades básicas insatisfechas eran: La Guajira, Cesar, Norte de Santander y Boyacá.

En 2004, la FNC, en colaboración con el Centro de Estudios Regionales Cafeteros y Empresariales (CRECE) y de los Consultores 
de Estudios Socioeconómicos (CES), emprendió la elaboración y ejecución de la Gran Encuesta sobre Condiciones de Vida en los Hogares Cafeteros (CVC), en (FNC-CRECE-CES, 2005) y (CES, 2005) con el fin de hacerle seguimiento intercensal a estos indicadores.

La encuesta se realizó a 14.176 hogares, representativos de 512.303 hogares cafeteros y 2.166 .455 personas (19\% de la población rural). El 91,4\% de estos hogares vivía en el área rural dispersa, $6,0 \%$ en los centros poblados y $2,6 \%$ en las áreas urbanas.

El tamaño promedio del hogar cafetero, había caído a 4,2 personas por hogar. Los análisis de la composición por edades de los miembros del hogar, mostró que los hogares cafeteros presentaban un nivel de envejecimiento mayor, en comparación con el promedio rural. En efecto, para los hogares cafeteros, la población menor de 14 años era de $28,2 \%$, mientras que, para el promedio rural era de 37,6\%. Así mismo, la proporción de personas mayores de 60 años en los hogares cafeteros ascendió a 14,1\%, mientras que para el promedio rural era de apenas $8,6 \%$.

Los resultados del estudio (FNC-CRECE-CES, 2005), pusieron en evidencia que los largos periodos de precios bajos del café, pudieron haber afectado los niveles de calidad de vida de los hogares cafeteros. Esta afirmación se sustentó en el hecho de que, en 2004, el Índice de Condiciones de Vida (ICV) para los cafete- ros registró un valor menor que el de la población rural en general (35,3 puntos versus 39,5 puntos) ${ }^{6}$. Además, el $71,9 \%$ de los hogares cafeteros obtuvo un ICV inferior a 40 puntos.

En 2004 los departamentos cafeteros con mejor estándar de vida, medido por el ICV, fueron Quindío, Valle, Risaralda y Caldas; en contraste, en el grupo de los más rezagados se encontraron La Guajira, Cesar, Norte de Santander y Magdalena.

Por componentes del ICV, el estudio encontró que las tasas de analfabetismo eran menores para los hogares cafeteros, "lo cual refleja que en algún momento la escolaridad del cafetero estuvo por encima de la persona promedio"(CES, 2005, pág. 11)

En cuanto a la afiliación en salud, el estudio mostró que el $72,9 \%$ de los cafeteros se encontraba afiliado, en comparación con el $51,7 \%$ del promedio rural, y de éstos, el 91\% pertenecía al régimen subsidiado (para el promedio rural, esta proporción era de 72,9\%).

Estos resultados, se compararon con la línea base del Censo de la Población Cafetera 1993-1997 incorporado en el SICA, encontrando progresos importantes en los indicadores de analfabetismo, conexión a acueductos, energía eléctrica y hacinamiento crítico; no obstante, se presentaron pocos avances en la calidad de los pisos de las viviendas y la conectividad (también medida por la tenencia

6 El ICV es un índice compuesto estandarizado entre cero (mínimo nivel de bienestar) y 100 (máximo nivel de bienestar), estimado a partir de 24 variables relativos a las condiciones de vida y la vulnerabilidad del hogar. 
de teléfonos fijos en las viviendas). Aunque la asistencia escolar (primaria y secundaria) tuvo una variación pequeña durante el periodo de estudio, la asistencia creció en todos los departamentos cafeteros, ubicándose la mayoría en un rango alto de asistencia.

En 2009, (Leibovich \& Botello, 2009) realizaron un análisis de los cambios demográficos en los municipios cafeteros y su relación con los cambios en la caficultura colombiana, a partir de la información de los Censos Nacionales de Población y Vivienda de 1993 y 2005.

Los autores estimaron un crecimiento poblacional en los departamentos cafeteros de $1,32 \%$, explicado principalmente por el crecimiento de la población urbana. La población en el área rural se mantuvo constante $(0,04 \%)$ con importantes diferencias entre los departamentos. Por ejemplo, las áreas rurales de La Guajira y Huila incrementaron su población a una tasa anual promedio de 5,3\% y $1,2 \%$ respectivamente en el período comprendido entre 1993 y 2005; por el contrario, las zonas rurales de los departamentos de Caldas $(-1,20 \%)$, Boyacá $(-1,15 \%)$, Quindío $(-1,0 \%)$ y Tolima $(-0,8 \%)$ perdieron población.

Los autores también encontraron evidencia del envejecimiento de la población en los municipios cafeteros, explicado por el descenso de las tasas de mortalidad y el aumento de la esperanza de vida. Entre 1993 y 2005 la población mayor de 65 años en los departamentos cafeteros creció su participación del $4 \%$ al $6 \%$, mientras que los menores de 15 años cayeron del 35 al 30\%. Los departamentos con mayor adelgazamiento de su pirámide poblacional fueron Antioquia, Caldas, Quindío, Risaralda, Tolima y Santander, en respuesta, principalmente, a la alta emigración.

Leibovich y Botello (2009), también confirmaron la mayor presencia de población masculina en el área rural de todos los departamentos cafeteros, con un promedio de 112 hombres por cada 100 mujeres. Los departamentos con mayor proporción de hombres fueron Quindío, Cesar, Magdalena, Norte de Santander y Santander. Por último, la tasa de dependencia demográfica, definida como la relación entre las personas en edades no productivas $^{7}$ con respecto a las que están en edad productiva se estimó en $72,7 \%$ en las áreas rurales de los departamentos cafeteros, reflejando una alta dependencia.

En 2018, la FNC con los investigadores Marcela Aguinaga y José Leibovich, analizaron la vulnerabilidad de los hogares cafeteros identificados en el Censo Nacional Agropecuario (CNA) de 2014, usando el Índice de Pobreza Multidimensional ajustado 8 .

\footnotetext{
Edades no productivas: menores de 14 y mayores de 65 años. Edad productiva: entre los 15 y los 65 años.

3 El Índice de Pobreza Multidimensional Ajustado tiene 10 de las 15 variables del Índice de Pobreza Multidimensional oficial. Estas variables se distribuyen en 4 dimensiones de la siguiente manera: i) Educación: analfabetismo y bajo logro educativo; ii) Condiciones de la niñez y la juventud: rezago escolar, inasistencia escolar, barreras al cuidado de la primera infancia; iii) Salud: Aseguramiento en salud; iv) Condiciones de la vivienda y servicios públicos: acceso a agua mejorada, inadecuada eliminación de excretas, material inadecuado de pisos y material inadecuado de paredes. 
Se habla de hogares identificados debido a que la unidad de análisis en el CNA-2014 fue la Unidad de Producción Agrícola (UPA); por lo tanto, se consideraron hogares cafeteros aquellos que habitaban en predios de más de 0,25 hectáreas sembradas de café. Las personas que hacen parte de estos hogares se denominaron la población cafetera ${ }^{9}$. De esta manera, con el CNA se identificaron 207.344 hogares con una población de 706.963 personas $(13,7 \%$ de la población censada).

Los resultados de las variables demográficas confirmaron los hallazgos de los estudios anteriores: en los hogares cafeteros predominaban los hombres, la población se estaba envejeciendo y la dependencia demográfica continuaba siendo alta. Ambos fenómenos se presentaron con mayor intensidad en la población cafetera en comparación con el resto de la población rural.

De las personas identificadas en las UPA's cafeteras, el $53,5 \%$ eran hombres y $46,5 \%$ mujeres; en el total rural nacional estas proporciones eran del $51,7 \%$ y $48,3 \%$, en su orden. Por su parte, la tasa de envejecimiento de la población cafetera se estimó en 38\%, es decir, por cada 38 adultos mayores de 65 años, había 100 niños en los hogares cafeteros. Esta relación era del 35,4\% para el rural nacional. Así mismo, la tasa de dependencia demográfica registró un valor de 55,5\% y la del rural total $56,6 \%$, mostrando que, si bien la población cafetera era más vieja, presentaba una menor dependencia demográfica por el menor número de niños.

El $46 \%$ de las personas en la UPA's cafeteras se encontraban en situación de pobreza multidimensional, proporción alta, aunque relativamente menor, en comparación con la de las personas promedio en la ruralidad (IPM de 48,1\%). Además, se evidenció una relación negativa entre la tasa de pobreza y la intensidad del cultivo.

Los datos del CNA reiteraron las fuertes deficiencias en el logro educativo de los hogares cafeteros que incluso los ubicaron en desventaja con respecto al resto de la población rural $^{10}$. Por ejemplo, el 88,3\% de los hogares presentaron bajo logro educativo ${ }^{11}$ y el $11,5 \%$ inasistencia escolar ${ }^{12}$, para el resto de los hogares rurales esta proporción era del $84,9 \%$ y $10,4 \%$, respectivamente.

También se reafirmó que los hogares cafeteros habían alcanzado un mayor acceso a la seguridad social en salud y habían logrado mejores condiciones habitacionales que el promedio de la población rural. Apenas el 8,2\% de los

9 Esta característica particular de identificación del Censo Agropecuario generó resultados contraintuitivos en las variables de educación, debido a que, por ejemplo, en las fincas de mayor tamaño el residente habitual es el mayordomo y su familia, no el productor y sus parientes.

10 Esta hipótesis también fue confirmada por el investigador Mateo Uribe-Castro en el paper "Café y desarrollo industrial en Colombia: Nuevos datos y conclusiones" https://uribecastro.files.wordpress.com/2019/11/uribecastro_imp_coffee-6.pdf

11 Un hogar presenta bajo logro educativo cuando los miembros mayores de 15 años, tienen en promedio menos de 9 años de educación.

12 Un hogar presenta inasistencia escolar cuando al menos un niño del hogar entre los 6 y los 16 años no asisten a un centro educativo. 
hogares cafeteros tenían algún miembro sin seguro de salud, la proporción de hogares con pisos inadecuados era del $24,3 \%$, sin acueducto $59,5 \%$ y sin alcantarillado $(94,1 \%)^{13}$.

En complemento, también en 2018, la FNC realizó la Encuesta Nacional de Caracterización Socioeconómica y Ambiental de los Hogares Cafeteros (ENHC-2018) entre 2.477 productores, representativos de 545.279 hogares cafeteros. La encuesta fue diseñada para que sus resultados fueran representativos para las cinco regiones cafeteras ${ }^{14} y$ cuatro tamaños del cultivo ${ }^{15}$. Los hallazgos se contrastaron con promedios del Censo $\mathrm{Na}$ cional Agropecuario (CNA).

Para 2018, la mayoría de los productores tenían sus predios en la región del Sur $(39,8 \%)^{16}$ y su tamaño del predio era menor a una hectárea $(51,4 \%)^{17}$. En cuanto a la composición demográfica, la ENHC- 18 ratificó que el cultivo del café era predominantemente masculino, superando incluso el $80 \%$ de productores hombres en los cultivos de café de más de 10 hectáreas.

El envejecimiento de la población también se hizo evidente junto con la necesidad urgente de reforzar las políticas para el empalme generacional. Para ese entonces, la edad promedio de los productores cafeteros era de 52 años, 4 años mayor que la registrada por los demás productores agrícolas, con el agravante que sólo $43,2 \%$ de los productores cafeteros declararon vincular cotidianamente a sus hijos en el aprendizaje del cultivo.

La ENHC-18 arrojó que los caficultores colombianos presentaron una tasa de alfabetismo mayor (91\%) que el resto de productores rurales (83\%). No obstante, el productor cafetero tenía sólo en promedio 4,9 años de estudio, equivalentes a la primaria completa, lo que de nuevo señaló los grandes retos para mejorar el logro educativo en la población cafetera. A diferencia de los resultados con el CNA-2014, los años de educación alcanzados por los hogares sí mostraron una correlación positiva con el tamaño del cultivo.

Otro hallazgo destacable fue la baja afiliación de los productores a algún régimen pensional, sólo el $8,8 \%$ de los productores cafeteros contaba con algún tipo de afiliación, a pesar que, casi la totalidad, 97\%, de los productores cafeteros estaban asegurados por algún régimen de seguridad social en salud.

13 La privación por alcantarillado es particularmente alta debido a que el CNA no contempló soluciones alternativas para la eliminación de excretas como la tenencia de pozos sépticos y que en el IPM oficial son consideradas como alternativas válidas para el hogar rural.

14 Regiones cafeteras: Sur (Huila, Cauca, Nariño y Caquetá); Eje Cafetero (Antioquia, Caldas, Risaralda, Quindío y Valle del Cauca); Centro (Tolima, Cundinamarca y Meta); Oriente (Santander, Boyacá, Norte de Santander y Casanare); y Norte (La Guajira, Cesar y Magdalena) Se excluyeron los departamentos de Bolívar, Putumayo y Chocó.

15 Tamaños del cultivo: Micro: Menos de 1 hectárea, Pequeños: Entre 1 y 5 hectáreas, Medianos: Entre 5 y 10 hectáreas y Grandes: Más de 10 hectáreas.

16 Distribución de los productores por regiones: Sur 39,8\%, Eje cafetero 29,4\%, Centro 17,0\%, Oriente 11,0\%.

17 Distribución de los productores por tamaño del cultivo: Micro 51,4\%, Pequeños 45,1\%, Medianos 2,6\% y Grandes 2,9\%. 
Según la ENHC-18, los caficultores también mostraron tener mejores condiciones habitacionales. Apenas para el $12 \%$ sus viviendas tenían pisos en tierra o arena, en comparación con el $28 \%$ de los otros productores rurales; el 39\% de las viviendas cafeteras no contaban con servicio de acueducto y $85 \%$ no tenían alcantarillado.

Por último, el estudio señaló que elevar el ingreso cafetero era otro de los grandes desafíos para el sector, debido a que el $60 \%$ de los hogares encuestados declararon que sus ingresos solo les alcanzaban para cubrir sus gastos mínimos y el $40 \%$ de los productores cafeteros declaró que se consideraba pobre.

SITUACIÓN DEMOGRÁFICA, DE INCLUSIÓN SOCIAL Y POBREZA DE LOS HOGARES CAFETEROS CON DESAGREGACIÓN DEPARTAMENTAL PARA EL AÑO 2020

El Sistema de Información de Hogares Cafeteros (SIHC) fue creado por la FNC para mejorar el seguimiento a la estrategia de valor del gremio cafetero en los ámbitos sociales, ambientales y de gobernanza. La información y los indicadores de SIHC se presentan a escala departamental y municipal y cubre a los productores cafeteros y los miembros de sus hogares. $\mathrm{El} \mathrm{SIHC}$ se nutre de varios registros administrativos externos e internos, cuyo nodo principal es la información del productor cafetero del Sistema de Información Cafetera SICA ${ }^{18}$.
El SIHC, como sistema de información, tiene varias ventajas con respecto a las fuentes usadas en los diagnósticos previos. En primer lugar, permite hacer comparaciones confiables entre la población cafetera y la no cafetera en todas las zonas (urbanas y rurales); en segundo lugar, hace posible obtener resultados a escala departamental y municipal, información que estaba ausente para la planificación de los Comités departamentales de la Federación; tercero, permite tener estadísticas confiables no sólo de los productores sino también de todos los miembros del hogar cafetero, y cuarto, facilita la microfocalización de los hogares, convirtiéndose en una herramienta poderosa para pasar del diagnóstico al desarrollo de acciones concretas para la diminución de las vulnerabilidades.

De acuerdo con la información del SIHC, para enero de 2020, en Colombia había 540.362 productores, los cuales viven en 483.389 hogares con una población estimada de 1.498.526 personas. El $82 \%$ de esta población potencial se encuentra registrada en el Sisbén. Se encontró una alta correspondencia en municipios muy cafeteros como Nariño $(91,6 \%)$, Huila $(91,2 \%)$, Antioquia $(90,6 \%)$, Santander $(88,2 \%)$, Boyacá $(86,7 \%)$, Tolima $(86,6 \%)$, Cundinamarca $(79,3)$, Risaralda $(76,5 \%)$ y Caldas $(74,3 \%)$.

Si bien, la alta correspondencia con el Sisbén, ya garantizaba estimadores confiables, se diseñó un factor de expansión a partir de la po-

18 Actualmente, el SIHC combina 7 registros administrativos: la información personal del caficultor SICA con la información del Sisbén, el Registro Social de Hogares, la base de cafeteros con cotización a BEPS de Colpensiones, el acceso a la tarjeta/cédula cafetera, el Censo electoral cafetero y la pertenencia a cooperativas. 
blación de productores registrada en el SICA y su probabilidad de pertenecer al Sisbén ${ }^{19}$. Para esto se usaron las variables de área cultivada en café (ha), tenencia de sombrío en el cultivo, juventud del cultivo, sexo y edad del productor, participación municipal de la población en el Sisbén y puntaje promedio del municipio en el Sisbén. De esta manera, todos los resultados estimados en este estudio representan al total de la población cafetera. El $82,9 \%$ de los hogares cafeteros residen en el área rural y $17,1 \%$ en el área urbana
(Gráfico 1). Esta fotografía consolida al café como uno de los productos con importante arraigo en la ruralidad, que, además, genera un alto valor económico.

De otra parte, se encontró un número no despreciable de hogares que viven del cultivo del café, pero que residen en las grandes ciudades, destacándose Bogotá con 5.873, Ibagué 5.331, Medellín 3.654, Neiva 3.206, Cali 3.229 y Manizales 2.358, dando luces de las importantes conexiones económicas entre el

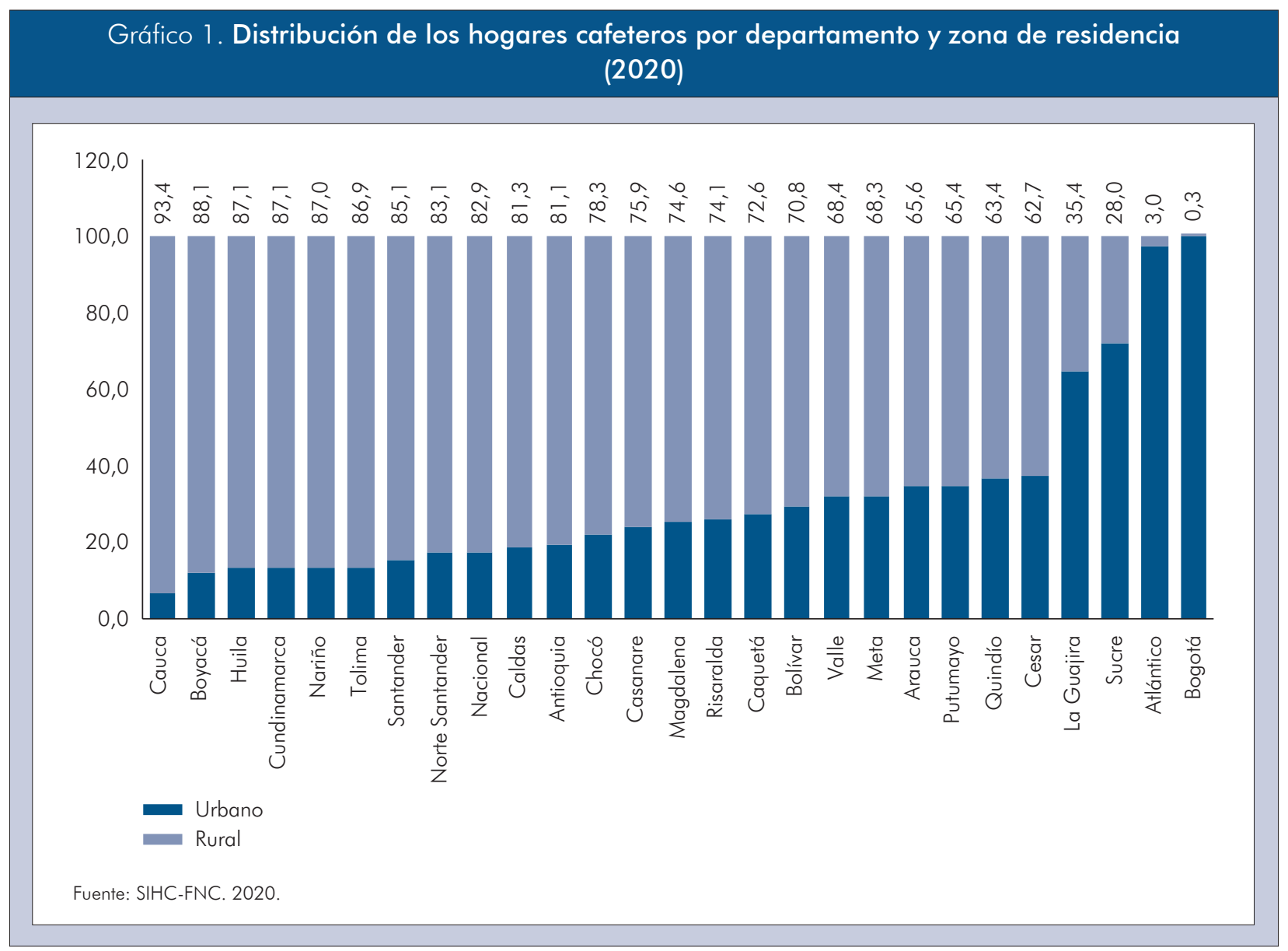

19 La estimación de la probabilidad se realizó usando un modelo Melogit en dos niveles, con el fin de incluir variables a nivel del productor y a nivel del municipio. 
campo y la ciudad que se manejan con los recursos del café.

Es importante anotar que en departamentos con alta tradición cafetera como Cauca, Boyacá, Huila, Cundinamarca, Nariño y Tolima los hogares residentes en el área rural son mayores a las de la media nacional.

\section{Demografía de los hogares cafeteros}

La población cafetera sigue siendo predominantemente masculina (Gráfico 2), el 54, $1 \%$ de los miembros en hogares cafeteros son hombres, mientras que el 45,9\% son mujeres. Este predominio masculino es mucho más intenso en comparación con el resto de hogares rurales no cafeteros que se encuentran el Sisbén ${ }^{20}$.

Por su parte, la jefatura femenina, la cual históricamente ha sido menor, tanto en las áreas urbanas como en las áreas rurales y persistentemente más baja en las áreas rurales, es aún menor en los hogares cafeteros. En ellos, apenas el 24,9\% de ellos tienen como jefe a una mujer (Gráfico 3), esta proporción es menor al del resto de los hogares rurales no cafeteros $(31,6 \%)$. Además, departamentos con alta tradición cafetera, revelan tener las tasas de jefatura femenina más bajas, este es el caso de Caldas (19,0\%), Huila $(21,6 \%)$, Antioquia $(21,9 \%)$ y Tolima $(22,1 \%)$.

El tamaño promedio del hogar cafetero continúa decreciendo, en 2020 se estimó en 3,1 miem-

\section{Gráfico 2. Distribución de los miembros de los hogares por sexo}

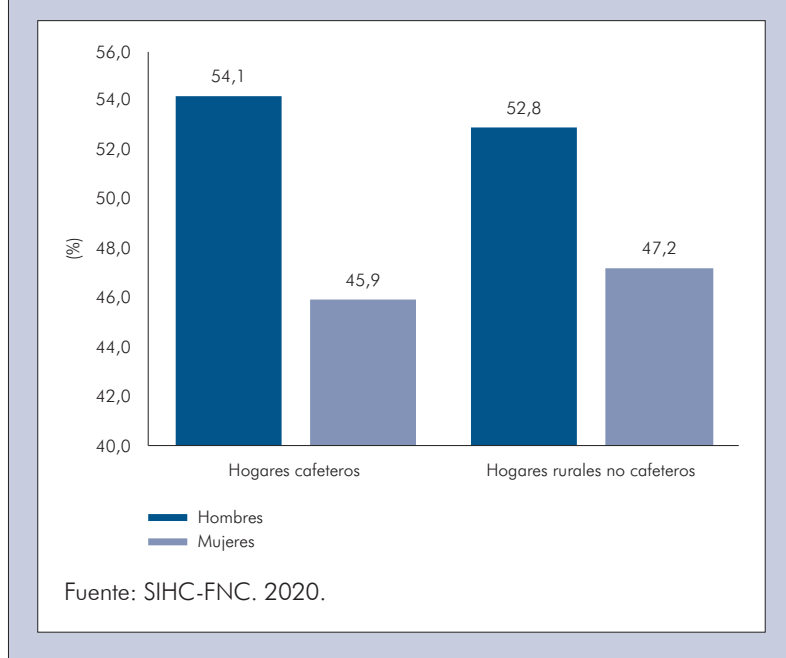

bros por hogar (Gráfico 4). Los hogares cafeteros de la zona norte son en promedio más grandes, destacándose Magdalena, Cesar y Atlántico. En contraste, los hogares más pequeños se encuentran en Cundinamarca, Putumayo, Quindío y Meta. Todo parece indicar que las grandes familias cafeteras ya son cosa del pasado.

La pirámide poblacional en los hogares cafeteros continúa adelgazándose al tiempo que la parte más alta de la pirámide se ensancha, revelando el mayor envejecimiento de la población cafetera. La población menor de 28 años representa el 43,5\%, este mismo grupo en los hogares rurales no cafeteros alcanza el 56,5\%. Entre tanto, la población mayor de 60 años en los hogares cafeteros es del $16,5 \%$ en comparación con el 10,6\% de los hogares rurales no cafeteros.

20 Incluso se observa esta mayor intensidad cuando se compara con el Censo Nacional de Población y Vivienda del año 2018. La distribución entre hombres mujeres en los hogares rurales era del $51,8 \%$ versus $48,2 \%$. 


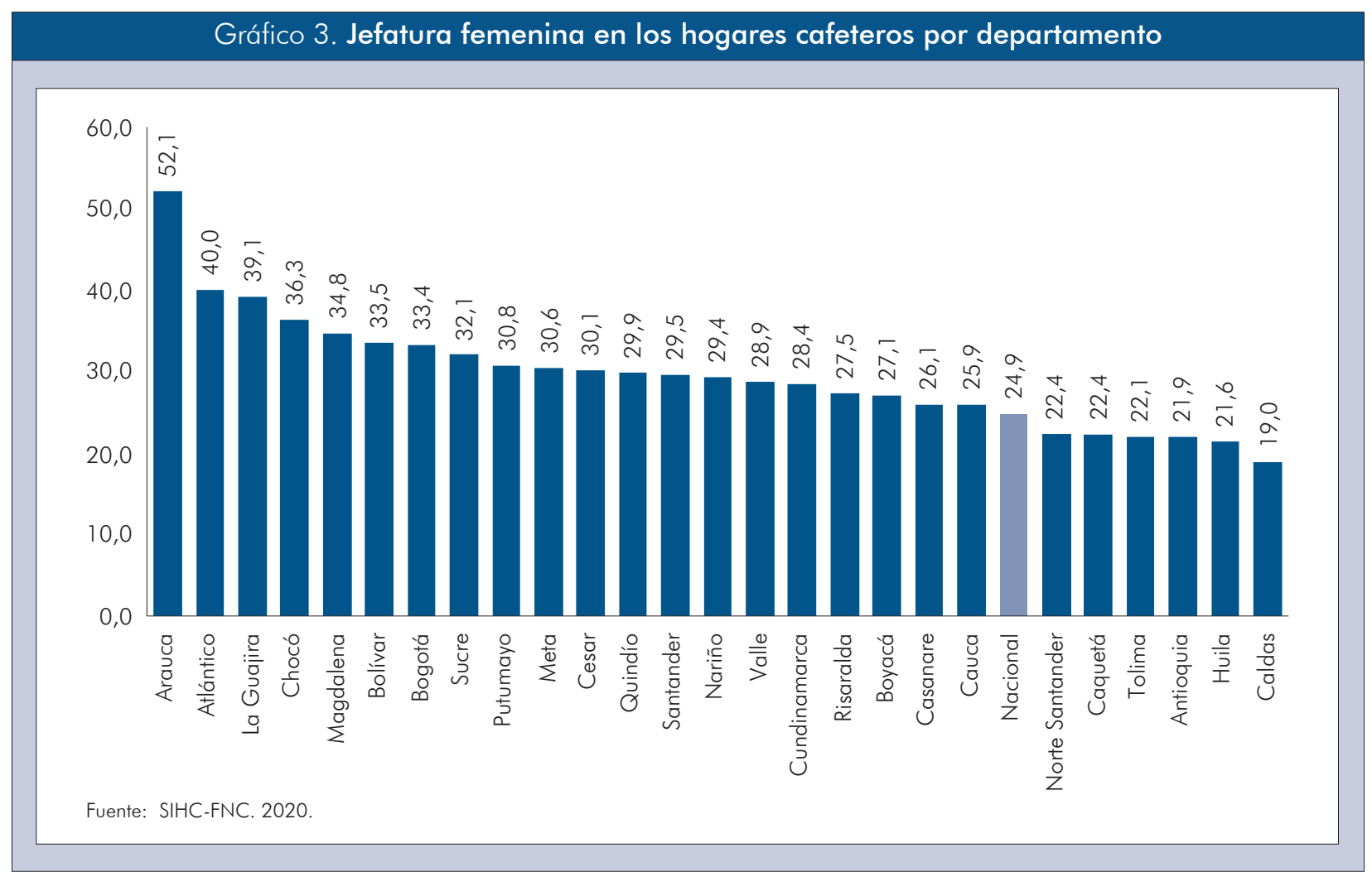

Gráfico 4. Tamaño del hogar cafetero por departamento

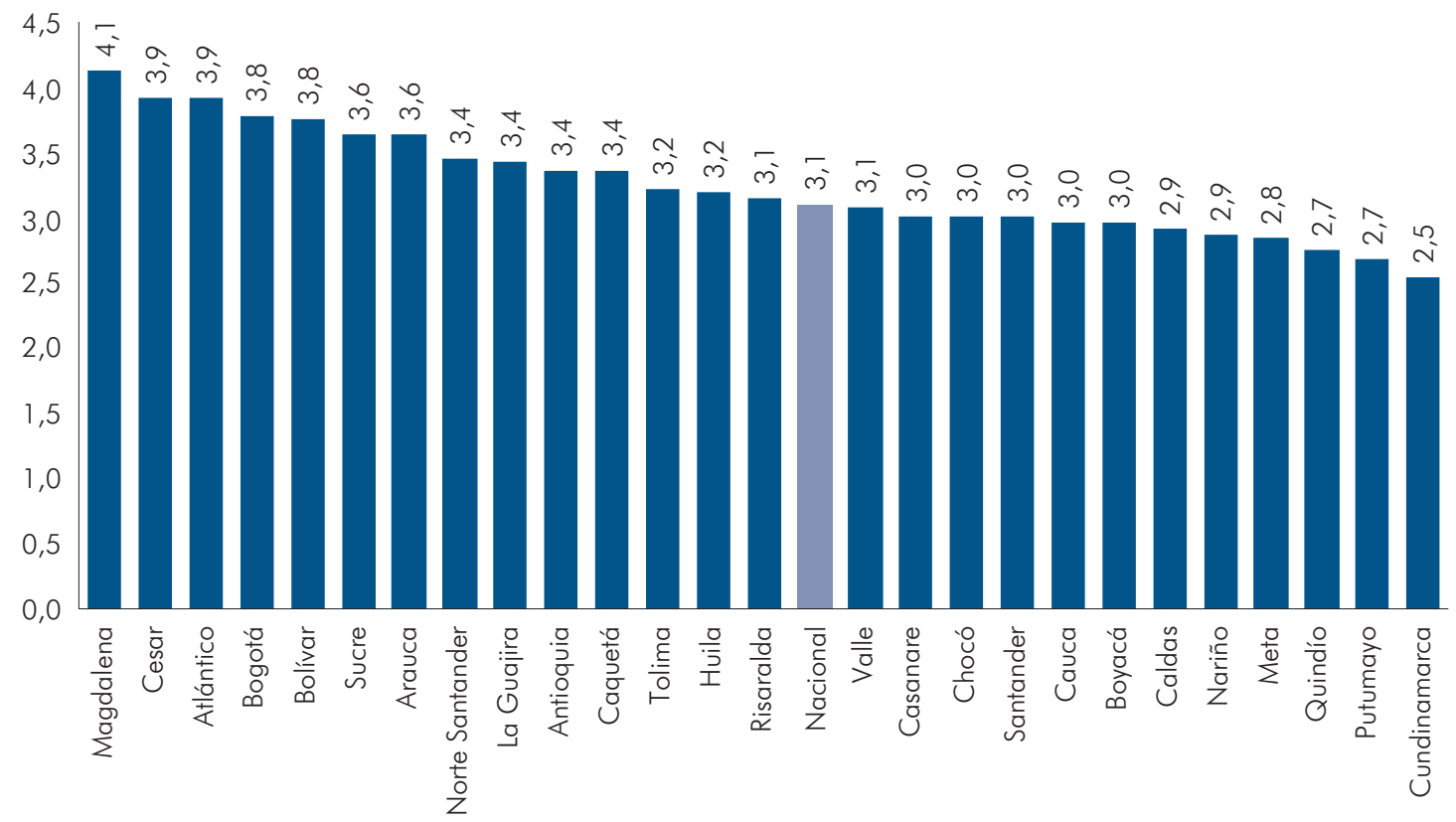

Fuente: SIHC-FNC. 2020. 
Estas diferencias en la pirámide poblacional también se reflejaron en la tasa de envejecimiento. Para la población cafetera este indicador tomó

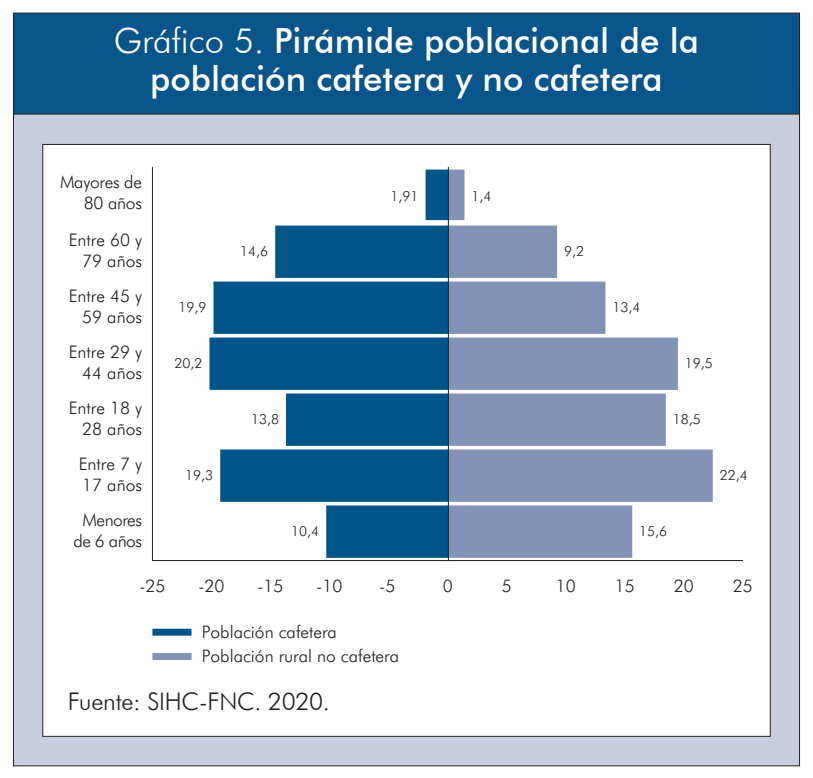

un valor de $44 \%$ (44 adultos mayores por cada 100 niños), en comparación con el 23\% de la población rural no cafetera. No sólo esta proporción fue más alta en los hogares cafeteros, sino que además se encontraron tasas extremadamente altas en los departamentos de Quindío (1 14\%), Cundinamarca (104\%), Nariño (85\%) y Caldas (78\%). Lo anterior, marca importantes retos de mediano plazo para el empalme generacional de la caficultura (Gráfico 6).

A pesar de que la tasa de envejecimiento es mayor para los hogares cafeteros, en comparación con los hogares rurales no cafeteros, su dependencia demográfica es menor, 52\% para los cafeteros y $59 \%$ para los rurales no cafeteros, esto en respuesta a la menor presencia de niños en los hogares cafeteros.

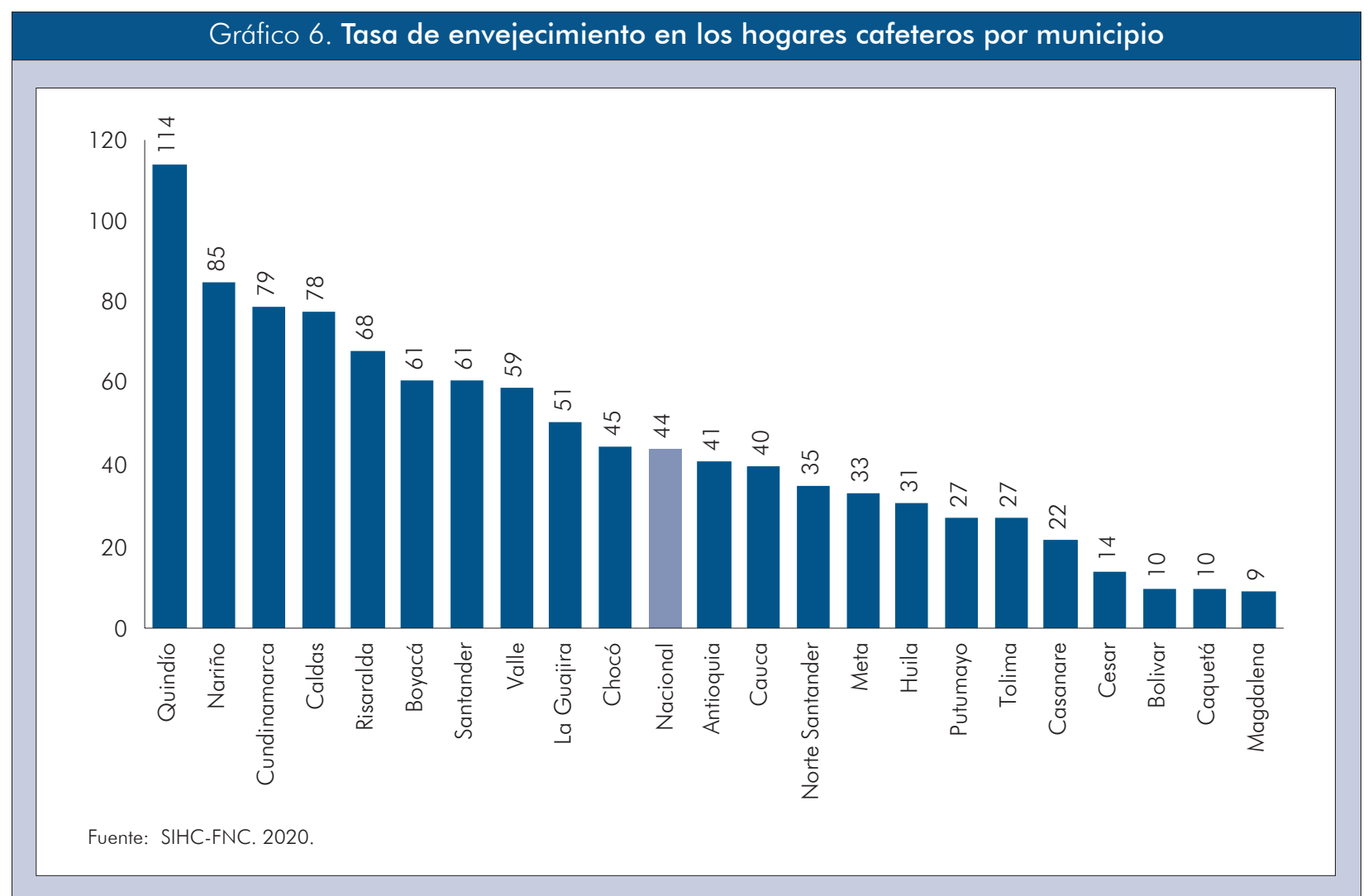




\section{Inclusión Social de los hogares cafeteros}

\section{Educación}

El logro educativo ha avanzado, pero muy lentamente, en comparación con los estudios de décadas anteriores. Para 2020, El 10,7\% de los miembros en los hogares cafeteros registró no tener ningún grado de educación formal, 57,0\% apenas había alcanzado la educación primaria, 27,6\% habían logrado la educación secundaria y media y sólo el 2,8\% tenía educación superior.

Al comparar los niveles educativos por separado para jóvenes y adultos en los hogares cafeteros, lo predominante es la educación primaria en la población adulta. Es importante tener presente que esta población es mayor de 28 años, ya se educó en el sistema formal, y salvo la existencia de algunos programas de educación flexible, no tiene grandes posibilidades de avanzar en este tipo de educación. Por el contrario, para los jóvenes (entre 18 y 28 años), lo predominante comienza a ser la superior: técnica/tecnológica o universitaria.

Esto revela que a nivel intergeneracional ha habido una mejora en el nivel educativo. No obstante, la primaria sigue teniendo un peso bien importante y el nivel educativo "ninguno" todavía sigue presente. Esto tiene que ver con la políitica pública nacional de educación, en donde la educación rural siempre ha estado relegada a un segundo lugar, dado que la población mayoritariamente vive en las ciudades y la política educativa se ha focalizado en los centros urbanos.
Como indicador complementario al nivel educativo, se evaluó la inasistencia escolar. En el 6,8\% de los hogares cafeteros hay niños que no asisten a la escuela, proporción menor que en los hogares rurales no cafeteros $(11,7 \%)$. Sin demeritar que la inasistencia escolar deba erradicarse, su valor actual muestra el compromiso de los hogares cafeteros con la educación de los más pequeños, la menor prevalencia del trabajo infantil en la población cafetera y los posibles efectos de la pertenencia de estos hogares a programas con Más Familias en Acción. Es importante tener presente algunas diferencias importantes entre departamentos, en especial, debido a los altos índices de inasistencia escolar en Atlántico, Caquetá, Magdalena y Bolívar.

\section{Protección Social}

Seguridad Social en salud

$87,7 \%$ de los miembros en los hogares cafeteros se encuentra afiliado a algún sistema de seguridad social en salud. $78,3 \%$ está afiliado al régimen subsidiado y $9,4 \%$ al régimen contributivo, sin duda, es uno de los principales logros en inclusión social que han alcanzado los hogares cafeteros. Se espera que con la nueva coyuntura de vacunación para la Covid-19, la brecha de afiliación que a 2020 asciende a 12,3\%, se cierre aún más.

\section{Acceso a las Transferencias Monetarias}

De acuerdo con Cepal (2017), las transferencias monetarias proveen un piso de protección social a las personas que viven en situación de 
pobreza y vulnerabilidad. En la medida que los hogares tienen asegurados niveles mínimos de subsistencia, es menos probable que el hogar recurra a estrategias de sobrevivencia como el trabajo infantil o la migración definitiva de uno de los miembros del hogar.

\section{Gráfico 7. Nivel educativo de jóvenes y adultos por municipio}

Nivel educativo de adultos

(mayores de 28 años)

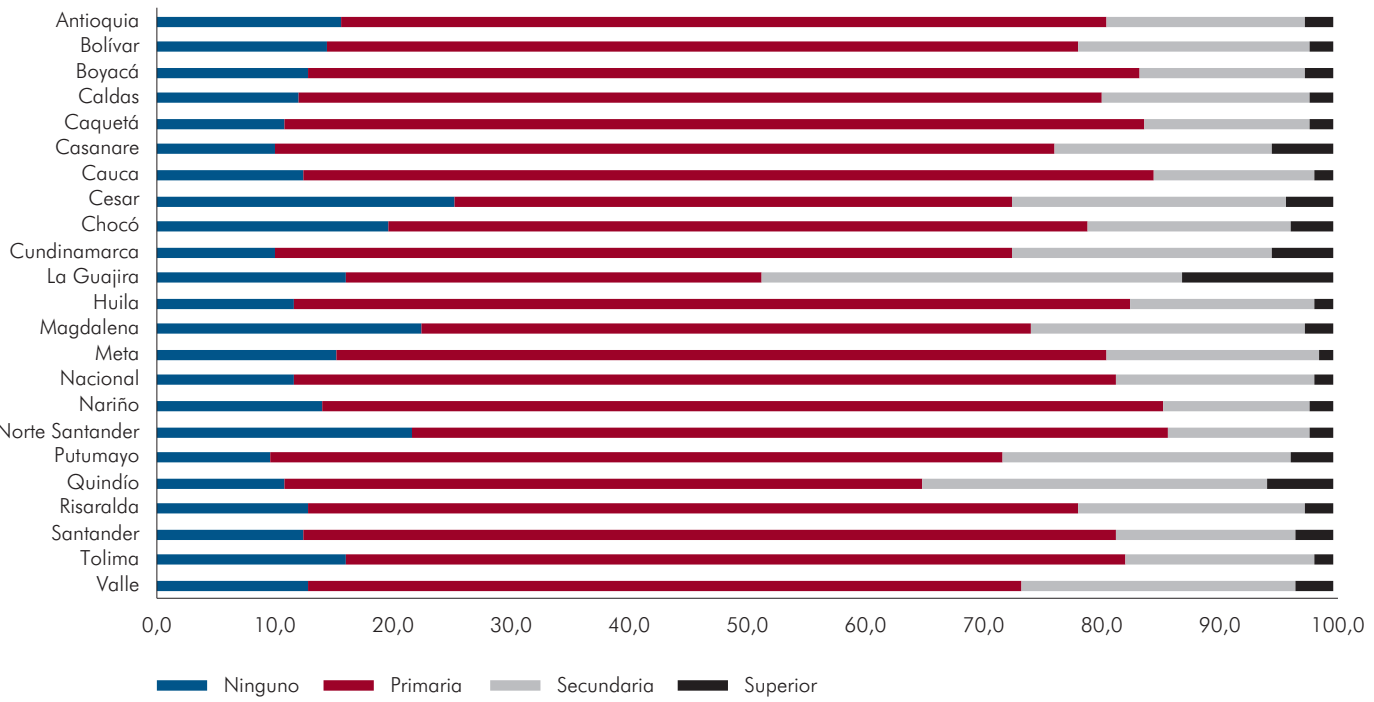

Nivel educativo de jóvenes

(entre 18 y 28 años)

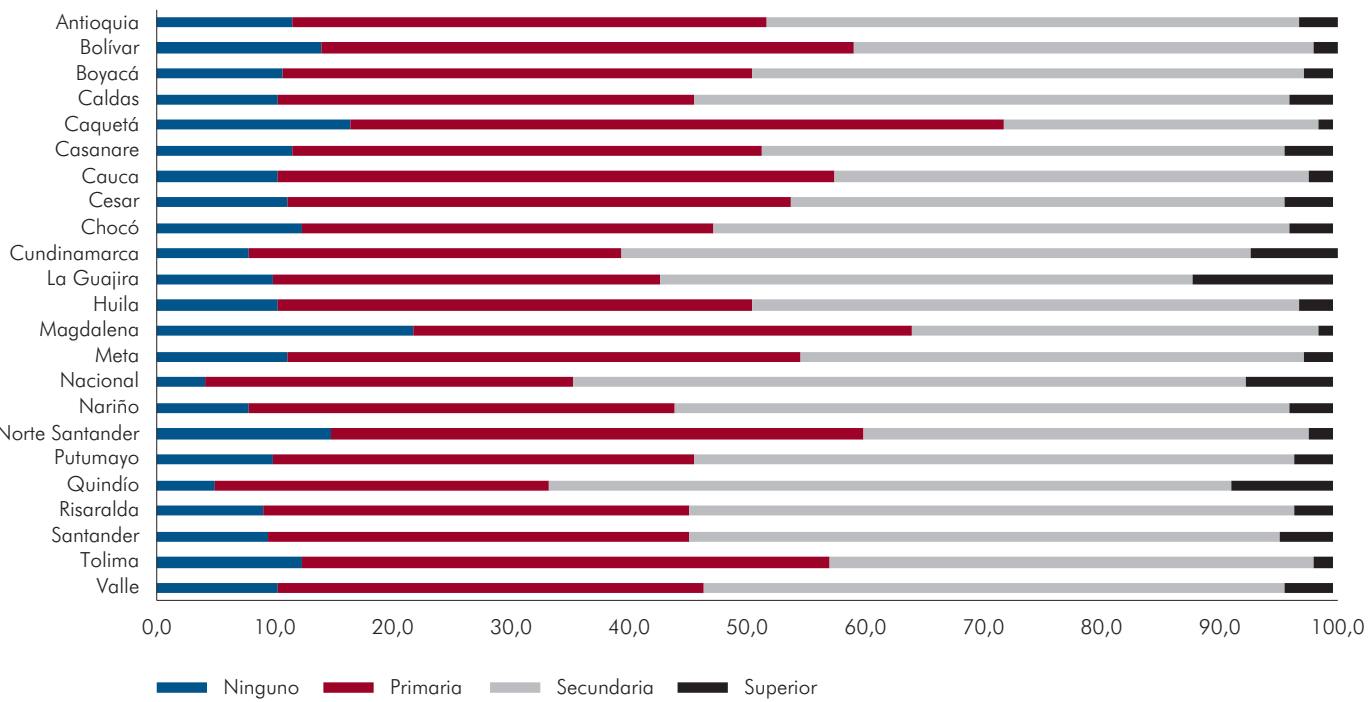

Fuente: SIHC-FNC. 2020 


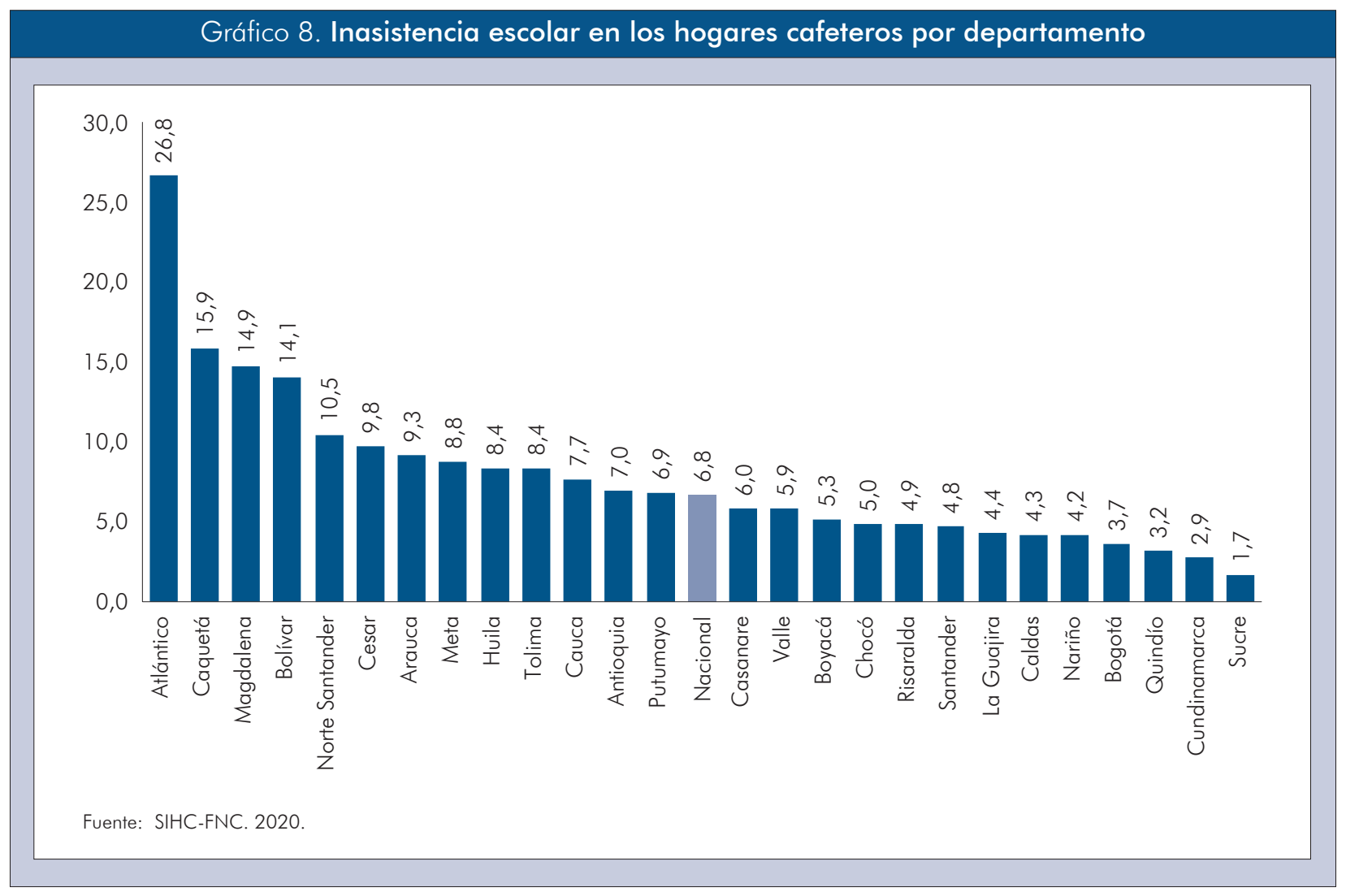

Así mismo, las transferencias monetarias permiten a los hogares ampliar las posibilidades de inserción al mercado laboral, debido a que disponen de recursos para la búsqueda de empleo, la realización de algún reentrenamiento o para contratar servicios de cuidado.

También, se considera que las transferencias monetarias tienen efectos virtuosos en la generación de ingresos, porque dan a los miembros del hogar mayor poder de negociación frente a salarios muy bajos o condiciones muy precarias de trabajo, o permite ahorrar recursos para invertir en sus actividades productivas. Además, el programa de transferencias monetarias condicionadas a la asistencia escolar y cuidado de salud de los niños (Familias en mostrado los impactos positivos de mediano plazo en el capital humano de las nuevas generaciones.

De los productores cafeteros activos, 337.427 $(65,2 \%)$ pertenece a un hogar beneficiario de transferencias monetarias del gobierno nacional. El programa más importante es Más Familias en Acción con 147.151 (28,4\%) productores. En concordancia con el envejecimiento de la población, el segundo programa más importante es el de Colombia Mayor, 100.258 $(19,4 \%)$ productores que pertenecen a hogares beneficiarios y de estos 75.250 son los mismos productores los titulares del beneficio.

Es importante destacar la importante participación de los productores en hogares benefi- 
ciarios del programa Ingreso Solidario 67.821 $(13,1 \%)$. Este programa fue creado en marzo de 2020 en respuesta a la emergencia económica y ambiental por la Covid-19 y en su primera puesta en marcha, lograron contactar a $61.955(91,3 \%)$ de los hogares potenciales de productores seleccionados con cuenta bancaria activa. Esto demuestra las sinergias virtuosas entre la inclusión social y la inclusión financiera que fortalecen las redes de protección social ${ }^{21}$.

Además, de esta importante participación de los productores cafeteros en hogares beneficiarios de programas de transferencias monetarias, se encontró que el $27,1 \%$ pertenece a hogares beneficiarios de más de un programa de transferencias.

Protección en la vejez

Apenas el 4,2\% de los productores cafeteros se encuentra cotizando a un fondo para
Gráfico 9. Acceso de los productores cafeteros

a los programas de transferencias monetarias

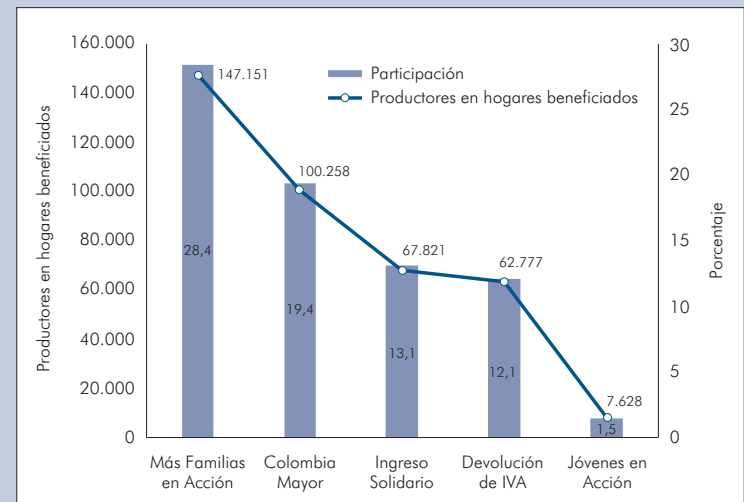

Fuente: SIHC-FNC. 2020.

pensionarse y un $1 \%$ ya está pensionado. De acuerdo con la GEIH-2020 esta proporción es de $14,6 \%$ para los ocupados rurales, lo que ubica al gremio cafetero en una clara desventaja frente a sus mismos pares rurales. En complemento, y de acuerdo a la información de Colpensiones, 44.290 productores

\section{Tabla 1. Concurrencia de los cafeteros en los programas de transferencias monetarias}

\begin{tabular}{|ccc|}
\hline No. de programas & No. de cafeteros en hogares beneficiados & Participación \\
\hline 1 programa & 190.509 & 36,80 \\
2 programas & 107.823 & 20,80 \\
3 programas & 28.156 & 5,40 \\
4 programas & 4.145 & 0,80 \\
5 programas & 156 & 0,03 \\
6 programas & 22 & 0,00 \\
No tienen acceso & 186.588 & 36,10 \\
Total Cafeteros & 517.399 & 100 \\
\hline
\end{tabular}

Fuente: SIHC-FNC. 2020.

21 De 5.866 hogares que no pudieron ser localizados en la primera fase del programa, $3.510(60 \%)$ recibieron los pagos acumulados en la segunda fase del programa, gracias al trabajo conjunto para su búsqueda activa entre el Departamento para la Prosperidad Social y la Federación Nacional de Cafeteros. 
$(8,5 \%)$ se encuentran vinculados a los Beneficios Económicos Periódicos, como alternativa de ahorro para su vejez. Esta proporción es marginalmente mayor al de los ocupados rurales (6,5\%). La garantía de recursos dignos, fuera de los laborales, para los cafeteros mayores de 65 años es una de las mayores preocupaciones de política para el gremio.

Infraestructura -Condiciones habitacionales-:

El 12,1\% de los hogares cafeteros está en viviendas consideradas no habitables (déficit cuantitativo). Lo anterior se produce porque presentan un alto hacinamiento $(6,3 \%)$, com- parten la vivienda con otros hogares $(4,3 \%)$, deficiencias en la calidad de las paredes de la vivienda $(2,8 \%)$ o por vivir en una vivienda inadecuada $(0,3 \%)$. Este déficit, aunque es relativamente bajo comparado con el resto de la ruralidad (18,4\%), reflejando posiblemente las inversiones hechas por el gremio en décadas anteriores, sin duda debe erradicarse.

Por su parte, el $77 \%$ de los hogares cafeteros necesitan mejoramientos parciales, que resueltos hacen que se pueda tener una vivienda digna. Las principales carencias se encuentran por no tener acueducto $(55,3 \%)^{22}$, tener

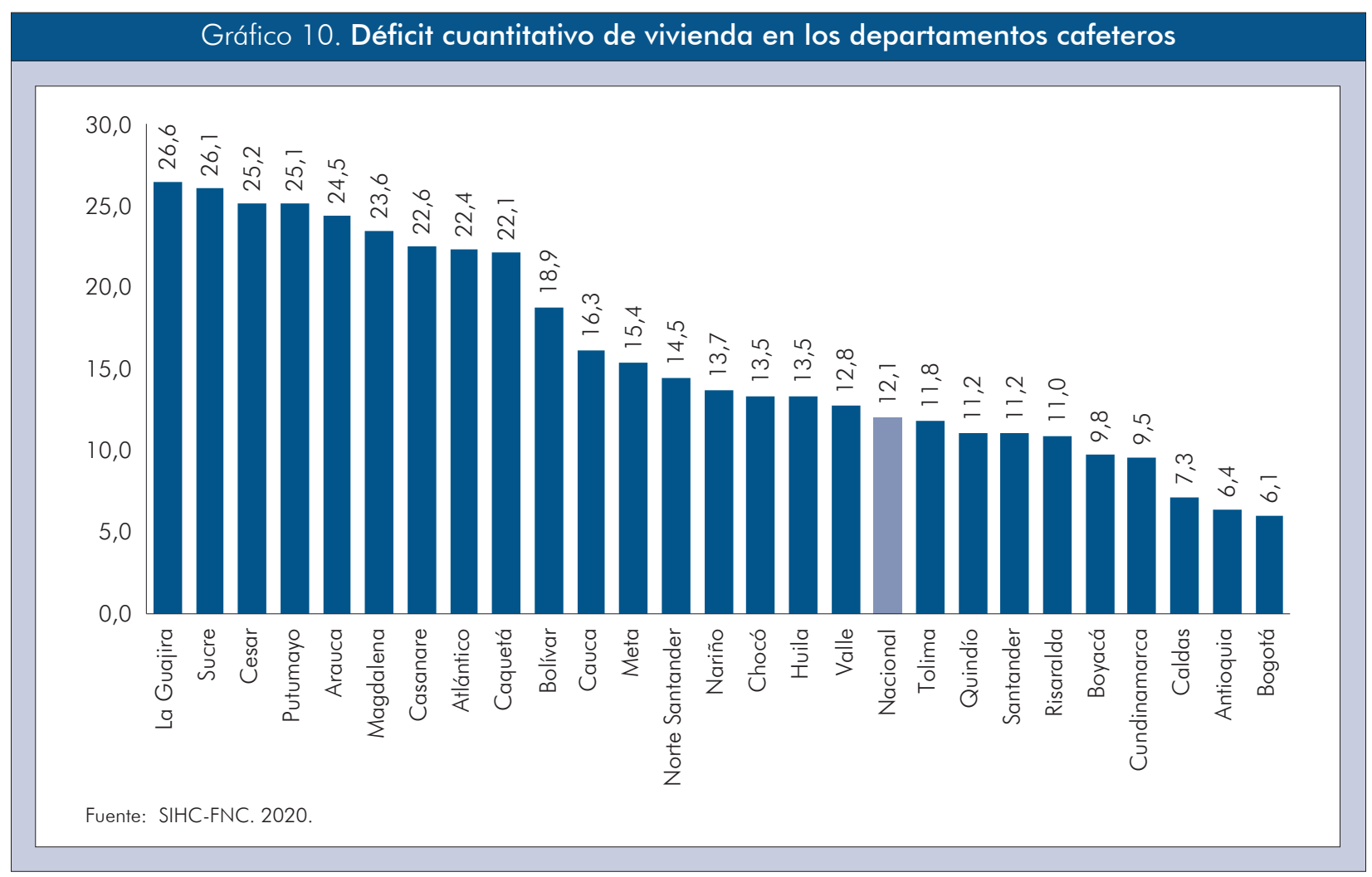

22 A pesar de la alta privación en acueducto, con la ENHC (2018) se encontró que el $81 \%$ de los productores no sufre de escasez de agua y el $92 \%$ no ha tenido conflicto por la misma. 
un sistema inadecuado para la eliminación de excretas $(35,8 \%)$, tener el piso en tierra o arena $(27,2 \%)$, ausencia de un lugar exclusivo para la cocina $(24,2 \%)$, vivir en hacinamiento mitigable $(15,2 \%)$ o no tener energía eléctrica en sus viviendas (8,2\%) (Gráfico 11).

En el Gráfico 12, se observa que, de nuevo, los mayores niveles de calidad de las viviendas se presentan en los departamentos del eje cafetero tradicional (Quindío, Risaralda, Caldas y Antioquia) y en los departamentos de Cundinamarca, Valle, Boyacá y Santander. La Guajira, Atlántico y Bogotá también clasifican en este grupo de punteros debido a su importante participación de población urbana, que se evidenció en el Gráfico 1.

Los resultados en déficit de vivienda demuestran la necesidad de fortalecer la política de vivienda rural y de estrechar, aún más, las relaciones de la FNC con el gobierno, ya que los Comités departamentales de los cafeteros son aliados estratégicos para sacar adelante los proyectos tanto por su experiencia en la ejecución como en la posibilidad que tiene para sumar recursos propios con los de cooperantes nacionales e internacionales.

\section{Vulnerabilidad de los hogares cafeteros de acuerdo con la clasificación oficial del Sis- bén IV}

La clasificación de los hogares que reporta el Sisbén IV, es realizada por el DNP a partir de la estimación de los ingresos del hogar, teniendo en cuenta sus características demográficas y de inclusión social. Por esta razón, son una buena medida global para describir la situación de vulnerabilidad en que se encuentran los hogares.

Como el ordenamiento de los hogares se hace a partir de los ingresos, los niveles de vulnerabilidad se definen desde la pobreza por ingresos, en donde la máxima vulnerabilidad es experimentada por los hogares que no tiene los ingresos suficientes para adquirir la canasta básica de alimentos (pobres extremos). En el siguiente nivel, se encuentran los hogares que no pueden comprar los bienes y servicios considerados básicos, de acuerdo con los hábitos de consumo del país (pobres moderados) y en el tercer nivel se encuentran los hogares que, a pesar de no ser pobres, sus ingresos no son lo suficientemente altos como para garantizar una separación definitiva de la pobreza (vulnerable a ser pobre).

De acuerdo con esta clasificación, el 54,4\% de los productores cafeteros está en pobreza o en vulnerabilidad a la pobreza. El 15,6\% de los productores cafeteros se encuentra en la pobreza extrema, $25 \%$ en la pobreza moderada y $13,8 \%$ es vulnerable a ser pobre.

El análisis por subgrupos del Sisbén evidencia, en un extremo, que 20.774 productores se encuentran en los niveles más precarios de ingresos (grupo A01) sobre los cuales se deberían priorizar buena parte de los esfuerzos en Desarrollo Social. En el otro extremo, se encuentran 5.815 productores, los cuales deberán comenzar una transición hacia los regímenes contributivos del Sistema de Protección Social.

La pobreza se relaciona de forma negativa con el tamaño del cultivo del café. Mientras los ho- 

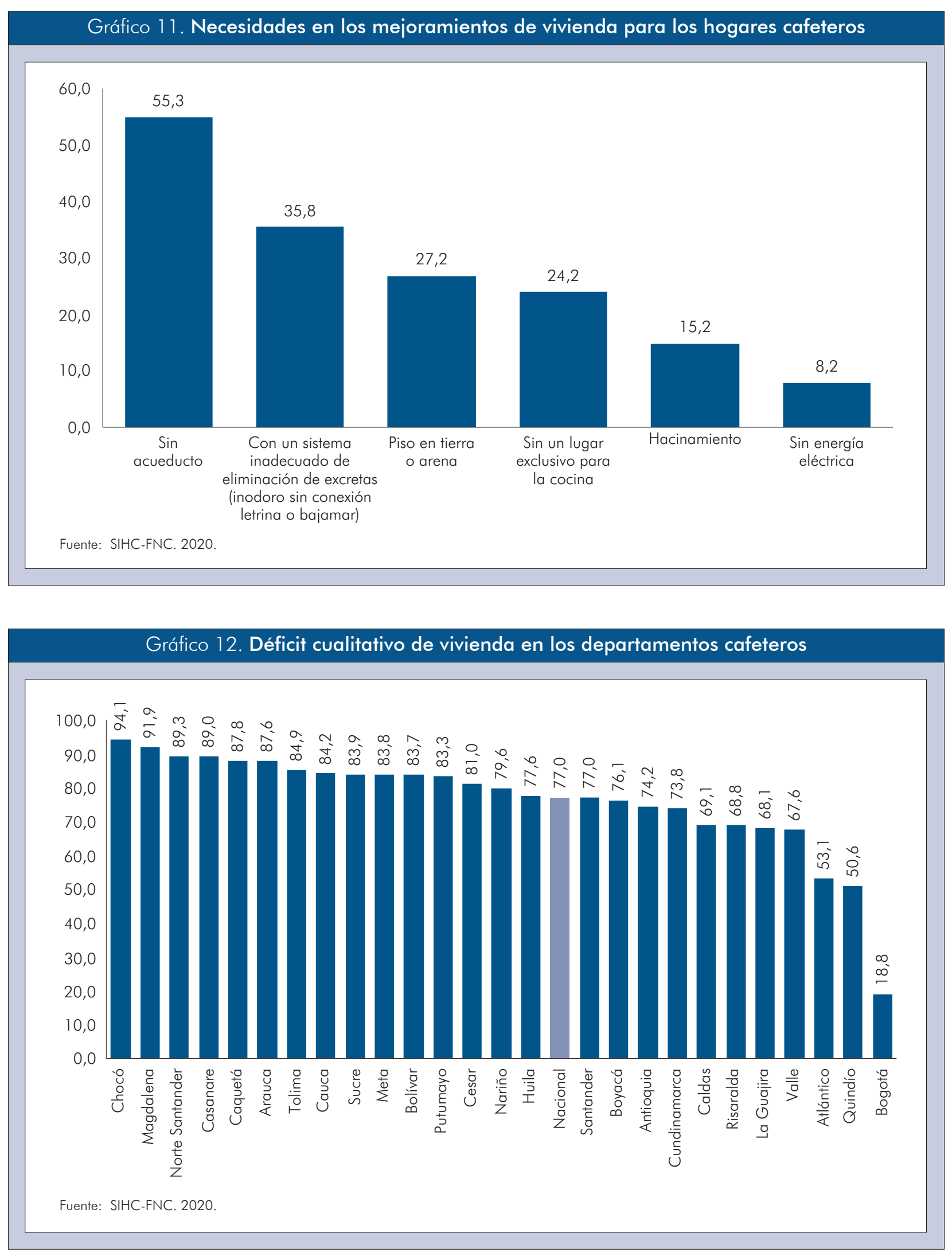
gares de productores en pobreza extrema tienen en promedio 1,1 hectáreas de café, los hogares que no han tenido la necesidad de solicitar el Sisbén, registran un tamaño promedio del cultivo de 2,1 hectáreas (Gráfico 14).
Otra forma de ver esta relación es a partir de la participación de los grupos de pobreza por tamaño del cultivo (Gráfico 15). Se observa cómo disminuye la participación de los productores en pobreza extrema, en pobreza

\section{Tabla 2. Clasificación de los productores cafeteros según grupos del Sisbén IV}

\begin{tabular}{|c|c|c|c|}
\hline Grupo Sisbén IV & Categoría & No. de productores & Participación \\
\hline A & Pobreza extrema & 80.635 & 15,58 \\
B & Pobreza moderada & 129.453 & 25,02 \\
C & Vulnerable a ser pobre & 71.291 & 13,78 \\
D & No pobre no vulnerable & 30.039 & 5,81 \\
NULL & Con Sisbén III pero sin actualización de Sisbén IV & 153.774 & 29,72 \\
No Cruza & No han solicitado Sisbén III NI Sisbén IV & 52.207 & 10,09 \\
\hline \multicolumn{2}{|c|}{ Total Productores } & 517.399 & 100 \\
\hline
\end{tabular}

Fuente: SIHC-FNC. 2020.

\section{Gráfico 13. Distribución de los productores cafeteros por segmentos del sisbén}

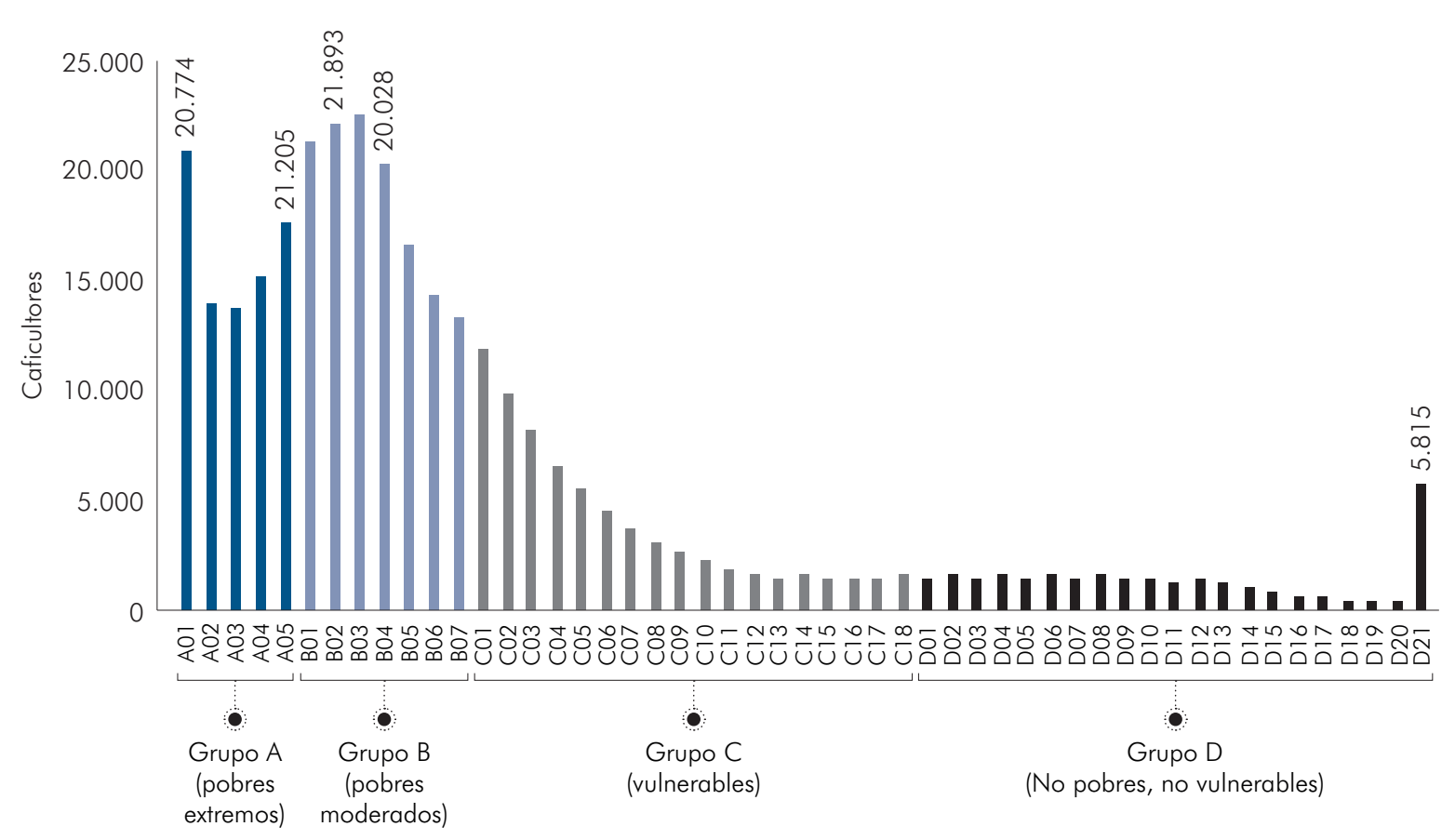

Fuente: SIHC-FNC. 2020 
moderada y en vulnerabilidad conforme el tamaño del cultivo es mayor, al tiempo que ganan participación los grupos que están fuera de la pobreza y la vulnerabilidad.

Esto es tan sólo una primera pincelada de las fuertes relaciones entre la inclusión social y la inclusión productiva que podrían potencializarse para dar saltos cualitativos en la calidad de vida de los hogares cafeteros.

\section{EVOLUCIÓN DE LOS INDICADORES ENTRE (1993-1997) Y 2020}

En el último cuarto de siglo, la situación demográfica y social de los hogares cafeteros ha experimentado cambios importantes. Aunque se mantienen características estructurales como la alta masculinidad y la ruralidad, los hogares cafeteros en 2020 son más pequeños y están más envejecidos. En una gene-

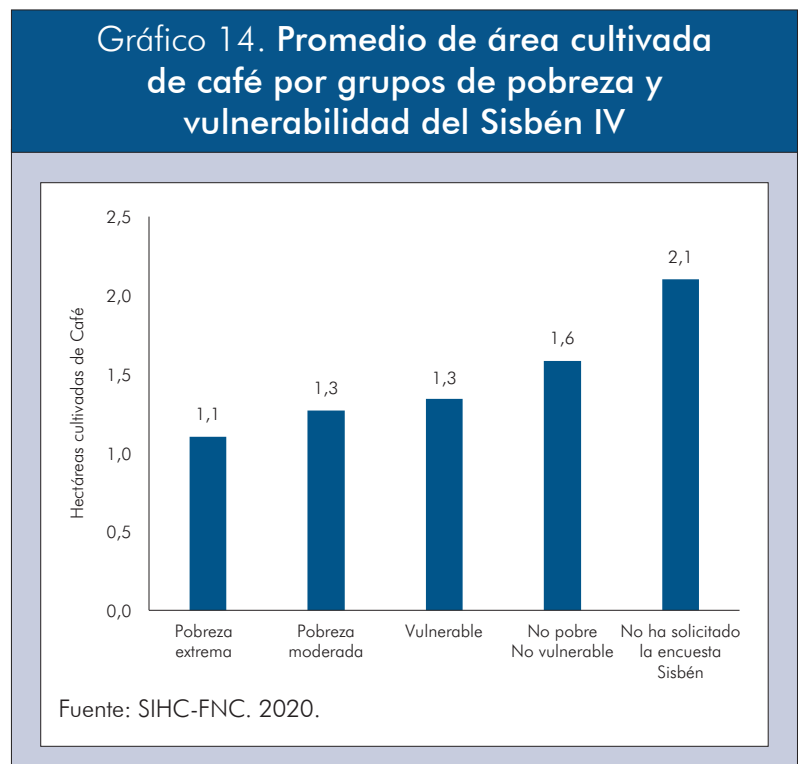

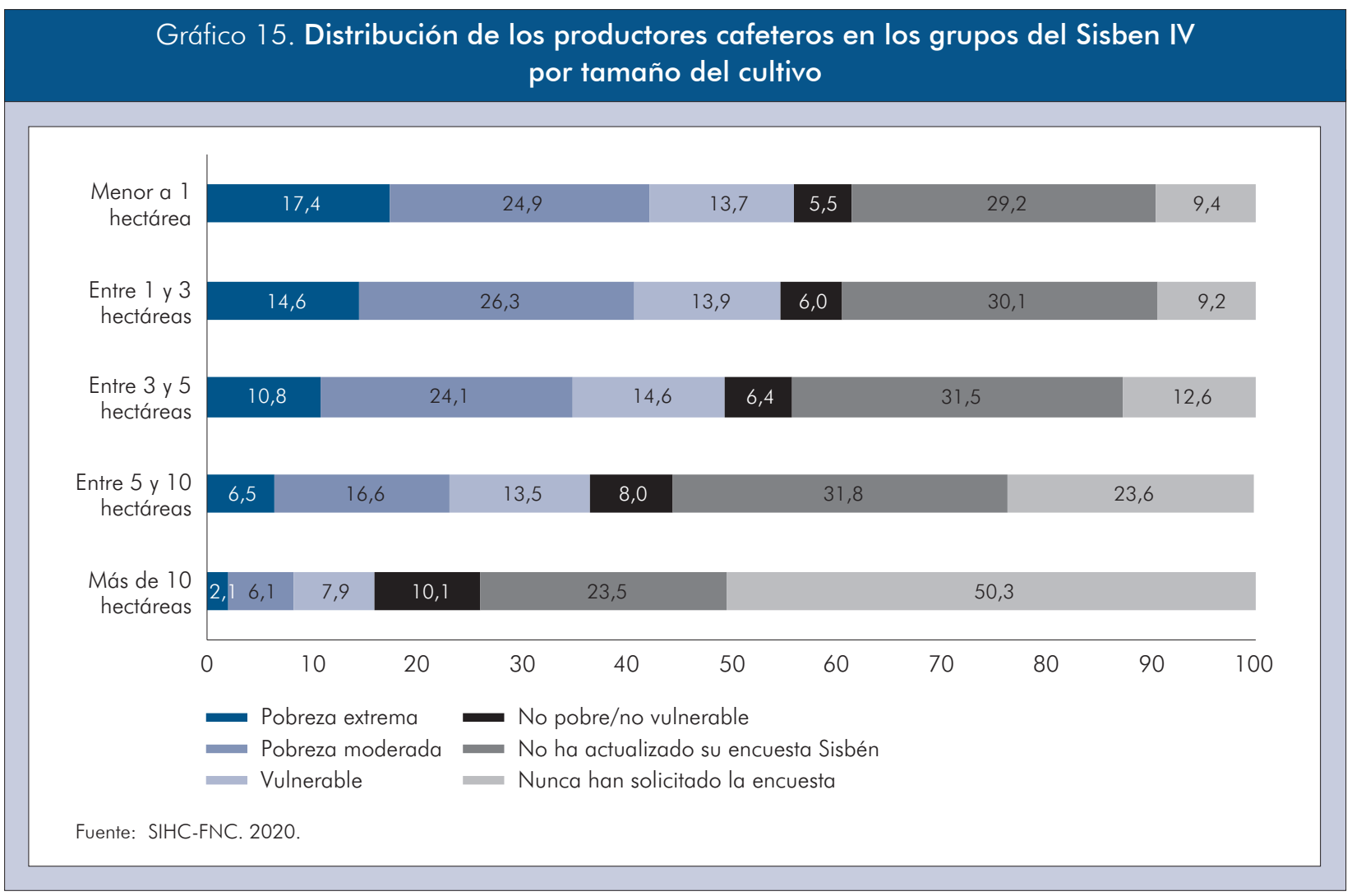


ración ${ }^{23}$, el tamaño del hogar cafetero se redujo en $38 \%$, la población cafetera en $24 \%$, mientras que la población mayor de 60 años aumentó en $120 \%$.

En educación el panorama es agridulce. Si bien, durante el periodo se presentaron reducciones sustanciales en el analfabetismo y la inasistencia escolar, el logro educativo ha venido mejorando, pero más lentamente.

Entre 1993 y 2020, la población con educación primaria había disminuido 12,5pp, mientras que la población con educación secundaria y superior había aumentado $12,5 \mathrm{pp}$ y 2,4 pp respectivamente.

Las ganancias en protección social han sido considerables (aseguramiento en salud y acceso a la Red de transferencias), no obstante, se necesitan cambios estructurales para garantizar ingresos y sistemas de cuidado adecuados para la población cafetera que llega a la vejez.

Las condiciones habitacionales continúan siendo un componente importante en la pobreza y vulnerabilidad de los hogares cafeteros. La calidad de los pisos, el acceso sistemas de acueducto y alcantarillado avanzan muy marginalmente, en incluso, para el caso del acceso acueductos se evidencia un retroceso desde 2011 . Por su parte de destacan los avances en las conexiones energía eléctrica y la reducción del hacinamiento en las viviendas.
Finalmente, las mediciones de pobreza registradas en cada periodo responden a los indicadores líderes de la época. En todo caso, se evidencia el importante número de hogares en pobreza y vulnerabilidad en cada periodo, marcando importantes retos para el futuro de la política cafetera.

\section{CONCLUSIONES}

El diagnóstico presentado en este documento evidencia los avances sociales que ha alcanzado la población cafetera en el último cuarto de siglo y los retos a los que se enfrentará en los próximos años para garantizar una reducción sustancial de la pobreza y la vulnerabilidad de la próxima generación cafetera.

Desde nuestra perspectiva y a la luz de los resultados, las principales líneas de trabajo deben concentrarse en:

O Generar los incentivos adecuados (en infraestructura e ingresos) para que los hogares cafeteros puedan seguir en la actividad cafetera, independientemente de si su residencia es urbana o rural.

O Desarrollar alianzas para que los niños y jóvenes de hogares cafeteros se capaciten a gran escala en el negocio del café.

O Diseñar engranajes entre la educación y los proyectos generadores de ingresos en la cadena del café para que los jóvenes

23 En demografía una generación se define como el periodo promedio, generalmente considerado como de 20 a 30 años, durante el cual los niños nacen y crecen, se convierten en adultos y comienzan a tener hijos. 
entre 18 y 28 aceleren su formación en educación superior, con pertinencia en la generación de ingresos.

O Propender acciones para erradicar la inasistencia escolar de los niños en los hogares cafeteros, con especial atención en los niños entre los 7 y 11 .

O Impulsar de forma urgente y decidida la afiliación al sistema de pensional de los productores cafeteros. Con el establecimiento reciente del Piso Mínimo de Protección Social, se facilita este propósito.

O Diseñar lineamientos de política y su implementación para adelantar un programa de cuidado de los adultos mayores que forman parte de la población cafetera.

O Impulsar alianzas con diferentes cooperantes para acelerar los avances en adecuación de las viviendas, en especial en temas de saneamiento básico y acceso adecuado al agua. 
Tabla 3. Evolución de los indicadores demográficos y sociales (1993-1997)-2020 para los hogares cafeteros

\begin{tabular}{|c|c|c|c|c|c|}
\hline Dimensión & Variable & $\begin{array}{c}\text { Censo cafetero } \\
1993-1997\end{array}$ & $\begin{array}{c}\text { Encuesta sobre condiciones } \\
\text { de vida en los hogares } \\
\text { cafeteros (2004) }\end{array}$ & $\begin{array}{l}\text { Sisbén III } \\
(2011)\end{array}$ & $\begin{array}{l}\text { Sisbén homologado } \\
\text { barrido Sisbén IV y registro } \\
\text { socila de hogares (2020) }\end{array}$ \\
\hline \multirow{11}{*}{ 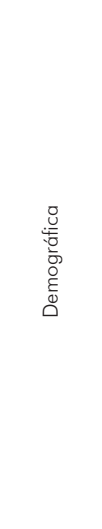 } & Productores cafeteros en el SICA & 524.184 & - & 559.265 & 540.362 \\
\hline & Personas en hogares cafeteros & 1.972 .736 & 2.166 .455 & 1.865 .571 & 1.498 .526 \\
\hline & Hogares cafeteros & 423.368 & 512.303 & 494.080 & 483.389 \\
\hline & Tamaño del hogar & 5,0 & 4,2 & 3,9 & 3,1 \\
\hline & Población mayor de 60 años (\%) & 7,5 & 14,1 & 14,0 & 16,5 \\
\hline & Población menor de 14 años (\%) & - & 28,2 & 27,5 & 24,3 \\
\hline & Dependencia demográfica (\%) & - & - & 57,6 & 52,0 \\
\hline & Población rural (\%) & - & 97,4 & 79,54 & 82,92 \\
\hline & Población urbana (\%) & - & 2,6 & 20,46 & 17,08 \\
\hline & Hogares con jefatura femenina (\%) & - & 22,3 & 20,4 & 24,9 \\
\hline & Hombres en hogares cafeteros (\%) & 53,0 & - & 53,2 & 54,1 \\
\hline \multirow{7}{*}{ 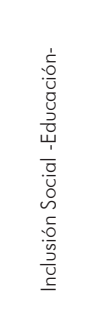 } & Población analfabeta (\%) & 23,3 & 15,1 & - & 10,7 \\
\hline & Población con educación primaria (\%) & 69,5 & - & 63,5 & 57,0 \\
\hline & Población con educación secundaria (\%) & 8,91 & - & 23,5 & 27,6 \\
\hline & Población con educación superior (\%) & 0,37 & - & 1,84 & 2,8 \\
\hline & Inasistencia escolar 7-11 años (\%) & 18,7 & - & 5,7 & 8,5 \\
\hline & Inasistencia escolar 12-17 años (\%) & 58,1 & - & 25,3 & 22,1 \\
\hline & Inasistencia escolar hogar (\%) & - & - & 9,7 & 6,8 \\
\hline \multirow{4}{*}{ 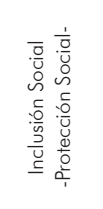 } & Población afiliada al sistema de salud (\%) & - & 72,9 & 84,4 & 87,7 \\
\hline & $\begin{array}{l}\text { Productore en hogares beneficiados de } \\
\text { transferencias gubernamentales (\%) }\end{array}$ & - & - & - & 63,9 \\
\hline & Productores que cotizan a Pensión (\%) & - & - & - & 4,5 \\
\hline & Productores que cotizan a BEPS & - & - & - & 8,5 \\
\hline \multirow{9}{*}{ 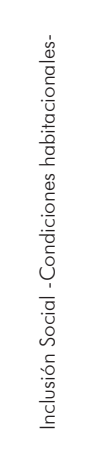 } & Viviendas con pisos inadecuados (\%) & - & 26,1 & 27,1 & 27,2 \\
\hline & Viviendas con paredes inadecuadas (\%) & - & 1,6 & 2,3 & 2,8 \\
\hline & Hogares en hacinamiento crítico (\%) & - & - & 18,7 & 15,2 \\
\hline & Viviendas sin energía eléctrica (\%) & 31,2 & - & 10,1 & 8,2 \\
\hline & Viviendas sin acueducto (\%) & 63,8 & 51,2 & 51,3 & 55,3 \\
\hline & $\begin{array}{l}\text { Viviendas sin alguna solución de } \\
\text { saneamiento básico (\%) }\end{array}$ & 39,4 & - & 40,6 & 35,8 \\
\hline & Viviendas sin alcantarillado (\%) & 94,1 & - & 76,7 & 79,1 \\
\hline & Déficit cuantitativo de vivienda & - & - & 11,5 & 12,11 \\
\hline & Déficit cualitativo de vivienda & - & - & 73,6 & 77,01 \\
\hline \multirow{4}{*}{ 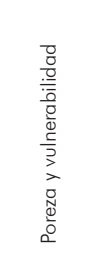 } & Pobreza y Vulnerabilidad (estructural) & 31,3 & 71,9 & 75,3 & 76 \\
\hline & & $\begin{array}{l}\text { Hogar con al menos } \\
\text { una Necesidad } \\
\text { Básica Insatisfecha }\end{array}$ & $\begin{array}{l}\mathrm{ICV} \text { en rango bajo } \\
\text { o medio bajo }\end{array}$ & $\begin{array}{c}\text { Puntaje Sisbén }<54,8 \\
\text { en urbano y }<\text { a } 37,8 \\
\text { en rural }\end{array}$ & $\begin{array}{c}\text { Puntaje Sisbén }<54,8 \\
\text { en urbano y }<\text { a } 37,8 \\
\text { en rural }\end{array}$ \\
\hline & $\begin{array}{l}\text { Pobreza y vulnerabilidad } \\
\text { (coyuntural-Ingresos) }\end{array}$ & - & - & - & 54,4 \\
\hline & - & & - & - & $\begin{array}{l}\text { Según grupos del } \\
\text { Sisbén IV }\end{array}$ \\
\hline
\end{tabular}




\section{REFERENCIAS BIBLIOGRAFICAS}

Caballero Argáez, C. (2016). La economía colombiana del siglo XX. Un recorrido por la historia. Bogotá: Debate.

Cepal (2017). Brechas, ejes y desafíos en el vínculo entre lo social y lo productivo. Santiago de Chile y Montevideo: Comisión Económica para América Latina y el Caribe.

CES (2005). Condiciones de vida de los hogares cafeteros: comparación entre las regiones cafeteras, entre los productores cafeteros y la población en general.

DPS (2018). Lineamientos para el diseño de la política para la Inclusión Social y Productiva en Colombia.

FNC (1993-1997). Censo Nacional Cafetero.

FNC (2017). 90 Años, Vivir el Café y sembrar el futuro (1927-2017). Bogotá: Federación Nacional de Cafeteros de Colombia.

FNC (2018). Pobreza y vulnerabilidad de los hogares cafeteros. Investigadores José Leibovich y Marcela Aguinaga. Ensayos de Economía Cafetera No 32.

FNC (2019). Resultados Encuesta Nacional de Hogares Cafeteros 2018.
FNC-CRECE-CES (2005). Encuesta sobre condiciones de vida de los hogares cafeteros. Índice de Calidad de Vida para los departamentos cafeteros. Resumen ejecutivo y análisis comparativo.

Leibovich, J., \& Botello, S. (2009). Análisis de los cambios demográficos en los municipios cafeteros y su relación con los cambios en la caficultura colombiana (1993-2005). Ensayos de Economía Cafetera. FNC.

PNUD (2015). Progreso multidimensional: bienestar más allá del ingreso. Informe regional sobre Desarrollo Humano para América Latina y el Caribe. New York: Programa de las Naciones Unidas para el Desarrollo.

Rodríguez, J. (2000). Vulnerabilidad y grupos vulnerables:un marco de referencia conceotual mirando a los jóvenes. Santiago de Chile: Comisión Económica para América Latina CEPAL.

Rodríguez, J. (2001). Vulnerabilidad y grupos vulnerables: Un marco de referencia conceptual mirando a los jóvenes. Santiago de Chile: Comisión Económica para América Latina y el Caribe CEPAL.

Sen, A. (1999). Desarrollo y Libertad. Barcelona: Planeta. 


\title{
La cosecha asistida de café y su impacto en la economía de la recolección en finca
}

\author{
Juan Rodrigo Sanz Uribe, Hernando Duque Orrego, Álvaro León Gaitán Bustamante
}

\section{RESUMEN}

La introducción del concepto de Cosecha Asistida en la recolección de café en Colombia implica la adopción de tres prácticas que pueden usarse de manera aditiva y escalarse independientemente del tamaño de la finca: retención de pases, recolección con lonas y uso de la Derribadora DSC18. Las pruebas de campo indican que el aumento en la masa de café cosechable producto de la retención, más la reducción de movimientos para desprender los frutos del árbol al usar las lonas, pueden incrementar la eficiencia de la recolección en un 40\%, y que el uso de la máquina DSC-18 puede aumentar esa eficiencia en 180\% en promedio. La reducción del costo unitario $(\mathrm{COP} / \mathrm{kg})$, que puede ser de un $50 \%$ o más, permite un margen de maniobra donde el recolector y el productor de café puedan acordar precios de cosecha que generen ganancias para ambas partes. De esta manera, la Cosecha Asistida contribuye a mejorar la rentabilidad en la finca a través de beneficios económicos por una mayor productividad de la mano de obra en la labor de recolección, y favorece a los recolectores haciendo más cómoda y eficiente su labor, con una mejor remuneración.

\begin{abstract}
The introduction of the Assisted Harvest concept in coffee harvesting in Colombia implies the adoption of three practices that can be used additively and be scaled-up regardless of the size of the farm: harvesting entries delay, harvesting with tarps on the ground and use of the DSC 18 branch shaker for selective coffee harvesting. Field tests indicate that the increase in the harvestable coffee mass due to retention, plus the reduction of movements to detach the fruits from the tree when using the tarps, can increase the harvesting efficiency by $40 \%$, and that the use of the DSC-18 machine can increase that efficiency by $180 \%$ on average. The reduction of cost-per-unit (COP / kg), which can be $50 \%$ or more, allows a margin of maneuver where the picker and the coffee producer can agree on harvest prices that generate profits for both parties. In this way, Assisted Harvesting contributes to improving the profitability of the farm through economic benefits due to greater productivity of the workforce in the harvesting work, and favors the picker by making their work more comfortable and efficient, with a better remuneration.
\end{abstract}

Palabras clave: Cosecha asistida, Cosecha selectiva, Cosecha manual de café, Cosecha semi-mecanizada de café, Retención de pases de cosecha e impacto económico

Códigos JEL: Q10, Q18

Key words: Assisted harvest, Selective harvesting, Manual coffee harvesting, Semi-mechanized coffee harvesting, Harvesting entries delay and economic impact

JEL code: Q10, Q18 



\title{
La cosecha asistida de café y su impacto en la economía de la recolección en finca
}

\author{
Juan Rodrigo Sanz Uribe', Hernando Duque Orrego², Álvaro León Gaitán Bustamante ${ }^{3}$
}

Para citar este artículo: Federación Nacional de Cafeteros de Colombia. (2021). La cosecha asistida de café y su impacto en la economía de la recolecciónen finca. Ensayos sobre Economía Cafetera, 34(1), 35-50.

\section{GENERALIDADES MACROECONÓMICAS}

El café ha sido el producto agrícola más importante de Colombia desde hace más de un siglo y genera una gran dinámica económica para el país, porque se produce en más de 600 municipios y alrededor de dos millones de familias derivan su sustento de esta actividad. A pesar del peso de esa tradición, la sostenibilidad de la caficultura depende en gran medida de su rentabilidad, y de ésta, otros componentes, como son el social y el ambiental, para que en su conjunto le permitan la continuidad a esta actividad en el futuro. La rentabilidad de la caficultura está influenciada por diversos factores externos e internos. Entre los externos, los más relevantes son la cotización de la libra de café en la bolsa de Nueva York y la Tasa Representativa del Mercado (TRM). Entre los factores internos se encuentran aquellos que tienen que ver di- rectamente con la productividad, la calidad y la comercialización local, y que pueden ser controlados en gran medida por el productor, adoptando tecnologías, realizando prácticas agronómicas oportunas y efectivas a nivel de la finca, y aprovechando las condiciones de compra y venta de café.

El manejo de la rentabilidad desde la finca consiste en buscar constantemente una productividad máxima, con la mejor calidad posible, a unos costos de producción racionales y con el menor impacto ambiental. Para tal fin, es necesaria la aplicación de componentes de manejo agronómico acertado, cuidadosamente seleccionados, para que los productores tengan cada vez mejores indicadores de producción, realizando prácticas clave para obtener café pergamino seco de alta calidad,

Líder Disciplina de Poscosecha del Centro Nacional de Investigaciones de café - Cenicafé (juanr.Sanz@cafedecolombia.com).

Gerente Técnico de la Federación Nacional de Cafeteros (Hernando.duque@cafecedcolombia.com).

Director de Investigación Científica y Tecnológica de la Federación Nacional de Cafeteros (alvaro.gaitan@cafedecolombia.com). 
y operando bajo un esquema de sostenibilidad en un cultivo perenne. Desde 2016, la Federación Nacional de Cafeteros viene trabajando la estrategia "Más Agronomía, Más Productividad, Más Calidad", que reúne estos elementos agronómicos fundamentados en la investigación científica, y que, transferidos por el Servicio de Extensión a los caficultores, han soportado producciones record y consistentes por 6 años consecutivos.

La implementación de esta estrategia, promoviendo densidades promedio de cultivos de café más altas, edades promedio más bajas, y mayor proporción de áreas sembradas con variedades resistentes a la roya del cafeto, además de favorecer la rentabilidad, ha permitido apalancar a la producción nacional en sistemas de producción más resistentes y resilientes a las variaciones climáticas, pero así mismo, ha incrementado la demanda de mano de obra para cosecha, y de infraestructura para beneficio.

\section{GENERALIDADES DE LOS CAFICULTORES DE COLOMBIA}

Para 2020, en Colombia se registraron 848.789 hectáreas en café, sembradas por un total de 539.741 caficultores, lo que da un promedio de 1,57 hectáreas por agricultor, indicando que la caficultura colombiana se basa principalmente en familias campesinas con pequeñas extensiones de tierra. Una importante proporción de estos caficultores $(23,4 \%)$ tiene solamente media hectárea o menos sembrada en café, y un $90 \%$ tiene un área menor o igual a 3,0 ha, siendo solamente un $0,9 \%$ quienes
El negocio de los pequeños productores (aquellos con menos de $5 \mathrm{ha}$ ), se diferencia del de los productores medianos y grandes, principalmente porque tiene menor productividad, debido a una edad promedio más alta de las plantaciones. Adicionalmente, el negocio de los pequeños productores de café tiene una componente importante de mano de obra familiar, con el fin de reducir egresos. Así las cosas, las labores realizadas por los integrantes de la familia se ven retribuidas cuando se vende el producto final. Así mismo, a los pequeños productores, por su volumen de producción, se les facilita un mayor control en el procesamiento de los granos, abriéndoles la oportunidad de vender cafés de mayor calidad, en medio de un auge de demanda por cafés diferenciados por taza, con lo que pueden mejorar la rentabilidad, a causa de obtener un mejor precio de venta. Por su parte, el negocio de los productores medianos y grandes está orientado hacia el modelo de alta productividad con precio estándar o bonificado, aunque también hay intentos por llegar al mercado de los cafés especiales con lotes pequeños que procesan aparte del flujo principal.

\section{GENERALIDADES DE LA COSECHA DE CAFÉ EN COLOMBIA}

La cosecha de café en Colombia presenta diferentes patrones de distribución, dependiendo de la ubicación latitudinal y de la altitud. Debido al movimiento particular del frente de Iluvias de la Zona de Confluencia Intertropical, con ausencia de periodos marcados de sequía, en el país se diferencian cuatro zonas latitudinales: zona Sur entre $1^{\circ}$ y $3^{\circ}$ de latitud 
Norte, zona Central Sur entre $3^{\circ}$ y $5^{\circ}$, zona Central Norte entre $5^{\circ}$ y $7^{\circ}$, y zona Norte entre $7^{\circ}$ y $10^{\circ}$, con caficultura desde los 1.000 $\mathrm{m}$ de altitud en la zona Norte hasta 2.000 $\mathrm{m}$ en la zona Sur. La distribución de las lluvias determina las floraciones, y por ende las cosechas, variando entonces para cada zona cafetera así: en la zona Sur prevalece la cosecha principal en el primer semestre del año, en la zona Central Sur ocurren dos cosechas en los dos semestres del año, en la zona Central Norte es característico que la cosecha del segundo semestre sea mayor $y$, finalmente, en la zona Norte se tiene una sola cosecha concentrada en el segundo semestre.

La ocurrencia de varios eventos de floración al año ocasiona diferencias en la maduración de los frutos entre regiones cercanas, entre lotes, e inclusive a nivel de ramas individuales, ampliando las semanas de cosecha. Este efecto es menor en zonas cafeteras donde se produce una sola cosecha al año, y donde se requieren menos pases de recolección por la concentración de frutos maduros, teniendo cada pase un volumen de carga importante. Por el contrario, en aquellos lugares donde se presentan dos cosechas, es frecuente realizar numerosos pases de recolección al año, alcanzando en muchos sitios una periodicidad cercana a los 17 días por lote, con cargas bajas de frutos maduros. A esta alta frecuencia de recolección por la dispersión de la maduración se le suma el temor de perder parte de la cosecha en el suelo, ya que las variedades susceptibles a la roya dejan caer los frutos maduros rápidamente, o la necesidad de tener flujo de caja para los requerimientos económicos de los productores.

La desigualdad en la maduración de los frutos ha determinado que la cosecha de café en Colombia se haga de manera selectiva, desprendiendo manualmente uno a uno los frutos maduros de los árboles y depositándolos temporalmente en un recipiente que cuelga de la cintura, denominado "coco recolector" o simplemente "coco." Los cambios en la cosecha manual del café no han sido relevantes en el último siglo en cuanto a su eficiencia, e incluyen el reemplazo del material de construcción del recipiente y las variaciones en la medida que sirve de referencia para el pago de los recolectores. El recipiente cambió de construirse en una fibra natural, denominada bejuco, a hacerse de plástico, y la medida dejo de ser el volumen de 18,9 litros (5 galones) conocida como "lata", en la cual cabía aproximadamente una arroba ${ }^{4}$ de frutos de café, para adoptarse el sistema de valoración por peso de las cerezas cosechadas, dada la variación en las densidades del grano de café por efecto del clima, el manejo agronómico y las enfermedades.

Otra consecuencia de la alta dispersión de la maduración es la variación de la contratación del personal dependiendo del momento

Una arroba es una medida de peso antigua que tiene origen árabe, por eso su símbolo (@), la cual corresponde a 25 libras de $454 \mathrm{~g}$ cada una, es decir, una arroba equivale a $11,35 \mathrm{~kg}$. No obstante, esta medida de uso único en la cotidianidad cafetera, ha cambiado en su concepto por la mezcla del Sistema Inglés con Sistema Internacional de Unidades, correspondiendo por consenso en la actualidad a $12,5 \mathrm{~kg}$. 
de la cosecha. Al inicio y al final del periodo de cosecha hay poca disponibilidad de frutos maduros en los árboles, lo que conduce a que se pacte con los recolectores de café una contratación por día, pagando por tiempo trabajado, lo que se conoce como "jornal". Cuando el flujo de café es mayor, normalmente se paga por el peso de los frutos de café recolectados, lo que es conocido como "contratación al destajo." La mayoría de la cosecha café es contratada por esta modalidad, ya que el costo por kilo de recolección de café contratada mediante jornales representa un valor que puede ser dos o tres veces mayor al precio de la misma masa pagada al destajo.

En cuanto a la eficiencia de la recolección, existen factores externos al recolector, relacionados con la plantación, que incluyen la oferta de frutos maduros, la edad de las plantas, la pendiente del terreno, y el clima reinante, entre otros. El rendimiento de un recolector también depende de factores in-

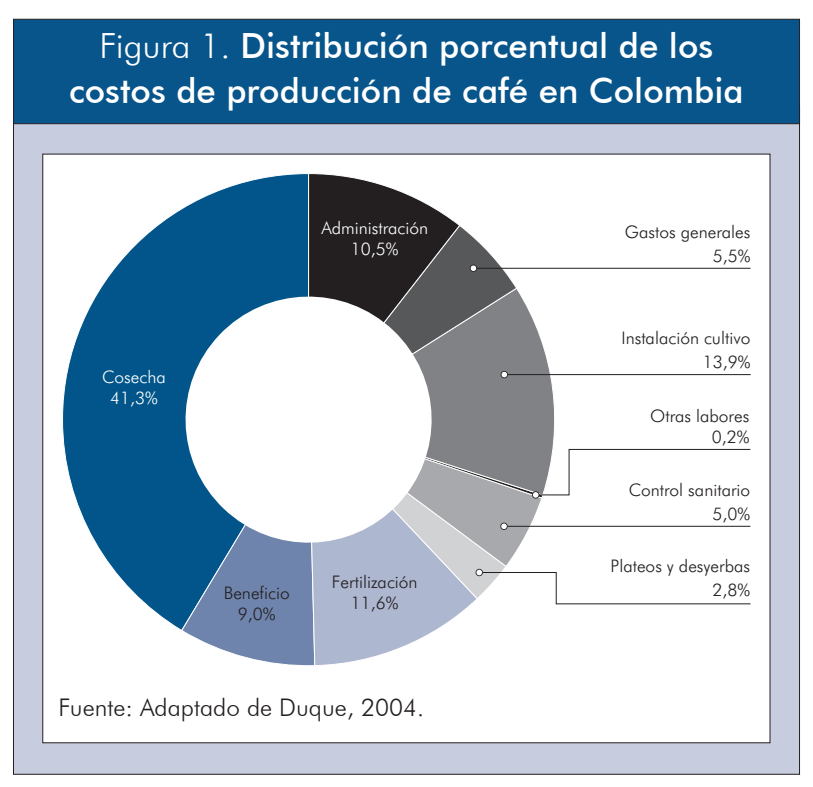

herentes a él, como son la técnica que utiliza, sus propias habilidades, su experiencia, y su motivación. Tal y como se realiza la cosecha manual en la actualidad, esta actividad representa cerca del $40 \%$ de los costos de producción (Duque, 2004), de manera que cualquier acción encaminada a reducir los costos de la recolección, impactará de manera significativa los costos de producción, y por ende la rentabilidad, por la gran participación que tiene este componente en la estructura de costos.

\section{Antecedentes de la Cosecha Asistida}

Las condiciones climáticas y geográficas de la caficultura colombiana hacen difícil el uso de implementos, máquinas portátiles o cosechadoras mecánicas. Aparte de la gran dispersión de la cosecha, hay otros aspectos como la pendiente de los terrenos (principalmente), la estructura y la fragilidad de los suelos, la coincidencia de la cosecha con la temporada lluviosa, a los que se suman componentes sociales como el apego a las costumbres de los caficultores y de los recolectores, y la carencia de mano de obra escolarizada.

Las investigaciones en cosecha de café iniciaron oficialmente en Cenicafé en el año de 1997 con la finalidad principal de reducir los costos de esta labor (Oliveros y Sanz, 201 1). Para tal fin se adelantó un plan de investigación en cosecha de café, conformado por cinco líneas: 1. determinación de las propiedades físicas y mecánicas de los órganos que conforman el árbol, incluyendo principalmente los frutos, con el fin de encontrar principios físicos en los que se pudiera ob- 
tener la selectividad deseada; 2 . desarrollo de implementos manuales y metodologías, para hacer más eficiente la recolección manual de café; 3. cosecha semi-mecanizada, enmarcada en el uso de herramientas motorizadas y portátiles para hacer la labor de desprendimiento de frutos; 4 . cosecha mecanizada, usando máquinas de gran envergadura, autopropulsadas o con fuente remota de potencia, para el desprendimiento masivo de frutos; y 5 . cosecha robotizada, usando técnicas y tecnologías de automatización avanzada para realizar la cosecha del café de manera selectiva.

Como resultados importantes se destacan la diferencia encontrada entre los frutos maduros e inmaduros para colapsar la estructura del pedúnculo del fruto por fatiga (Cardona, 2006), la posibilidad de reducir u obviar micro-movimientos realizados por los recolectores durante la cosecha (Vélez et al., 1999), la adopción del uso de las lonas para la cosecha manual de café eliminando el uso del "coco recolector" (Oliveros et al., 2006), y el desarrollo de la derribadora selectiva de café DSC18 (Sanz \& Duque, 2020). La aplicación de estos hallazgos ha permitido el aumento del rendimiento de los recolectores, y son el fundamento de la Cosecha Asistida de café.

\section{Componentes de la Cosecha Asistida de Café}

La Cosecha Asistida de café es un concepto de la Gerencia Técnica de la Federación Nacional de Cafeteros, en el cual se busca contribuir a la rentabilidad del negocio para los caficultores a través de obtener beneficios económicos por una mayor productividad de la mano de obra en la labor de recolección. La Cosecha Asistida no pretende reemplazar la fuerza de trabajo, sino favorecer a los recolectores haciendo más cómoda y eficiente su labor, de manera que ganen tanto los caficultores como los recolectores.

Los 3 componentes de la Cosecha Asistida de café son:

\section{Retención de pases de cosecha}

Debido a la variabilidad en la carga y concentración de frutos maduros de café se requieren numerosos pases de cosecha durante el año. Como consecuencia de la falta de mano de obra para esta labor en determinadas regiones y momentos de cosecha, algunos caficultores se han visto obligados a dejar más tiempo los frutos maduros en los árboles, con buenos resultados al momento de reingresar a los lotes. Con base en esta observación, estudios realizados por Sanz et al. (2018a) demostraron que en las variedades resistentes a la roya del cafeto desarrolladas en Cenicafé, es posible retener hasta un máximo de 35 días entre pases de cosecha, con el fin de garantizar mayor disponibilidad de frutos maduros para la recolección, siempre y cuando la infestación por broca no sea mayor o igual a $2,0 \%$, pues se pueden alcanzar valores muy altos de infestación luego de 30 días.

Para hacer retención de pases es muy importante llevar rigurosamente los registros de floración, para estimar con buena aproximación sobre cuándo van a tener lugar los pases de cosecha más importantes (Rendón et al., 2008) 
y para hacer una correcta planeación de la cosecha y las necesidades de mano de obra.

\section{Recolección de café con Lonas}

A partir de los trabajos de tiempos y movimientos de Vélez et al. (1999), quienes encontraron que se pueden reducir o eliminar micro-movimientos de los recolectores durante la cosecha, se dedujo que al tener un área muy grande donde recibir los frutos desprendidos, el único micro-movimiento necesario para la cosecha de café era desprenderlos para dejarlos caer libremente.

Para este propósito, los mejores resultados se obtuvieron con la cosecha manual con lonas (Figura 2A; Sanz et al, 2018b), la cual consiste en desplegar unas mallas de polipropileno de $12,5 \times 3 \mathrm{~m}$ por las calles del cafetal, en cuyos lados más largos tienen cierres velcro ${ }^{\circledR}$, con el fin de juntar lateralmente 2 lonas bajo los árboles y así conformar una cobertura total del suelo. La reducción de micro-movimientos con este sistema, y la comodidad de desplazamiento de los recolectores, que ya no cargan los frutos recogidos consigo, conllevaron a un aumento de la eficiencia.

\section{Cosecha de café con la Derribadora DSC18}

Cardona (2006) descubrió que, con la aplicación de movimientos repetidos, los frutos de café se desprenden por acumulación de ciclos en el pedúnculo (falla por fatiga), y no por resonancia mecánica. Así mismo, encontró que el pedúnculo de los frutos maduros necesita una menor cantidad de ciclos para
No obstante, para que el desprendimiento sea en tiempos menores a un segundo, se necesitan vibraciones con frecuencias mayores de $200 \mathrm{~Hz}$.

Con base en estos resultados, el trabajo conjunto entre la empresa brasileña Brudden Equipamentos y Cenicafé concluyó con el desarrollo de la Derribadora Selectiva de Café, Brudden DSC 18 (Figura 2B, Sanz \& Duque, 2020). Para aplicar el principio de falla del pedúnculo por fatiga, la máquina tiene un mecanismo que termina en una horquilla que oscila a $220 \mathrm{~Hz}$, con una pequeña amplitud $\left(1,1^{\circ}\right)$. Para que las ondas se propaguen de manera efectiva sobre la rama, el punto de contacto debe ser en el lugar donde es más rígida, lo cual ocurre a unos $5 \circ 10 \mathrm{~cm}$ de distancia desde la inserción de la rama al tallo principal. La derribadora es una tecnología que debe usarse con los otros dos componentes de la Cosecha Asistida de café.

De acuerdo con observaciones de Sanz et al. (2018a) y Sanz e Hincapié (2020), el café proveniente de prácticas de Cosecha Asistida no presentó defectos en la calidad de la bebida.

\section{Concepto de aplicación de la Cosecha Asistida}

Cuando el periodo de cosecha está iniciando, se recogen los pocos frutos maduros que hay en los árboles para evitar una potencial infestación por broca. Aunque en esos momentos es posible realizar la retención de pases, por el bajo volumen de frutos maduros presente se debe proceder a recolectar el café con coco. 


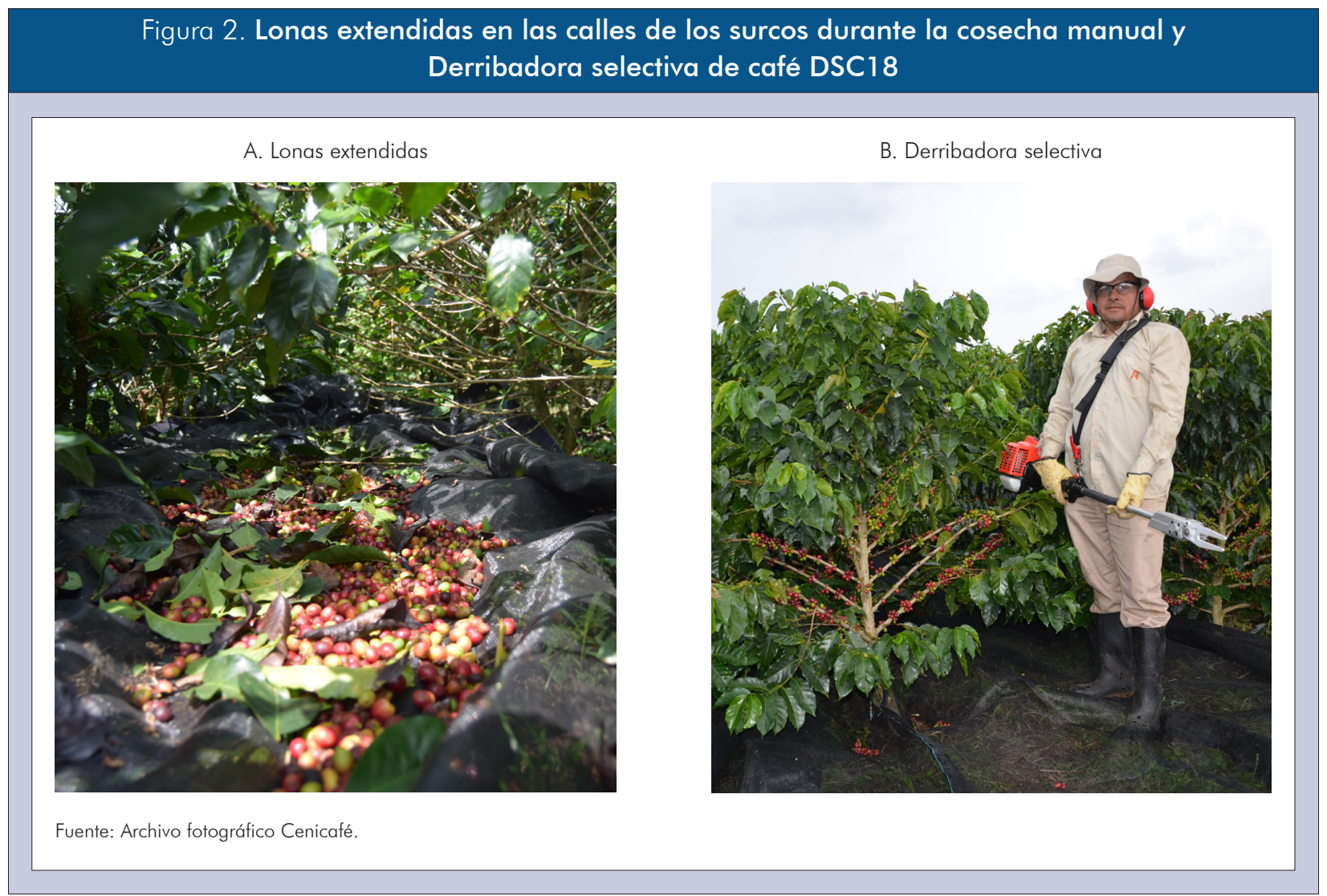

En la medida en que la masa de frutos maduros va aumentando, se continua con la retención de pases, absteniéndose de entrar a recolectar a los lotes en periodos inferiores a 30 días, siempre y cuando la infestación por broca sea menor del 2,0\% al inicio la retención. Al momento de ingresar al cafetal retenido, se extienden las lonas, y se procede a derribar el café de manera manual, o si la carga de café maduro es muy alta, se puede hacer uso de la máquina DSC18.

En un ejemplo teórico de aplicación de la Cosecha Asistida de café en una finca de la zona central cafetera, a nivel de lote, con retención de pases entre 30 y 31 días (Figura 3), la mayoría de las veces se hace recolección de ma- nera tradicional con coco, pagando la mayor cantidad de pases de esa cosecha por jornal. En los meses 4 y 5 , donde se tienen los dos pases más importantes de la cosecha del primer semestre, se aplica el método de recolección manual de café con lonas. Hacia el mes 9 aparece un pase de cosecha de buenas proporciones que igualmente se debe hacer con lonas, mientras que el pase del mes 10, el cual es el mayor de todo el año, es una oportunidad para la cosecha con la derribadora DSC18. De esta manera, la proporción recolectada con máquina representaría el $42,46 \%$, y con cosecha manual con lonas sumaría un total de $39,30 \%$, es decir, el café recolectado con las ventajas de la Cosecha Asistida de Café, totalizaría $81,77 \%$ del total producido en el año. 
En este ejemplo pueden considerarse variaciones, como cosechar el mes 5 con la derribadora DSC 18, debido a que los pases de cosecha que le siguen son de poca magnitud y los frutos verdes de la cosecha principal están todavía muy pequeños; o hacer la cosecha de manera manual con lonas para el pase del mes 10, si no se tiene la derribadora DSC18; finalmente, es posible efectuar el pase del mes 11 con cosecha manual con lonas, a pesar del poco café que habría en los árboles.

Figura 3. Ejemplo de la aplicación de la Cosecha Asistida a lo largo del año en una finca de la zona central cafetera de acuerdo con el porcentaje esperado de cosecha

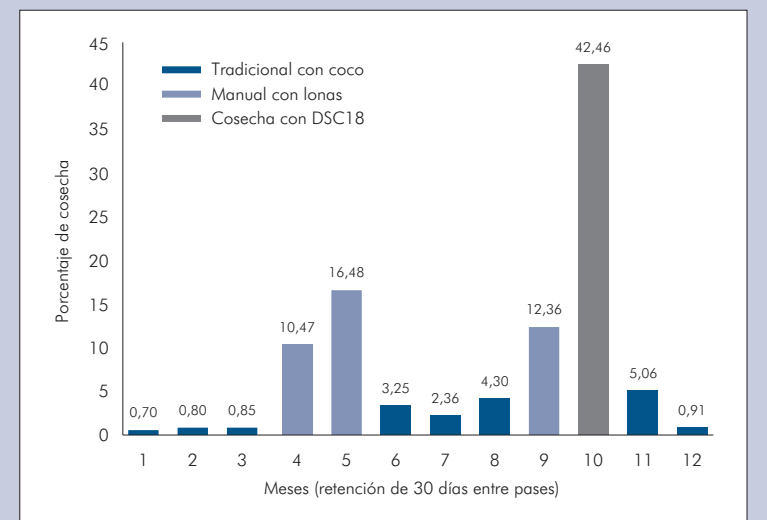

Fuente: elaboración de los autores.

\section{Evaluaciones en campo de la Cosecha Asistida}

Para determinar la factibilidad de la retención de pases, Sanz e Hincapié (2020) realizaron un estudio en la segunda cosecha de 2019 de la dinámica de la maduración de los frutos de café en los municipios de Fresno, Líbano, Ibagué, Valle de San Juan, San Antonio, Chaparral, Planadas y Dolores, del departamento ron dos fincas y en cada una se escogió un lote con edad entre 4 y 5 años. Por la geografía de la vertiente oriental de la Cordillera Central y de la occidental de la Cordillera Oriental, la cobertura de la muestra fue representativa del departamento, y en general de la caficultura nacional.

Se encontró una dinámica de la maduración muy similar en los ocho municipios. Cuando se realizaron retenciones de hasta 35 días, el aumento de frutos cosechables entre el día 17 y el día 35 varió entre 2,97 y 4,00 veces más. Así mismo, las pérdidas representadas por frutos secos y caídos al suelo fueron menores del $2,0 \%$, estando la mayoría de las veces por debajo del 1,0\%. Estos resultados demuestran la efectividad de extender los tiempos entre pases de cosecha, y responden a las preocupaciones de los caficultores por los volúmenes de frutos de café secado en los árboles que se desprenden por sobremaduración.

En cuanto a los resultados de la cosecha manual de café con lonas, Sanz et al. (2018b) encontraron un aumento promedio de $41 \%$ en el rendimiento de los operarios, en comparación con la cosecha manual tradicional con coco. Sanz e Hincapié (2020) reportan que los recolectores obtuvieron un $101 \%$ más de rendimiento trabajando con lonas que los que recolectaron con sistema tradicional. Adicionalmente, los frutos verdes en la masa cosechada estuvieron en rangos muy bajos, lo mismo que los frutos maduros dejados en los árboles. Aunque las pérdidas al suelo fueron bajas para ambos métodos, las obtenidas con el sistema tradicional fueron casi tres veces las obtenidas con el sistema manual con lonas, 
lo que refuerza el argumento que con las lonas se obtienen menores pérdidas de frutos al suelo y se contribuye al manejo integrado de la broca.

Finalmente, para evaluar el desempeño en condiciones reales de la derribadora DSC18, en conjunto con la retención de pases de cosecha y el uso de lonas, se realizaron pruebas en lotes con diferentes pendientes de terreno, edades de los árboles y densidad de siembra, en las Estaciones Experimentales de Cenicafé (Sanz \& Duque, 2020). Los resultados mostraron que cuando se tiene una carga superior a $1,0 \mathrm{~kg}$ árbol-1 y maduración superior al $50 \%$, se obtiene un rendimiento promedio de 28,53 $\mathrm{kg} \cdot \mathrm{h}^{-1}$, que es un $180 \%$ mayor que el obtenido por un recolector promedio (Figura 4).

En el mismo trabajo se obtuvo un contenido de frutos verdes en la masa cosechada de $6,07 \%$, lo que demuestra el carácter selectivo de la máquina, puesto que la presencia de frutos verdes en la rama siempre estuvo entre

Figura 4. Histogramas de rendimiento de la cosecha manual tradicional y de la cosecha con derribadora DSC 18

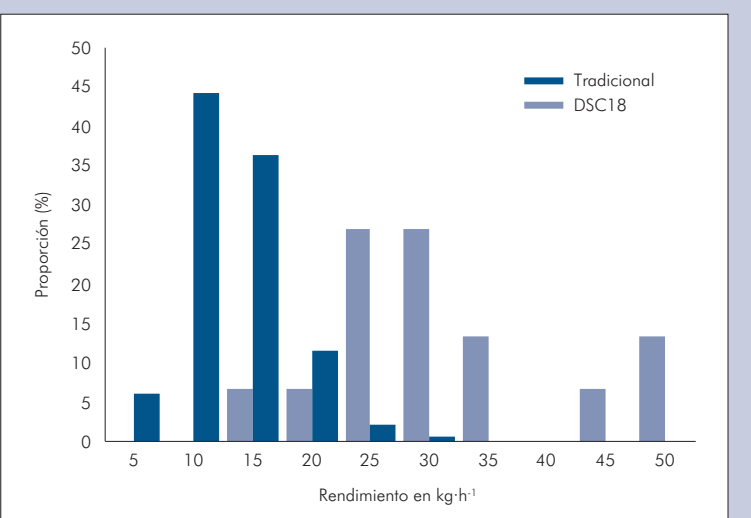

Fuente: elaboración de los autores.
15 y $30 \%$. Adicionalmente, se dejaron en los árboles 6,67 unidades sitio-1 de frutos cosechables en promedio, que es un valor muy cercano al máximo aceptado para manejo integrado de la broca.

\section{Impacto económico de la Cosecha Asistida de Café}

La retención de pases es una práctica sin costo alguno, que debe ser usada tanto en la cosecha asistida de café, como en el sistema tradicional de recolección con coco, donde también puede mejorar el rendimiento de los recolectores.

Por su parte, el uso de un juego de 2 lonas requiere de una inversión inicial, que a la fecha corresponde a COP $\$ 375.000$, y que es muy superior al valor de un par de cocos nuevos (COP \$40.000). Esta inversión debe ser compensada por un mayor rendimiento de la labor, una duración más prolongada de las lonas (más de cinco años), una menor cantidad de mano de obra requerida en picos de cosecha, una mayor ergonomía durante la actividad, una reducción de las pérdidas de café en la cosecha, y por ende una disminución de la infestación de broca, resultando en su conjunto en una ventaja económica, tanto para el recolector como para quien contrate el servicio, y en general, en un trabajo más digno. El aumento del rendimiento de los recolectores encontrado en las pruebas de campo también se expresa en una menor necesidad de infraestructura para alojamiento y alimentación de trabajadores, que también contribuye a la reducción del costo unitario expresado en COP. $\mathrm{kg}^{-1}$. 
Una curva de isoingreso que relacione el cambio del porcentaje del costo unitario con respecto al rendimiento de recolección, se describe con la siguiente ecuación:

$$
C_{u}=\frac{100 \%}{100 \%+A}
$$

Donde $C_{u}$ es el costo unitario expresado en porcentaje y $\mathrm{A}$ es el aumento del rendimiento, también expresado en porcentaje. Esta curva indica los valores porcentuales en los que el recolector mantiene el mismo ingreso mientras se disminuye el costo unitario para el productor por un aumento en la eficiencia. Si se examina el área comprendida entre la línea isoingreso y el $100 \%$ del precio unitario de la región, se encuentra un área de maniobra donde pueden ganar tanto recolectores como productores. Así, si se trabajara con un aumento del $40 \%$ del rendimiento, como el que genera el uso de las lonas, se disminuye en un $30 \%$ costo de mano de obra por unidad de café cosechados, y se podría pactar un precio unitario intermedio (marcado con una cruz en la Figura 5) en el que los caficultores obtendrían una reducción del 14,3\% del precio unitario y los recolectores obtendrían un 14,3\% más de ingreso, comparado con cosechar con el sistema tradicional con coco recolector.

De manera similar, considerando que el mayor impacto positivo sobre el componente de la cosecha puede obtenerse cuando la retención es usada en combinación con la cosecha manual con lonas y con la cosecha con derribadora DSC 18, las reducciones porcentuales en el costo unitario pueden ser aún

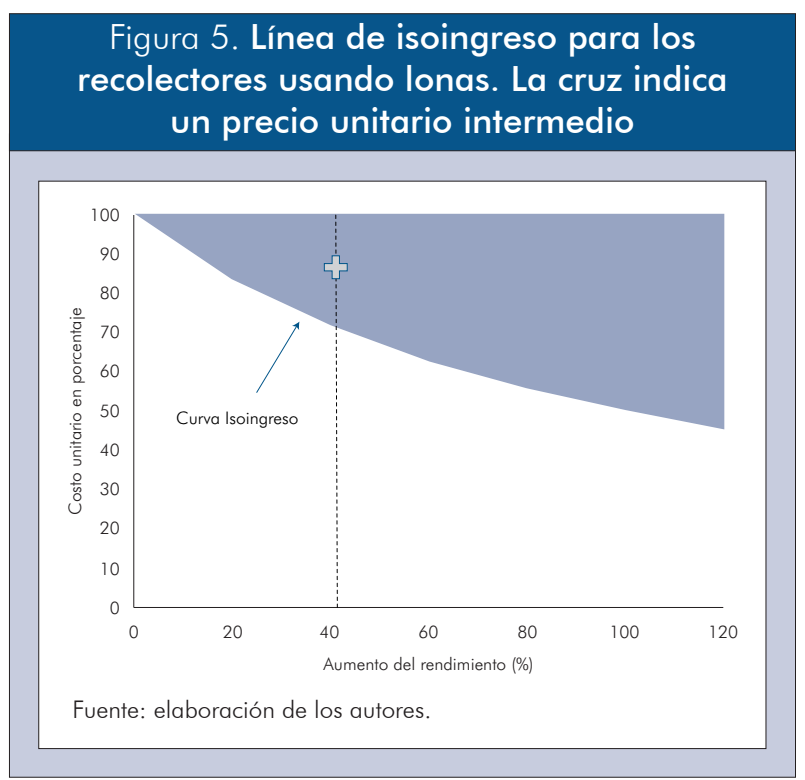

Para determinar el efecto del uso de la derribadora sobre la economía del caficultor, se halla el costo total anual de operación de la máquina, $\mathrm{CT}$, que incluye los costos fijos y costos variables, como muestra la Ecuación 2, y con él se obtiene el costo unitario, es decir el valor que corresponde al uso de la nueva tecnología por kilogramo de café recolectado.

$$
\mathrm{CT}=\mathrm{CV}+\mathrm{CF}
$$

Donde CT son los costos totales, CV los costos variables y CF son los costos fijos. Los costos variables o de operación son aquellos asociados con el uso del sistema de cosecha, que para este caso son la mano de obra, los lubricantes, las reparaciones y el mantenimiento. Por otro lado, los costos fijos son aquellos que necesita pagar el caficultor por ser dueño del equipo.

Para calcular los costos fijos anuales, CF, se utiliza la Ecuación 3 que tiene una amplia utilización internacional, la cual contempla un 
sistema de depreciación lineal de la máquina y los accesorios (Srivastava et al., 2006),

$$
C F=\left[\left(1-S_{v}\right)\left(\frac{I_{r}\left(1-I_{r}\right)^{\tau_{L}}}{\left(1-I_{r}\right)^{\tau_{L}}-1}\right]+K_{\text {tis }} P_{u}\right.
$$

Donde $S_{v}$ es el valor de salvación de máquina expresado en porcentaje del valor inicial de la inversión, $I_{r}$ es el interés real anual expresado en forma decimal, $\tau_{L}$ es el tiempo económico de vida del equipo en años, $K_{\text {tis }}$ es el costo total anual de los impuestos, seguros y garaje expresado en forma decimal, y $P_{U}$ es el valor de compra del equipo. A su vez, el interés real $I_{r^{\prime}}$ que relaciona el interés bancario y la inflación, está dado por la Ecuación 4,

$I_{r}=\frac{I-I_{f}}{1+I_{f}}$

Donde I es el interés bancario e $I_{f}$ es la inflación, ambas expresadas en forma decimal.

Por otro lado, los costos variables anuales $C_{V}$ están dados por la siguiente expresión:

$C V=C_{M O}+C_{C}+C_{R}+C_{M}$

Donde $\mathrm{C}_{M O}$ son los costos anuales asociados a la mano de obra, basado en el valor del jornal pagado en la finca, $C_{C}$ son los costos anuales de lubricantes, $C_{R}$ son los costos de reparación del equipo durante el año y $C_{M}$ son los costos de mantenimiento anuales.

Para obtener el costo total anual correspondiente al uso de la máquina y las lonas se utilizaron los datos de la Tabla 1 en las ecuaciones
Tabla 1. Valores usados para calcular el costo total anual

\begin{tabular}{|lrr|}
\hline & $\begin{array}{r}\text { Valores } \\
\text { DSC18 }\end{array}$ & $\begin{array}{c}\text { Derribadora } \\
\text { Lonas }\end{array}$ \\
\hline Precio de compra $\left(P_{U}\right)$ & $\$ 2.200 .000$ & $\$ 375.000$ \\
Salvación $\left(S_{v}\right)$ & $10 \%$ & $0 \%$ \\
Tiempo de Vida $\left(\tau_{L}\right)$ & 5 años & 5 años \\
Interés bancario $(I)$ & $12 \%$ & $12 \%$ \\
Inflación $\left(I_{f}\right)$ & $3,80 \%$ & $3,80 \%$ \\
Impuestos anuales $\left(K_{\text {tis }}\right)$ & $2,0 \%$ & $2,0 \%$ \\
Tiempo de uso por año & $120 \mathrm{~h}$ & $500 \mathrm{~h}$ \\
Consumo de combustible & $0,25 \mathrm{~L} / \mathrm{h}$ & $\mathrm{N} / \mathrm{A}$ \\
Precio combustible & $\$ 2.113,61 / \mathrm{L}$ & $\mathrm{N} / \mathrm{A}$ \\
Lubricantes por año $\left(C_{C}\right)$ & $1,0 \%$ & $\mathrm{~N} / \mathrm{A}$ \\
Reparación por año $\left(C_{R}\right)$ & $5,0 \%$ & $\mathrm{~N} / \mathrm{A}$ \\
Seguros por año $\left(\mathrm{C}_{S}\right)$ & $1,5 \%$ & $\mathrm{~N} / \mathrm{A}$ \\
Costo unitario cosecha tradicional & $\$ 550 / \mathrm{kg}$ & \\
Promedio recolección tradicional & $100 \mathrm{~kg} / \mathrm{día}$ & \\
Jornal & $\$ 35.000 / \mathrm{día}$ & \\
\hline Fuente: elaboración de los autores. & & \\
\hline
\end{tabular}

2 a 5. Con esos parámetros, el Costo Total es de COP $\$ 26.254,59 / \mathrm{h}$. Con los costos totales relacionados con el uso de las máquinas y las lonas, se obtiene el costo unitario que representa el uso de la máquina, en COP/ $\mathrm{kg}$, el cual es función del aumento del rendimiento (A) en comparación con la cosecha manual tradicional; a mayor aumento del rendimiento menor es el costo unitario asociado al uso de la máquina y sus accesorios.

Con esos datos, se construyó la función de isoingreso con la adición de los costos que representan el uso de la máquina y las lonas (Figura 6), donde se observa que con el aumento observado de un $180 \%$ en el rendimiento, usando la máquina, se obtiene una reducción del costo unitario hasta llegar a casi un 50\%, generando un área de maniobra mucho mayor para un esquema gana-gana recolector-productor. Sin 
embargo, también cabe anotar que, si no se logra un aumento del rendimiento de por lo menos el $45 \%$, el uso de la cosechadora portátil puede generar pérdidas económicas.

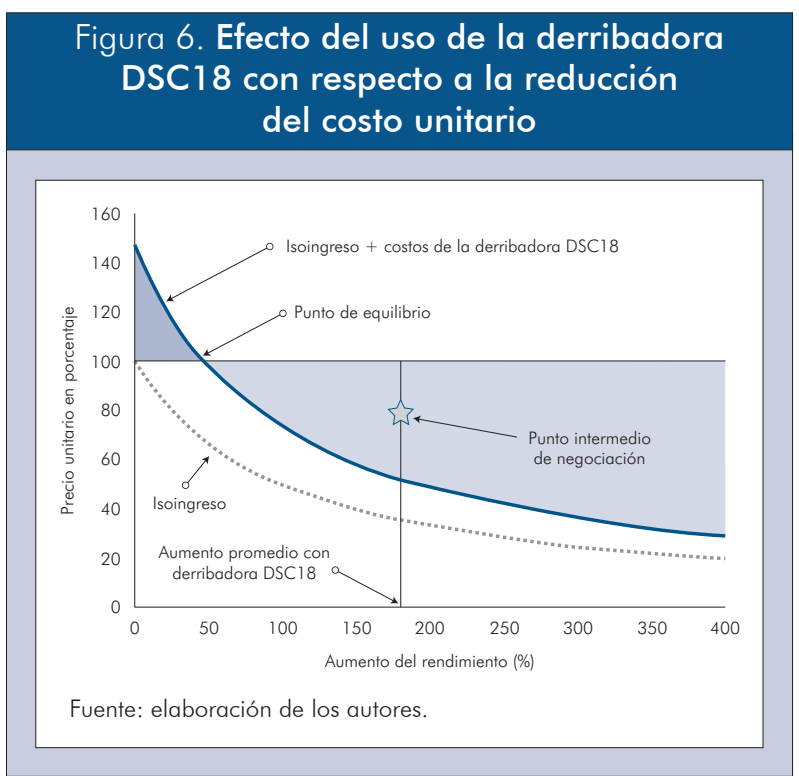

Es de esperarse que con el aumento del rendimiento debido a una adopción cada vez mayor de los conceptos de Cosecha Asistida, haya un movimiento gradual hacia los valores de área de maniobra, que disminuya el costo unitario para los productores, pero simultáneamente incremente el ingreso de los recolectores.

\section{Otras consecuencias de la adopción de la Cosecha Asistida}

Los ensayos realizados, así como las observaciones de los primeros adoptantes de la Cosecha Asistida, indican que además de los cambios en la demanda de mano de obra y los costos, se presenta una serie de aspectos agronómicos, logísticos y administrativos que facilitan la implementación rutinaria de este
Como primera medida, un aspecto agronómico a tener en cuenta es el trazado de las siembras y las condiciones de limpieza de las calles, para que los lotes de café sean aptos para el uso efectivo de las lonas. Si se tienen cultivos intercalados, como plátano o árboles de sombrío, deben ubicarse en lugares donde no interfieran con el uso de las lonas, muy probablemente en los mismos surcos en los cuales está sembrado el café. También se pueden evaluar económicamente prácticas que faciliten el manejo de las lonas, como por ejemplo la poda de las ramas bajeras, donde en los años finales del ciclo hay muy baja producción, y cuya eliminación aumentaría el espacio debajo de los árboles, pero con una adición de mano de obra.

De otro lado, el uso de las lonas para la cosecha manual se facilita cuando se trabaja en pareja o en equipo, especialmente al desplegar y recoger las lonas en los lotes. Esta modalidad tiene influencia sobre el sistema de pago individual actual, ya que en valor de la actividad debe repartirse entre los miembros de la pareja o equipo.

El uso de derribadoras implicará personal más especializado para su manejo y mantenimiento apropiados, para lo cual serán importantes las certificaciones de capacidades laborales, tanto para ejecutar de manera eficiente la labor, como para cumplir con los requisitos de seguridad y salud en el trabajo. Las inversiones en lonas y derribadoras, así como la frecuencia de su uso a lo largo de la cosecha, y la posibilidad de escalar la tecnología a diversos tamaños de fincas, pueden promover iniciativas de venta de servicios por parte de personas individuales 
con equipamientos propios, o de empresas especializadas, que le eviten gastos al caficultor en compra y almacenamiento de implementos que solo utilizaría en unos pases al año.

Desde el punto de vista de salud en el trabajo, se puede afirmar que la manera como se realiza la labor de cosecha en estos momentos es poco ergonómica por los esfuerzos realizados sobre el sistema musculo-esquelético a causa del coco recolector colgado en la cintura, que con el tiempo puede acumular lesiones con consecuencias físicas y económicas.

\section{CONCLUSIONES}

La Cosecha Asistida es una opción para aumentar la rentabilidad de la caficultura, mediante la reducción de los costos de producción por medio de un aumento en la eficiencia del trabajo manual, en una caficultura que requiere selectividad en el fruto recogido para producir un grano de alta calidad, bajo las condiciones climáticas, geográficas y de oferta laboral de Colombia.
En la Cosecha Asistida se aplican 3 conceptos de una manera secuencial y escalable, lo que permite su adaptación a fincas de diversos tamaños y con distribuciones de cosecha muy variables, respondiendo a las condiciones y necesidades de la caficultura del país.

La adopción de los sistemas de recolección manual de café con lonas y la recolección con derribadora tendrán mayor efecto en la medida en que se acuerde el valor del kilogramo de frutos de café recolectado, para que ganen cada una de las partes involucradas en la actividad de cosecha.

Existen ventajas económicas adicionales por el uso de los componentes de la Cosecha Asistida de café, que son difícilmente cuantificables y que dependen mucho de la idiosincrasia, la capacidad administrativa y la inversión en la infraestructura de las fincas cafeteras, y donde se necesitarían evaluaciones más detalladas para totalizar el efecto global de la adopción de esta tecnología, tanto a nivel de finca como a nivel regional o del país. 


\section{REFERENCIAS BIBLIOGRAFICAS}

Ashby, J. (1986). Aspectos socioeconómicos de la adopción de nuevas recomendaciones de fertilizantes para los agricultores. Centro Internacional de Agricultura Tropical - CIAT.

Bustillo, A. E., Cárdenas, R., Villalba, D. A., Benavides, P., Orozco, J., \& Posada, F. J. (1998). Manejo integrado de la broca del café Hypothenemus hampei (Ferrari) en Colombia. Cenicafé. http://hdl.handle.net/10778/848

Cardona, J. A. (2006). Diseño de una máquina portátil para la cosecha asistida de Café [Tesis Pregrado]. Universidad Tecnológica de Pereira.

Duque, H. (2004). Cómo reducir los costos de producción en la finca cafetera (2da. ed.). Cenicafé.

Duque, H. (2018). La adopción de tecnologías agrícolas: bases para su comprensión. Cenicafé. http:// hdl.handle.net/10778/4245

Interaction Design Foundation (2016). The diffusion of innovation - strategies for adoption of products. [En Línea]. 2016. Disponible en Internet: https:// www.interaction-design.org/.../the-difusion-of-innovation. (Consultado en abril de 2018).

Marín, S. M., Arcila, J., Montoya, E. C., \& Oliveros, C. E. (2003). Relación entre el estado de madurez del fruto del café y las características de beneficio, rendimiento y calidad de la bebida. Revista Cenicafé, 54(4), 297-315. http://hdl.handle.net/10778/254

Oliveros, C. E., Alvarez, J. A., Ramirez, C. A., Sanz, J. R., Moreno, E. L., \& Peñuela, A. E. (2006). Cosecha manual de café utilizando mallas plásticas. Avances Técnicos Cenicafé, 354, 1-8. http://hdl.handle. $\underline{\text { net/10778/398 }}$

Oliveros, C. E., \& Sanz, J. R. (201 1). Ingeniería y café en Colombia. Revista de Ingeniería, 33, 99-114.
Rendón, J. R. (2016). Sistemas de renovación de cafetales para recuperar y estabilizar la producción. Avances Técnicos Cenicafé, 463, 1-8. http://hdl. handle.net/10778/701

Rendón, J. R., Arcila, J., \& Montoya, E. C. (2008). Estimación de la producción de café con base en los registros de floración. Revista Cenicafé, 59(3), 238-259. http://hdl.handle.net/10778/108

Sanz, J. R., \& Duque, H. (2020). Evaluación de la Derribadora Selectiva de Café Brudden DSC18. Revista Cenicafé, $71(2)$, 92-104. https://doi. org/10.38141/10778/71207

Sanz-Uribe, J. R., \& Hincapié, J. D. (2020). Aplicación de nuevas tecnologías para la cosecha asistida de café en el departamento del Tolima. Cenicafé. https://doi.org/10.38141/cenbook-0006

Sanz, J. R., Oliveros, C. E., Duque, H., Mejía, C. G., Benavides, P., \& Rivera, R. D. (2018). Retención de pases: una opción para mejorar la productividad de la mano de obra en la cosecha de café. Avances Técnicos Cenicafé, 488, 1-8. http://hdl.handle.net/10778/4218

Sanz, J. R., Duque, H., Menza, H. D., Zamudio, G. E., Oliveros, C. E., \& Ramírez, C. A. (2018). Lonas para asistir la cosecha de café. Avances Técnicos Cenicafé, 487, 1-8. http://hdl.handle. net/10778/4219

Srivastava, A. K., Goering, C. E., Rohrbach, R. P., \& Buckmaster, D. R. (2006). Engineering Principles of Agricultural Machines (2nd ed). American Society of Agricultural and Biological Engineers.

Vélez, J. C., Montoya, E. C., \& Oliveros, C. E. (1999) Estudio de tiempos y movimientos para el mejoramiento de la cosecha manual de café. Boletín Técnico Cenicafé, 21, 1-91. http://hdl.handle. net/10778/593 


\title{
Caracterización ambiental del sector cafetero en Colombia
}

\author{
Dirección de Investigaciones Económicas - Federación Nacional de Cafeteros
}

\section{RESUMEN}

El levantamiento de estadísticas ambientales es un camino necesario para que los sistemas de producción de café se desarrollen en armonía con los recursos naturales y así sean resilientes a la variabilidad climática. De acuerdo a la información disponible y la estrategia de valor del gremio cafetero, el objetivo de la investigación es presentar indicadores ambientales los cuales servirán como línea base para el seguimiento de las políticas públicas. Las estadísticas que se presentan en este artículo se dividen en tres subgrupos; cuidado del recurso hídrico, conservación del suelo y protección de la biodiversidad. Los resultados de esta caracterización muestran los principales retos ambientales en las fincas cafeteras; incrementar la proporción de cafeteros que realizan tratamiento de aguas residuales en el beneficio del café, aumentar los análisis de suelo para elaborar planes de fertilización adecuados, mejorar los sistemas de eliminación de residuos mediante el uso de fosas de compostaje y, por último, la no realización de quemas en su finca.

\begin{abstract}
The collection of environmental statistics is a necessary way for coffee production systems to develop in harmony with natural resources and thus be resilient to climate variability. According to the available information and the value strategy of the coffee guild, the objective of this research is to present environmental indicators that will serve as a baseline for the monitoring of public policies. The statistics presented in this article are divided into three subgroups; care of water resources, soil conservation and protection of biodiversity. The results of this characterization show the main environmental challenges in coffee farms; increase the proportion of coffee growers that carry out waste water treatment in coffee processing, to increase soil analysis in order to elaborate adequate fertilization plans, to improve waste disposal systems through the use of compost pits, and finally, to avoid burning on their farms.
\end{abstract}

Palabras clave: Café, Ambiental, Biodiversidad, Suelo, Agua, Indicadores

Códigos JEL: Q01, Q57, O13

Key words: Coffee, Environmental, Biodiversity, Soil, Water, Indicators

JEL Codes: Q01, Q57, O13 



\title{
Caracterización ambiental del sector cafetero en Colombia
}

\author{
Dirección de Investigaciones Económicas - Federación Nacional de Cafeteros' \\ Para citar este artículo: Federación Nacional de Cafeteros de Colombia. (2021). Caracterización ambiental \\ del sector cafetero en Colombia. Ensayos sobre Economía Cafetera, 34(1), 51-73.
}

\section{INTRODUCCIÓN}

La Federación Nacional de Cafeteros (FNC) en su preocupación por el cuidado del medio ambiente ha realizado a lo largo de sus 94 años de existencia diversos programas de promoción y apoyo a prácticas ecológicas amigables con el entorno de la actividad cafetera, siempre buscando un equilibrio entre la productividad de los cultivos, el uso responsable de los recursos y el tratamiento de residuos de la cadena productiva.

En 2018, la FNC desarrolló la Encuesta Nacional de Hogares Cafeteros (ENHC) con el objetivo de caracterizar a los hogares que viven del cultivo del café en aspectos socioe- conómicos y ambientales. Esta encuesta es representativa ${ }^{2}$ para todo el país, por regiones y por tamaño y reveló información importante sobre aspectos sociales, económicos y ambientales. En complemento, el Sistema de Información de Hogares Cafeteros (SIHC) creado en 2020 por la FNC, permitió obtener estadísticas sobre la vivienda cafetera. Todos estos aspectos son relevantes para entender la forma en que los hogares cafeteros cuidan el medio ambiente, con alta representación estadística.

Este artículo tiene dos propósitos principales; el primero es documentar e informar sobre la

\footnotetext{
Equipo de Investigación: Méndez, J. (jose.mendez@cafedecolombia.com); Gutiérrez, G. (geegutierrezpo@unal.edu.co); Leibovich J. (jose.leibovich@cafedecolombia.com). Agradecimientos a los comentarios realizados por Raúl Jaime Hernández Restrepo (Director de desarrollo ambiental de la FNC), Mario Villamil (especialista en la DIE) y Claudia Córdoba (especialista en la DIE).

2 La encuesta se realizó a 2.477 productores por muestreo probabilístico representativos de 545.279 hogares cafeteros. Por tamaño, se organizó; Micro (menos de 1 hectárea sembrada en café), pequeños (entre 1 y 5 hectáreas), medianos (entre 5 y 10 hectáreas) y grandes (más de 10 hectáreas). Con respecto a las regiones; Sur (Huila, Cauca, Nariño, Caquetá), Eje cafetero (Antioquia, Caldas, Risaralda, Quindío, Valle del cauca), Centro (Tolima, Cundinamarca y Meta), Oriente (Santander, Boyacá, Norte de Santander y Casanare), y Norte: (Guajira, Cesar y Magdalena). Se excluyeron Bolívar, Putumayo y Chocó.
} 
situación ambiental de la actividad cafetera, haciendo énfasis en las actividades realizadas en las fincas. En segundo lugar, se pretende enriquecer la estrategia de valor que propuso la Dirección Ambiental de la FNC en 2020, sirviendo de instrumento de caracterización y línea base. Por esta razón, el marco teórico del artículo seguirá el hilo conductor de las principales propuestas de la estrategia de valor.

El texto se divide en seis secciones. i) Introducción, ii) Contexto y estrategia de valor ambiental, iii) Indicadores sobre el cuidado del recurso hídrico, iv) Indicadores sobre la conservación y uso del suelo, v) Indicadores sobre la conservación de la biodiversidad, flora y fauna; y vi) Conclusiones sobre la caracterización y retos para la agenda 2027.

\section{CONTEXTO Y ESTRATEGIA DE VALOR AMBIENTAL DE LA FNC}

Según la encuesta sobre el reporte de riesgos globales que realiza anualmente el Foro Económico Mundial (2021), los cambios meteorológicos extremos, la pérdida de biodiversidad y la crisis de los recursos naturales hacen parte de las diez amenazas más importantes que tiene la agenda de la humanidad para la década 2020-2030. No obstante, a pesar de que los principales líderes mundiales manifiestan su empatía y preocupación, algunos expertos ambientalistas como Wallace (2017) consideran que en general las acciones ambientales de los gobiernos en los últimos años han sido lentas y tardías, el cambio climático avanza más rápido de lo que parece y eso requerirá que los gobiernos nacionales e in-
Esta preocupación mundial también fue recogida por los 193 firmantes de los Objetivos de Desarrollo Sostenible (ODS), con la fuerte convicción que no era posible pensar el desarrollo económico, independientemente de la sostenibilidad ambiental. Sin lugar a duda, la acción ambiental será una gran preocupación para Colombia y el mundo en los próximos años. Para afrontar este desafío se necesita involucrar a todos los actores de la sociedad, tanto a las empresas como a los hogares. Cada hogar, empresa o sector económico tendrá que identificar y realizar acciones específicas que mitiguen el impacto ambiental de acuerdo con su actividad y capacidad. Lo que se busca es que las economías lineales se conviertan en economías circulares para que así las actividades productivas y domesticas tengan un cierre óptimo de los ciclos de vida de los materias y productos (ENEC,2020).

En Colombia, los gobiernos de turno han ido fortaleciendo su estrategia ambiental en las últimas décadas. En 1994 el país ratificó su participación en el marco de las Naciones Unidas sobre cambio climático mediante la Ley 614. Además, Colombia se unió al Convenio de Diversidad Biológica (CDB), mediante la Ley 165 de 1994, con el objetivo de promover la conservación de la biodiversidad y su uso sostenible, aumentar la participación justa y equitativa de los actores que se benefician de su uso. Años más tarde, hizo parte del acuerdo de Kioto y para el 2009 levantó un inventario nacional de fuentes y sumideros de Gases Efecto Invernadero. En 2011 firmó el CONPES 3700 donde se buscó articular políticas y acciones para minimizar el cambio climático, lo cual Ilevó en 2012 a presentar el 
Plan nacional de adaptación y mitigación del cambio climático. Desde 2016 han aparecido plataformas de políticas que han ido fortaleciendo las acciones ambientales; el CONPES 3874 (Gestión integral de residuos sólidos), CONPES 3934 (Política de crecimiento verde) y CONPES 3866, el cual creó el Sistema Nacional de Cambio Climático (SISCLIMA). Otras acciones de política recientes han sido impulsar la reducción del uso de plásticos de un solo uso, aumentar la justicia climática y la protección de los páramos y la Amazonía. Estos hitos muestran que la política nacional ha venido incluyendo dentro de su agenda acciones ambientales. Sin embargo, existe aún un largo camino por recorrer, como lo mostró el reciente Informe de la Contraloría General de la República (2020) que muestra que la realidad ambiental de Colombia está llena de carencias, y falta un diseño institucional más fuerte y eficaz, acompañado de una destinación de recursos acorde a las necesidades.

Al mismo tiempo, cuando se piensa en política ambiental, suele relacionarse con todas aquellas acciones que deben implementarse en ciudades con sus zonas industriales por tener actividades de alta contaminación, sin embargo, también es imperativo incluir la zona rural a la hora de enfrentar y mitigar los impactos medioambientales. Según la FAO (2018) la contaminación agrícola ha sido subestimada tanto por responsables de las políticas como por los mismos agricultores. En algunos países el agro es el mayor productor de aguas residuales contaminadas. Además, los usos inadecuados de los agroquímicos presentan un verdadero riesgo para el suelo, la salud humana y las especies animales nativas.
El informe de la FAO también muestra que los instrumentos normativos "tradicionales" como permisos para vertimientos, estándares de calidad de agua, y la restricción de algunas prácticas, dependiendo de la actividad agrícola, son herramientas claves para mitigar la contaminación agrícola. De otra parte, la implementación de herramientas modernas como pagos por servicios ambientales y algunos impuestos pigouvianos que se han promovido en América Latina no han tenido un efecto claro. En general estas herramientas han sido difíciles de aplicar por la incapacidad de identificar a los verdaderos responsables y se requiere establecer derechos de propiedad claros sobre la tierra para corregir las asimetrías de información (Aguilar et al., 2018).

Colombia no es ajena a la contaminación ambiental por la actividad agrícola. Para el columnista Ferley Henao (2020), la Colombia ambiental se ha visto afectada por la Colombia rural debido a las malas prácticas y a la falta de implementación de tecnologías modernas. Sumado a esto, la falta de diagnósticos que cuantifiquen el impacto ambiental hace más complicado llevar acciones al territorio. Dada la extensión del territorio, su condición geográfica, la cantidad de reservas y su gran riqueza natural, el país tiene una enorme responsabilidad ambiental consigo mismo y con la humanidad.

En este contexto, la actividad cafetera aparece en el país como un actor relevante para llevar a cabo acciones ambientales en la zona rural. Está presente en 23 departamentos, y cuenta con cerca de 540 mil familias caficultoras que representan alrededor de 1,5 millo- 
nes de personas. Además, la participación en el PIB nacional en 2020 fue de $0,9 \%$, en el PIB agropecuario 11\% (Dane, 2020). Tanto la institucionalidad cafetera como los caficultores y sus familias deben incluirse en este esfuerzo mundial por gestionar acciones ambientales que mitiguen el impacto del ser humano en el ecosistema. Con el ánimo de contribuir a este fin, la FNC fortaleció su estrategia de valor en 2020 y creó la Dirección de gestión Ambiental para potencializar las acciones que han venido siendo implementadas y aumentar el impacto positivo en el medio ambiente y en la vida de las familias productoras. La alineación de la FNC con los Objetivos de Desarrollo Sostenible 2030 hace parte importante de la estrategia. La estrategia ambiental está enmarcada en cinco de los ODS; agua limpia y saneamiento, producción y consumo responsables, acción por el clima, vida de ecosistemas terrestres, y, por último, alianzas para lograr los objetivos.

\section{Estrategia de valor ambiental de la FNC y recomendaciones ambientales para café}

La caracterización ambiental que pretende realizar este artículo, al igual que la estrategia de la FNC, se enfoca entre las etapas de siembra y pos-cosecha (ver ciclo del café, anexo 1). El objetivo de la FNC en materia ambiental para las fincas cafeteras es promover la sostenibilidad ambiental en los sistemas de producción de café, de tal manera que se desarrollen en armonía con los recursos naturales y que los cultivos sean resilientes a la variabilidad climática.

Para reducir el impacto en los recursos natu- sables, ecológicos y sostenibles, y así limitar la contaminación al máximo. Las prioridades que tiene la FNC en el caso de la vivienda son, reducir el consumo de agua, y hacer el tratamiento y disposición adecuada de las aguas residuales (sistemas sépticos). En el caso de la finca cafetera, se pretende disminuir el consumo de agua en el cultivo, especialmente en el beneficio del café, así mismo, mejorar el tratamiento y disposición adecuada de los vertimientos. Además, para evitar la contaminación, será importante promover en las fincas cafeteras un adecuado tratamiento de residuos sólidos provenientes de las actividades domésticas y agrícolas.

El manejo eficiente y amigable con los recursos naturales también implican la protección del suelo y la conservación de la biodiversidad. Prácticas como la siembra a través de la pendiente, uso y manejo de coberturas nobles, no prácticas de quema y la utilización responsable de herbicidas y fertilizantes son la prioridad para la conservación del suelo. Con respecto a la biodiversidad, la fauna en el entorno cafetero siempre será relevante para el gremio, para esto se pretende que no se realicen actividades de cacería ni de cautiverio, y se incentive el no uso de plaguicidas restringidos. Además, se fomenta la conservación de los bosques naturales y su conectividad biológica mediante la construcción de corredores de conservación, los cuales favorecerán un entorno amigable para la fauna y flora.

Frente a la variabilidad climática y sus efectos negativos sobre el cultivo de café, la estrategia plantea aumentar la resiliencia de los cultivos mediante el incremento de las activida- 
des forestales y agroforestales, logrando con ellas aumentar la captura de gases de efecto invernadero (GEI) y generar las condiciones microclimáticas para la protección del cultivo del café ante la presencia de los fenómenos del Niño y La Niña.
Finalmente, vale la pena resaltar que Cenicafé, el Centro Nacional de Investigaciones de Café, se ha dedicado desde sus comienzos a desarrollar tecnologías innovadoras y adaptadas a las condiciones de la caficultura colombiana. En sus investigaciones siembre ha

\section{Infografía 1. Estrategia de valor de la FNC en materia ambiental para las fincas cafeteras}

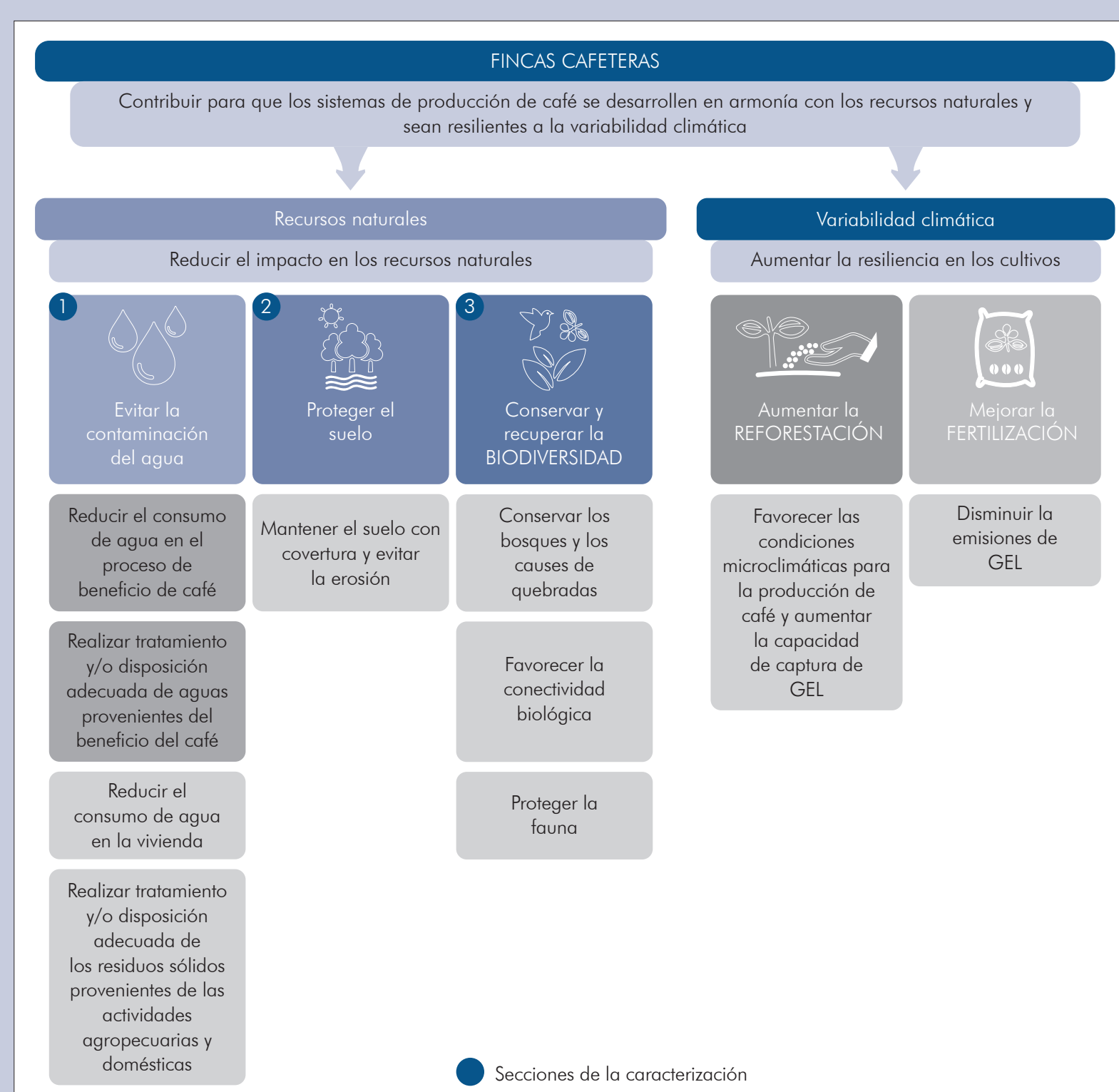

Fuente: FNC. Dirección Ambiental. 
mantenido el propósito de conservar y cuidar los recursos naturales, incorporando en sus proyectos de investigación conceptos como: producción limpia, mejores prácticas agrícolas, economía circular y manejo integrado.

Los indicadores que se mostrarán a continuación se concentran en las tres secciones como se muestra en la Infografía 1. La primera dedicada al cuidado del recurso hídrico para promover su conservación y evitar así su contaminación, la segunda dedicada al uso y conservación del suelo. La tercera se concentra en la biodiversidad vista desde la flora y la fauna.

\section{INDICADORES SOBRE EL CUIDADO DEL RECURSO HÍDRICO}

Para medir el cuidado del recurso hídrico se deben tener en cuenta el acceso y la calidad del agua, además aspectos como la tenencia de activos y/o la realización de prácticas ecológicas son importantes para reducir el consumo en las actividades domésticas y agrícolas. En relación con lo anterior, el análisis se desarrolla desde dos perspectivas; la vivienda y la finca cafetera. Además, se incluyó el manejo de residuos orgánicos y sólidos, ya que el agua puede ser contaminada con un manejo inadecuado de estos residuos.

La vivienda cafetera, según el SIHC (2020), que contiene información oficial registrada en Sisbén, reporta que el $44 \%$ de los hogares cafeteros cuentan con servicio de acueducto para recibir agua en sus viviendas. Si bien la principal fuente de abastecimiento de agua otras fuentes importantes como son los nacimientos propios, quebradas, arroyos, ríos, carro tanques, etc., debido a que los cafeteros se encuentran ubicados principalmente en el sector rural disperso del país.

\section{Gráfico 1. Acceso al agua de los hogares que están registrados en Sisbén}

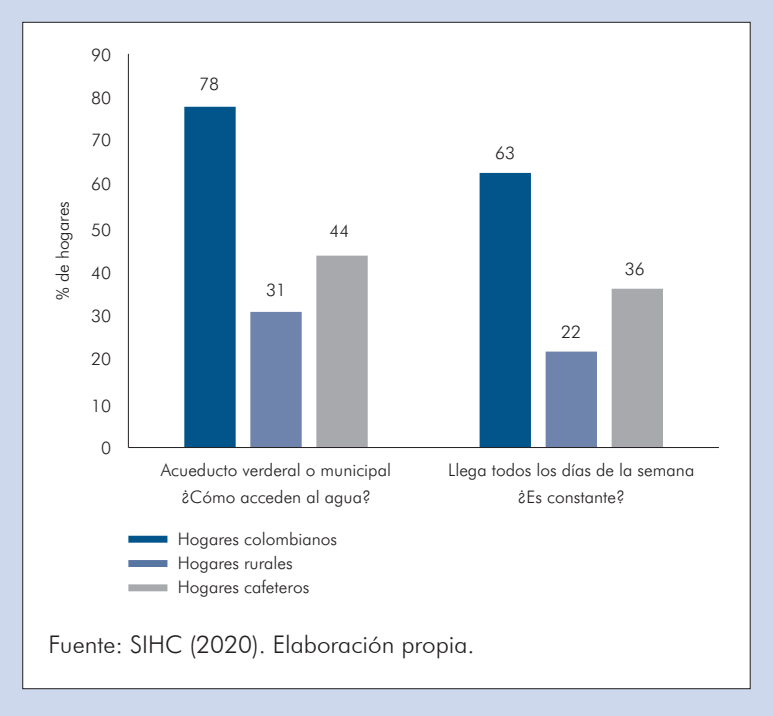

En los hogares cafeteros la cobertura del acueducto es mayor que en los hogares que habitan en el sector rural disperso en general, los cuales presentan una cobertura del $31 \%$. Sin embargo, la cobertura en los cafeteros es menor que la del total de hogares colombianos que realizaron la encuesta Sisbén, que asciende al 78\%. Lo anterior, muestra el gran desafío que existe en el país por llevar el recurso hídrico a las zonas rurales, en especial a las más vulnerables, bien sea por acueducto a por alguna otra fuente de agua potable.

Los cafeteros también se encuentran en una mejor situación en cuanto al suministro constante de agua con respecto al promedio de 
los hogares rurales, el $36 \%$ de los cafeteros cuenta con un suministro continuo, mientras que en el caso de los hogares rurales solo el $23 \%$. Aun así, continúan siendo cifras muy por debajo del $63 \%$ del total de hogares colombianos que están registrados en Sisbén y que manifestaron recibir agua en su vivienda siete días a la semana.

En la ENHC (2018) se les consultó a los hogares cafeteros si desde su perspectiva consideraban haber tenido problemas de escasez o de calidad en el agua, o conflictos por el recurso ${ }^{3}$. Se encontró que la gran mayoría de los cafeteros no sufren de escasez en su hogar. Como se muestra en el Gráfico 2, el $81 \%$ de los hogares cafeteros manifestaron no haber tenido problemas por escasez de agua en su vivienda, el 92\% afirmaron que en los últimos años el productor, su hogar y las personas que habitan en su vereda, no han tenido conflictos relacionados con el recurso. Es importante resaltar que esta tendencia se mantiene a lo largo de las cinco regiones y por tamaño del productor.

La información presentada muestra que la gran mayoría de hogares cafeteros no tienen

\section{Gráfico 2. Cuidado del recurso hídrico desde la percepción de los hogares cafeteros}

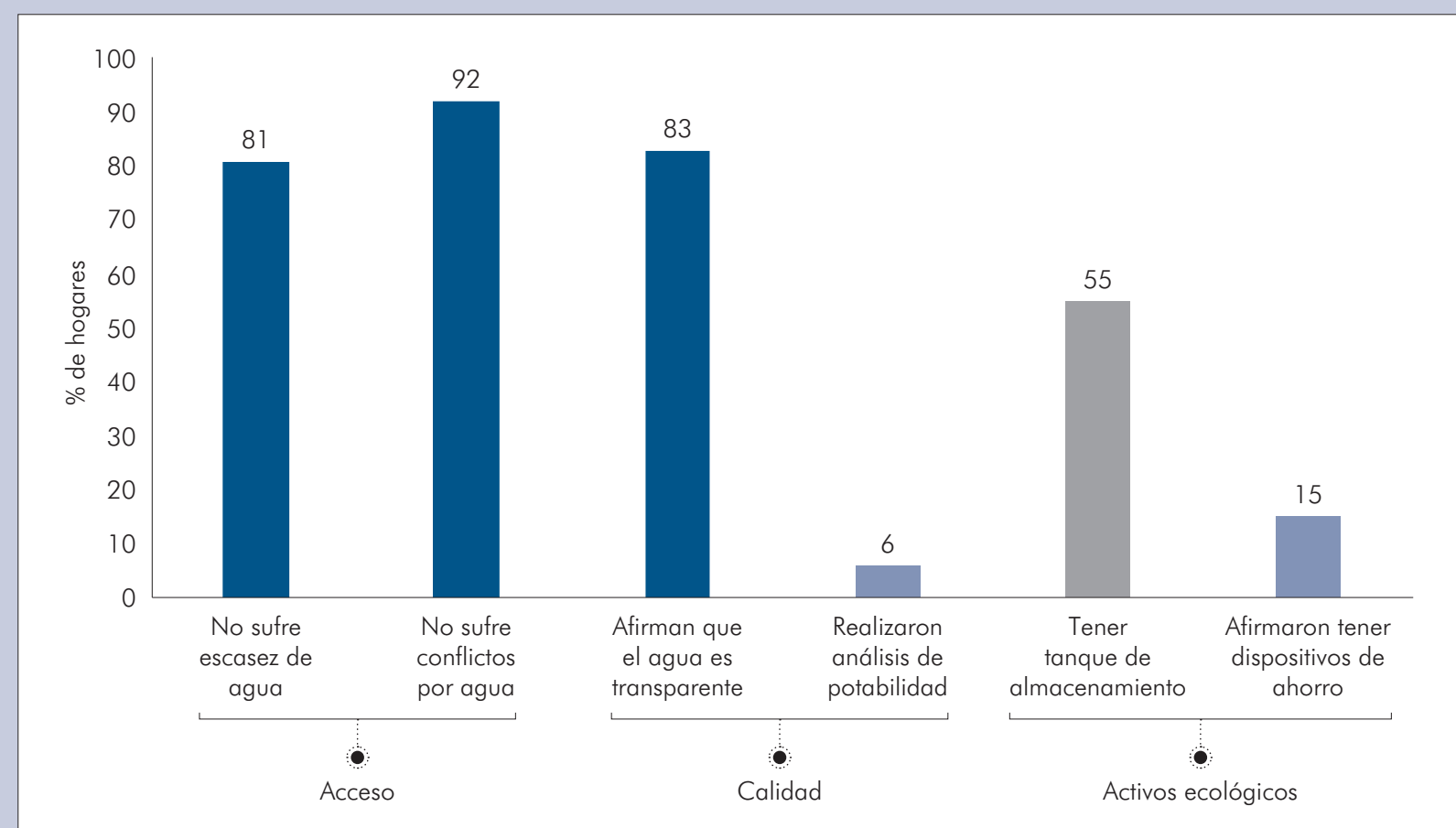

Fuente: ENHC (2018). Elaboración propia.

3 En la ENHC (2018) se les pregunto a los caficultores: ¿̇En los en los años recientes ha tenido conflictos en su comunidad por el agua? 
problemas con el suministro de agua, a pesar de que la cobertura de acueducto está presente en menos de la mitad. Con base en la encuesta se dedujo que las viviendas utilizan otras fuentes de agua para su consumo, como nacimientos propios, ríos, carros tanques, lagos, entre otros.

Se les consultó a los cafeteros acerca de su percepción de la calidad del agua que llega a su finca, y el 83\% la calificó como "transparente", los demás afirmaron que el agua llegaba "turbia" o "pantanosa". Para el Ministerio de Vivienda (2019), en el informe IRCA se presenta que en promedio el sector rural no presenta riesgo en cuanto a calidad del agua para consumo humano ya que el índice se ubica en $10,68 \%$, cifra que representa riesgo muy bajo. Sin embargo, la potabilidad se garantiza por medio de análisis que realizan en laboratorios especializados y certificados, los cuales, solo el $6 \%$ de los cafeteros manifestó haberlos hecho en alguna oportunidad (ENHC, 2018).

Dentro de la tenencia de activos ecológicos, los tanques de almacenamiento se han convertido en una característica importante para el cuidado del recurso hídrico porque mitiga el riesgo de no tener agua siempre disponible, mejorando así el acceso de ésta, además, facilita el tratamiento del agua restaurando la calidad, e incluso puede promover prácticas de reciclaje y economía circular. La ENHC (2018) encontró que el 55\% de las viviendas cafeteras poseen tanques de almacenamiento de agua. Por regiones, los caficultores de Centro y Oriente manifiestan tenerlos en una ro que se encuentra sobre la media nacional, mientras que la región Norte obtuvo la proporción más baja. Además, se encontró una relación positiva entre el tamaño del productor y la tenencia de tanques de agua, a medida que aumenta el tamaño de los productores, la disposición a pagar e instalar tanques aumenta considerablemente como se observa en el Gráfico 3. El 84\% de los cafeteros manifestó no lavar el tanque frecuentemente, lo cual, es importante para mantener las condiciones de higiene adecuada dado que el destino del agua es principalmente el consumo humano.

Aparte de la tenencia de tanques de almacenamiento, existe un conjunto de prácticas y dispositivos que facilitan el ahorro de agua en el hogar. En el mercado existen dispositivos que se encuentran fácilmente como grifos aireadores o válvulas de restricción de salida, que reducen el caudal del agua y ahorran hasta un $40 \%$ del recurso, también se encuentran lavadoras, duchas o cisternas más eficientes, que consumen entre 6 y 9 litros de agua menos por descarga. Desde la FNC se observa que prácticas sencillas como el cierre oportuno del grifo, es decir, no dejar la llave abierta, evitan el consumo innecesario del recurso. Cuando se les consultó a los cafeteros, el $85 \%$ de los productores manifestaron no tener ningún dispositivo de ahorro de agua en la vivienda (ENHC, 2018). La promoción de estas prácticas y la facilitación del acceso de estos instrumentos en la zona rural es un desafío de las autoridades competentes.

Desde la perspectiva de la finca cafetera, los retos son un poco diferentes. A partir de la 
encuesta del 2018 se encontró que la mayoría de los cafetales no requieren que se les suministren grandes cantidades de agua, pues el agua lluvia es suficiente para su desarrollo. Sin embargo, se debe tener atención con los rangos de lluvia óptimo para el cultivo de café. En caso de dos meses de lluvias consecutivas se recomienda intensificar las prácticas de conservación del suelo, o si la lluvia es muy intensa no se aconseja la fertilización (Cenicafé, 2010). Además, en la ENHC (2018) se les consultó a los productores si han tenido que regar el cultivo, y el $86 \%$ manifestó no haber tenido que hacerlo, y a lo largo de todo el territorio nacional no se encontraron diferencias significativas por regiones o tamaño de los cultivos. Caso contrario a lo que ocurre en otros cultivos como la caña, la palma, el plátano o el arroz, donde se requiere de un consumo de agua para riego significativo.

Si bien la finca cafetera no consume mucha agua en el cultivo, sí la consume para realizar el proceso del beneficio del café. Se le consultó a los caficultores sobre la principal fuente de agua para realizar el beneficio de su café, y la mayoría respondió que son los acueductos veredales o municipales (49\%), en segundo lugar, están las quebradas, ríos y arroyos (32\%), y lo demás procede de agua lluvia, pozos y nacimientos de otras fincas (ENHC, 2018). Es importante aclarar que en muchas ocasiones los productores cafeteros arriendan la maquinaria para realizar el beneficio de su café, y acuden a asociaciones, cooperativas o microcentrales de beneficio de la comunidad.

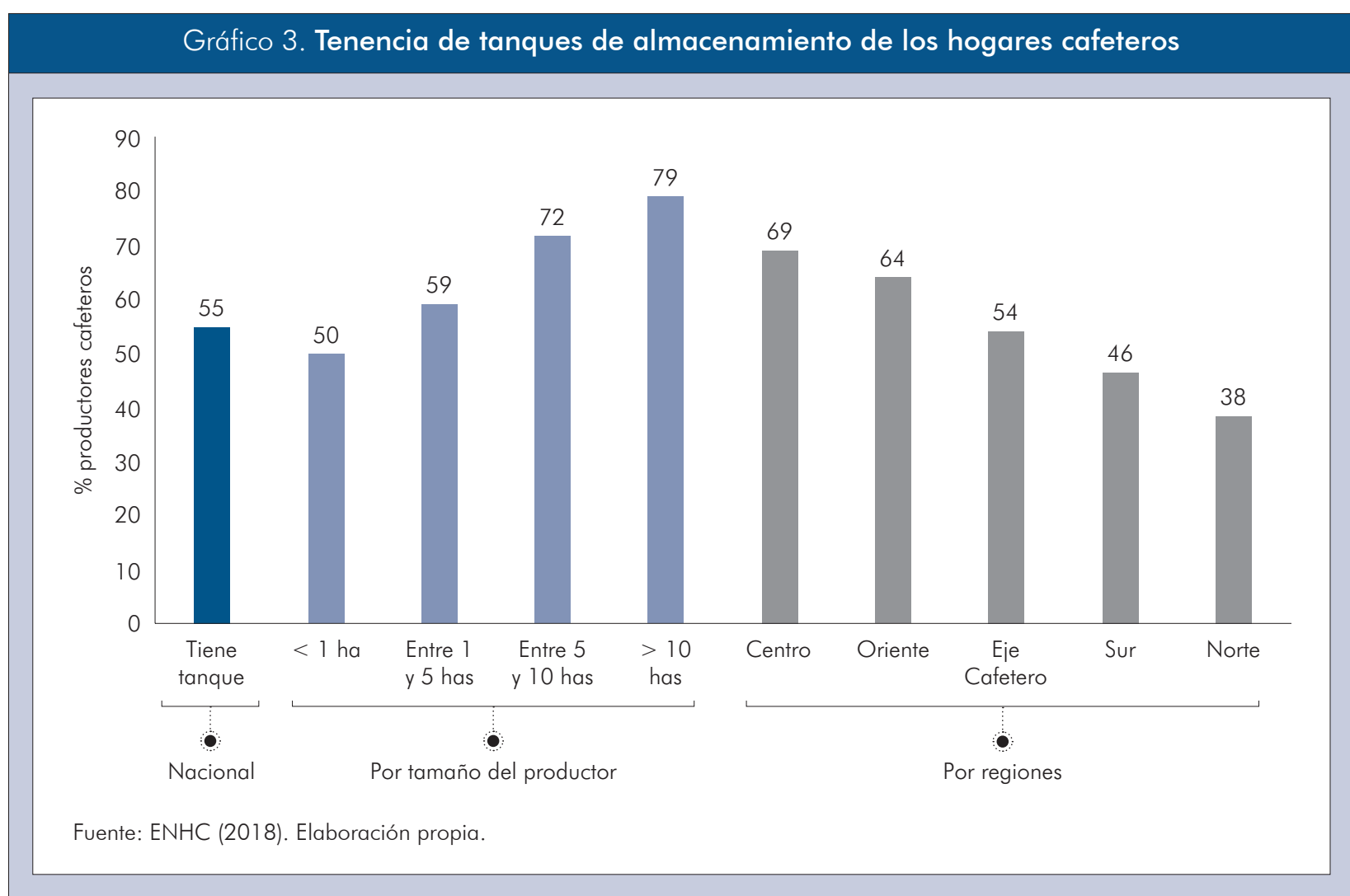


Es decir, no es necesario que la totalidad de las fincas cafeteras cuenten con infraestructura del beneficio, de hecho, es mejor que sea así.

La estrategia de valor propone que la reducción del consumo de agua y el tratamiento adecuado de los vertimientos son prioridad para el cuidado del recurso hídrico en el proceso del beneficio. La reducción del consumo puede darse mediante la implementación de prácticas como la no utilización de agua en el despulpado o en el transporte, así como, mediante el uso de tecnologías Becolsub y Ecomill, que reducen considerablemente el consumo de agua, y la recirculan.
Por otra parte, alrededor de la mitad de los caficultores manifestó que en el lugar donde realizan el beneficio, despulpan el café sin agua y no utilizan agua para su transporte, basta con utilizar medios mecánicos que aprovechan la gravedad para llevar a cabo estos procesos. En cuanto a la tenencia de activos ecológicos se encontró que la cuarta parte de productores tienen y utilizan una fosa de compostaje para la pulpa. Desde la FNC y Cenicafé se ha impulsado la implementación de la fosa de compostaje, la cual sirve para generar abono orgánico efectivo para el cultivo, y que, además, bajo el concepto de recirculación, termina apoyando la dispo-

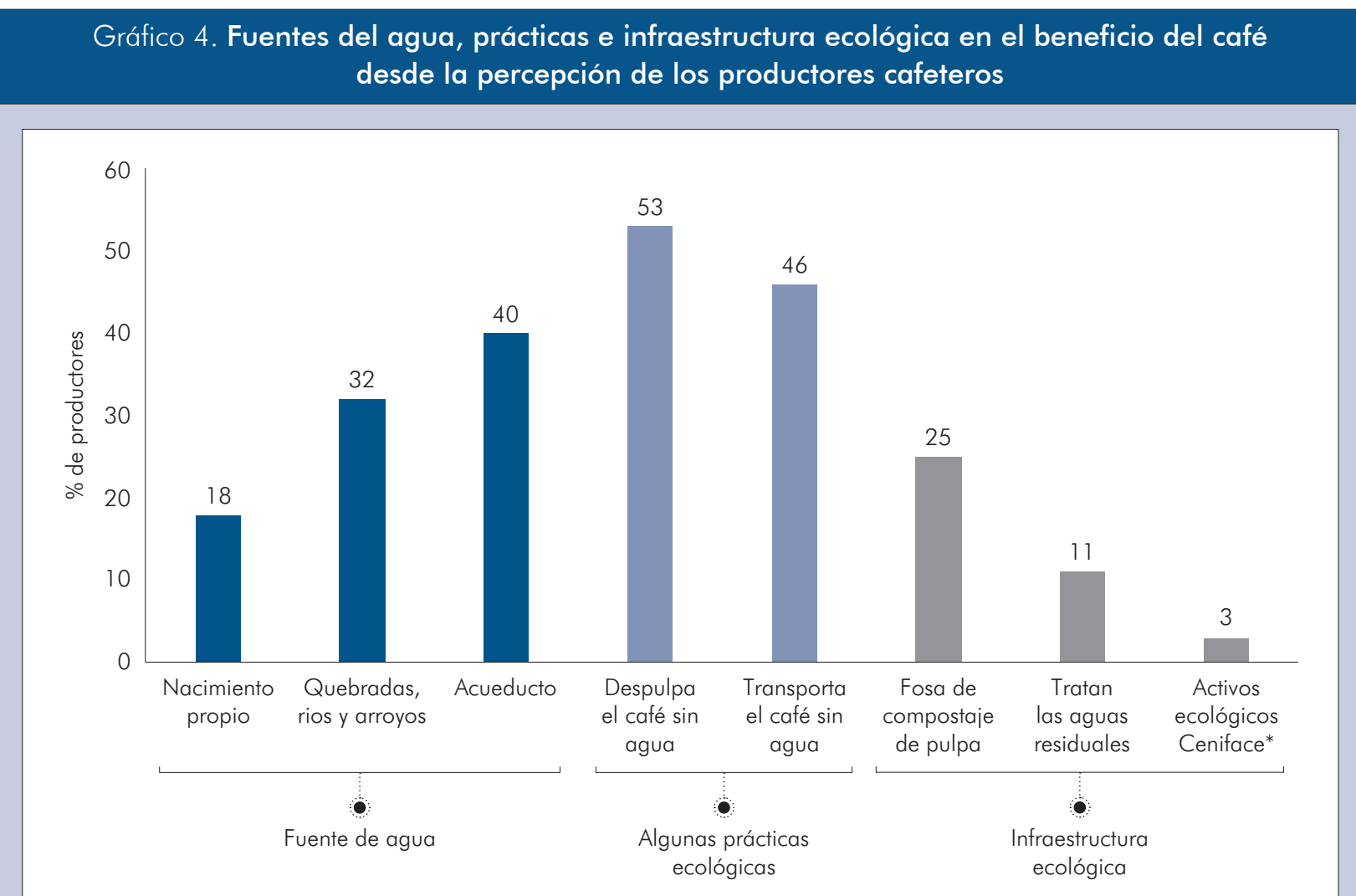

Nota: La sumatoria de las categorías no suman 100\%.

* Activos ecológicos corresponden a uso de tecnologías Becolsub y Ecomill.

Fuente: ENHC (2018). Elaboración propia. 
sición adecuada de las aguas residuales del beneficio.

A pesar de los esfuerzos institucionales que pone a disposición la tecnología ECOMILL y BECOLSUB, la ENHC (2018) encontró que apenas el $3 \%$ de los caficultores beneficia su café utilizando esta tecnología. No obstante, la infraestructura ecológica para el beneficio del café es diversa, si bien existen máquinas sofisticadas como las que brinda Cenicafé y otras empresas de alta tecnología agroindustrial, el caficultor puede emplear prácticas y maquinaria menos sofisticadas que permiten que ahorre agua y realice tratamiento de aguas residuales mediante métodos biológicos, físicos o químicos.

Para la estrategia de valor es una prioridad el tratamiento de las aguas residuales. Sin embargo, el reto es grande pues la consulta realizada por la encuesta encontró que solo el $11 \%$ de los productores manifestaron realizar tratamiento, el resto las vierte sin tratamiento, y de estos, el $80 \%$ lo hace al suelo y el $20 \%$ a las fuentes hídricas. Sumado a lo anterior, el $94 \%$ de los caficultores manifestó que en el lugar donde realizan el beneficio no se preocupan por tener permisos para vertimientos en lugares adecuados para este fin.

En su preocupación por los recursos hídricos, la FNC desarrolló programas como Manos al Agua-Gestión Inteligente del Agua (GIA), un proyecto con una inversión de más de 25 millones de euros, el cual fue posible gracias a una alianza público-privada entre la FNCCenicafé, Nestlé, Nespresso, la Universidad Wageningen- WUR y la Netherlands Enter- prise Agency- RVO. GIA fue ejecutado entre 2013 y 2018, con intervención en 25 microcuencas en los departamentos de Antioquia, Caldas, Cauca, Nariño y Valle del Cauca, beneficiando a 11.600 familias cafeteras. Como resultado del proyecto, y específicamente en el municipio de Aguadas, se les preguntó a los productores en 2013 si hacen tratamiento de aguas residuales para su cultivo, el $2 \%$ expreso no hacerlo. Para el 2017, se les hizo la misma pregunta, y $43 \%$ de los productores respondió que efectivamente lo estaban haciendo. Lo anterior, ejemplifica el impacto positivo que se puede obtener realizando programas adecuados donde los esfuerzos se enfoquen a problemas específicos.

\section{Manejo de residuos sólidos y orgánicos}

Los hogares cafeteros eliminan los residuos orgánicos principalmente mediante la conexión a pozos sépticos (45\%), ver gráfico 5 . Por el contrario, en los hogares colombianos el servicio de alcantarillado es el principal método de eliminación de desechos, el 64\% de aquellos que están en el Sisbén manifestaron poseer este servicio. Por supuesto, esto se explica debido a que llevar conexión de alcantarillado a la totalidad de los sectores rurales resulta en extremo costoso. No obstante, la cobertura de alcantarillado de los cafeteros es en promedio mayor a la de los hogares que habitan en la zona rural, el 19\% de los hogares cafeteros cuenta con servicio de alcantarillado, mientras que solo el $4 \%$ de hogares rurales posee este servicio. La presencia de alcantarillado tiene una alta correspondencia con los hogares cafeteros que viven en las cabeceras y centros poblados, los 
cuales corresponden a cerca del $23 \%$ de la población cafetera (SIHC,2020).

Además, una alta proporción de hogares rurales tienen un sistema inadecuado de eliminación de excretas, a nivel nacional el 45\% cuenta con un sistema inadecuado, en el caso de los cafeteros es el 36\%. Según el Sisbén, se considera como inadecuado si el inodoro del hogar está sin conexión o utiliza letrina o bajamar. Ahora bien, en la ruralidad colombiana prima el uso de pozo séptico como la opción más adecuada para la buena disposición de residuos, y parte importante de tenerlo es realizar procesos de limpieza y mantenimiento de los mismos, si la materia orgánica no es contenida adecuadamente puede contaminar fuentes hídricas o el suelo. Al consultarles a los productores cafeteros que cuentan con pozo séptico si le realizaban mantenimiento, solo el 25\% manifestó haberlo hecho en alguna oportunidad reciente. (ENHC,2018).

La eliminación y tratamiento de residuos sólidos también es una preocupación del gremio, por eso desde la FNC se recomienda tener una disposición adecuada de residuos de todas las actividades agropecuarias y domés-

\section{Gráfico 5. Eliminación de residuos sólidos y orgánicos de los hogares cafeteros}

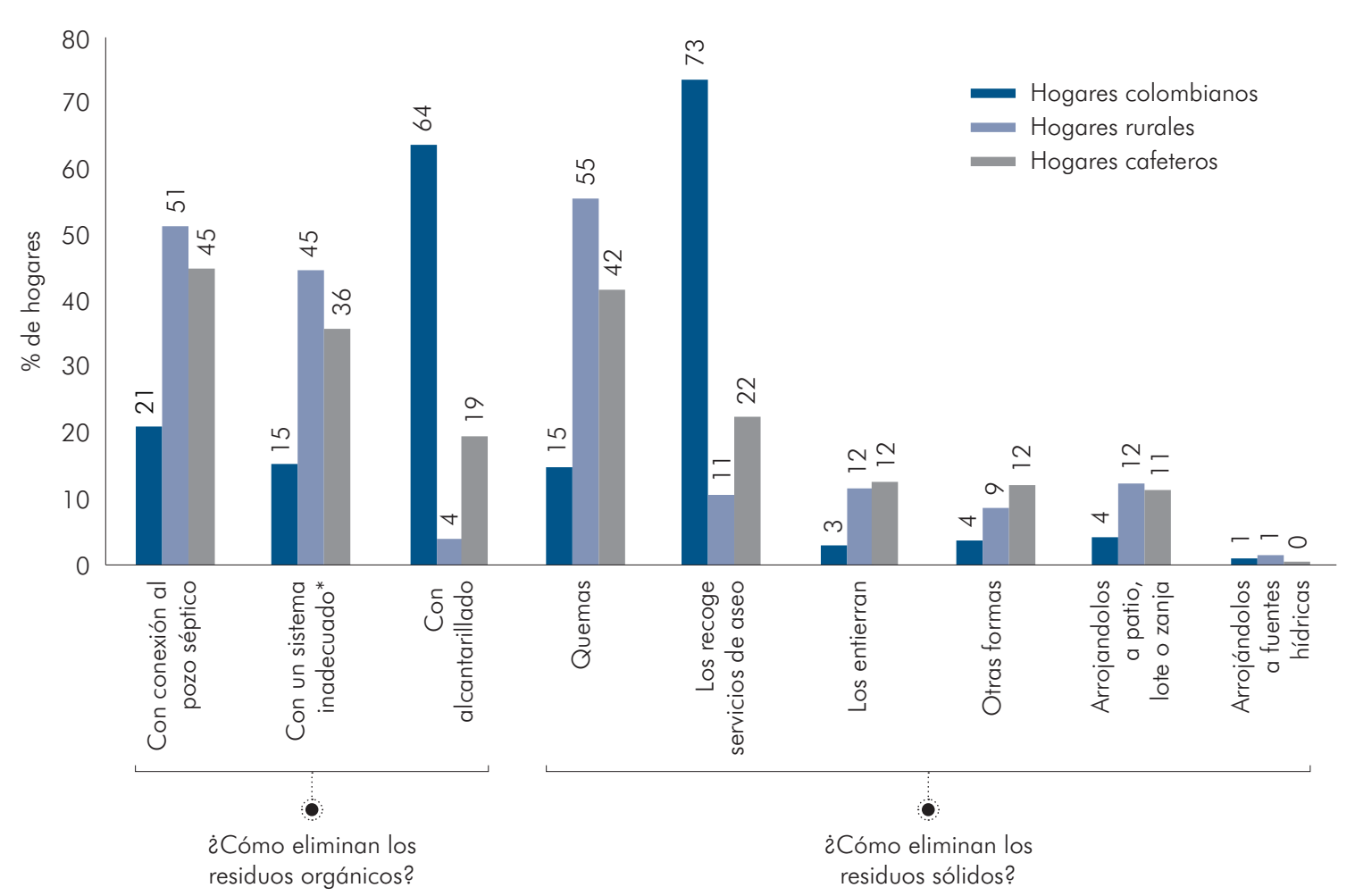

* Sistema inadecuado puede ser sin conexión alguna, uso de letrina o bajamar o la vivienda no cuenta con algún sistema. Fuente: SIHC (2020). Elaboración propia. 
ticas de la finca. En el caso de la población cafetera, se encontró que, si bien los hogares no vierten los residuos sólidos a las fuentes hídricas, existe una alta proporción (42\%) que los eliminan principalmente mediante quemas, y esto se explica porque la cobertura de los servicios de aseo en las zonas cafeteras es relativamente baja (22\%), aunque mejor que el promedio nacional rural, ver Gráfico 5.

\section{INDICADORES SOBRE LA CONSERVACIÓN Y USO DEL SUELO, DESDE LA PERSPECTIVA DE LA FINCA CAFETERA}

Para obtener estadísticas sobre la conservación del suelo se les consultó a los productores sobre la realización de algunas prácticas de conservación como uso de agroquímicos y presencia de erosión en zonas de la finca. Además, con información del SIHC se logró identificar realización de quemas por departamentos y tamaño del productor, las cuales no son recomendables.

Dentro de algunas prácticas amigables con el medio ambiente se recomienda mantener el suelo de la finca con coberturas vivas y muertas, siempre teniendo presente el adecuado manejo de arvenses. El $61 \%$ de los productores manifestó usar coberturas muertas en su lote cafetero y $43 \%$ vivas (ENHC,2018), refiriéndose vivas al uso de nobles los cuales previenen o disminuyen la erosión del suelo. Adicionalmente, según Cenicafé, lo más adecuado para el cultivo es no regar la pulpa fresca sobre el cafetal, en vez de esto se debe preparar el compostaje en una fosa para que luego de un tiempo determinado se convierta en abono orgánico. El $57 \%$ de los producto- res manifestó no regar la pulpa y como vimos anteriormente, el 25\% tienen fosa de compostaje (ENHC, 2018).

En cuanto a la eliminación de residuos sólidos no aprovechables, el $42 \%$ de los hogares cafeteros lo realizan mediante quemas. Al analizar esta práctica por tamaño del predio cafetero, se encontró que a medida que los productores son más grandes, realizan quemas en una menor proporción. Son los productores menores a $1 \mathrm{Ha}$ y entre 1-5 Ha, los que utilizan esta práctica más frecuentemente. En términos relativos, por departamentos se evidencias amplias diferencias. Quindío es el departamento donde la realización de quemas es más baja y Boyacá donde es más alta, (ver Gráfico 7). Ahora bien, los departamentos con mayor número de productores (Antioquia, Huila, Cauca, Tolima) presentan un nivel de quemas de residuos sólidos similar al promedio nacional (42\%).

Asimismo, y con el ánimo de mitigar el riesgo de producir incendios forestales y quemas indiscriminadas, se recomienda no realizar quemas en las fincas, tanto para eliminar residuos del hogar como también para preparar el terreno a cultivar.

Por otra parte, el uso adecuado de los agroquímicos (fertilizantes, herbicidas, plaguicidas, fungicidas e insecticidas) es parte esencial de la acción ambiental. Por esta razón, la FNC por medio de los comités departamentales y municipales ha promovido dos aspectos importantes; el primero es el uso adecuado de herbicidas, el segundo, es utilizar las cantidades correctas de fertilizantes. Para llevar a 
cabo éste último ha impulsado la realización de los análisis de suelo y/o la utilización de los agroquimicos desarrollados por Cenicafé, los cuales permiten establecer un plan de fertilización adecuado que incremente la productividad y así evitar la contaminación por exceso de nutrientes.

La encuesta primero consultó a los productores si utilizan fertilizantes o alguna clase de agroquímicos como fungicidas, herbicidas y o plaguicidas, $70 \%$ de los productores manifestó haberlos usado, además, se encontró una relación positiva entre el tamaño del productor y el uso de agroquímicos, a medida que incrementa el tamaño del productor también aumenta el uso de los agroquímicos. Sin embargo, puede estar ocurriendo que estén utilizando fertilizantes, pero no en las cantidades óptimas, de allí deriva la importancia de los análisis de suelos. La encuesta encontró que el $20 \%$ de los cafeteros realizaron estudios

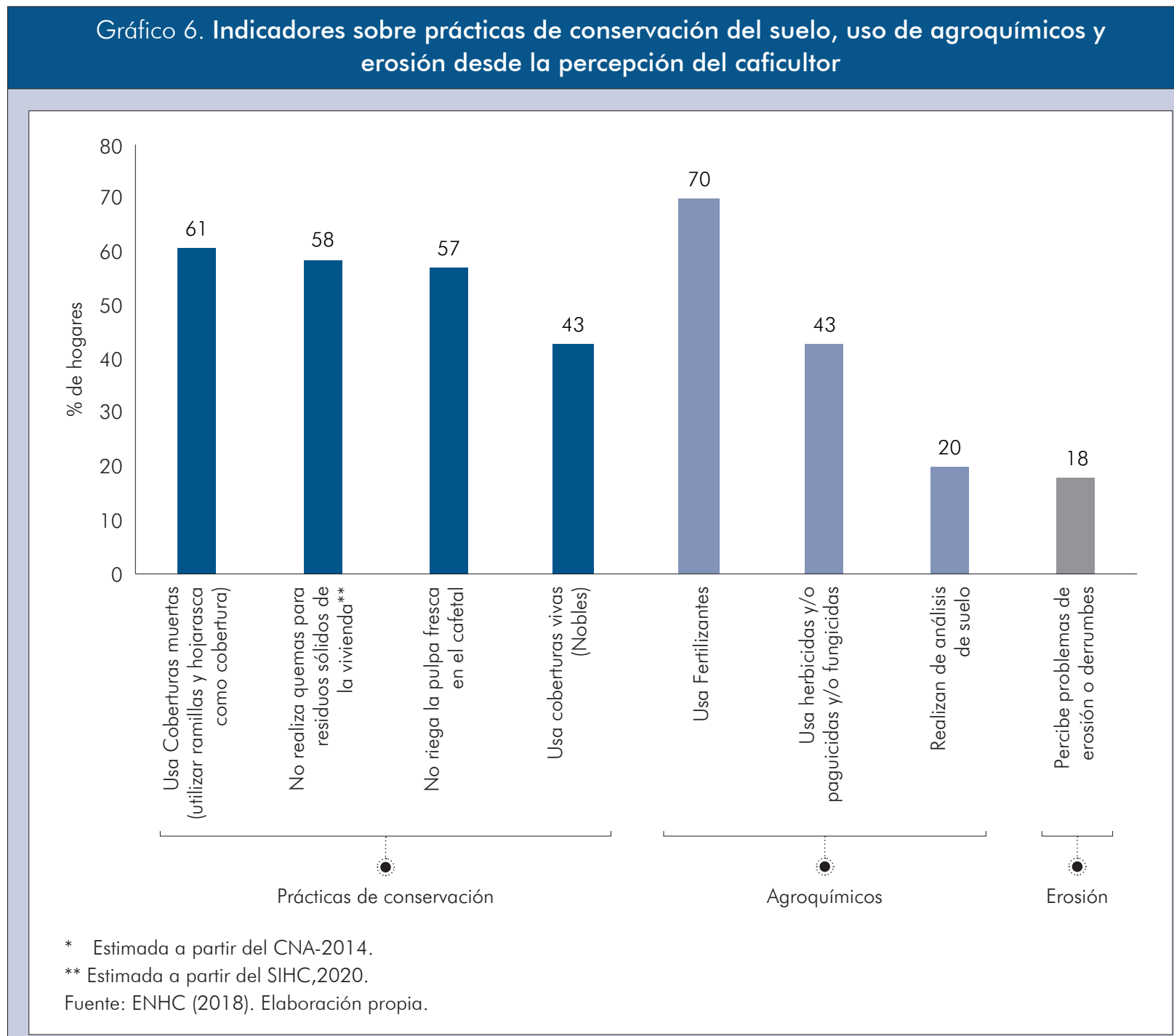


de suelos; el eje cafetero y la región norte se encuentran por encima del promedio con un $34 \%$ y $23 \%$ respectivamente, mientras que las regiones sur, centro y oriente se encuentran en un nivel inferior a la media. Los productores más grandes realizan análisis de suelos en mayor proporción que los productores más pequeños.

Finalmente, para la conservación del suelo es importante el manejo integrado de arvenses, ya que la eliminación total de arvenses en los cultivos puede traer graves problemas. Dejar el suelo cafetero completamente desnudo puede ocasionar erosión, y más en las fincas con pendientes pronunciadas, debido a que las plantas reducen la velocidad a la que fluye el agua más superficial del suelo, por lo tanto, reducen la erosión del mismo y la probabilidad de que ocurran deslizamientos en los lugares más empinados de las fincas productivas.

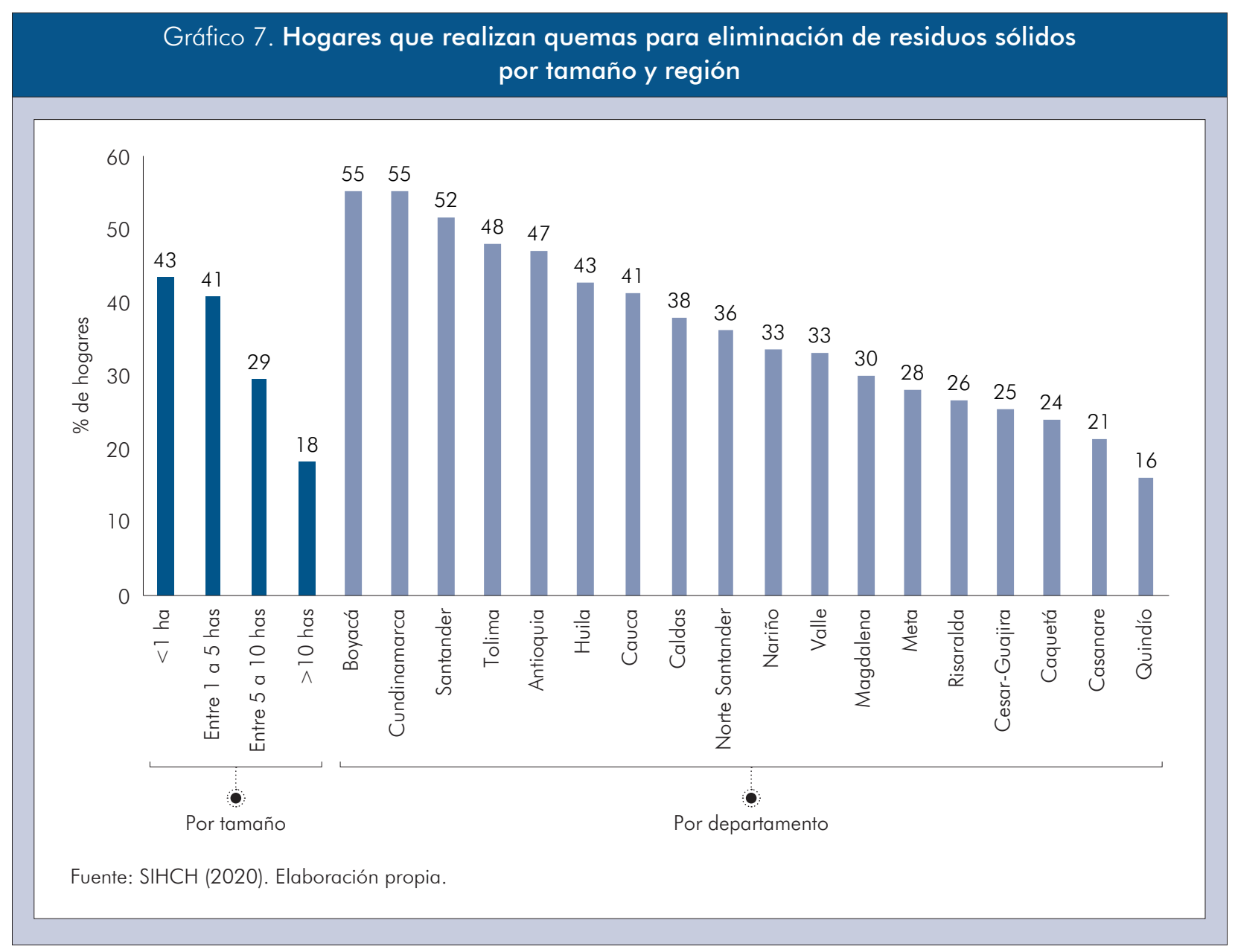




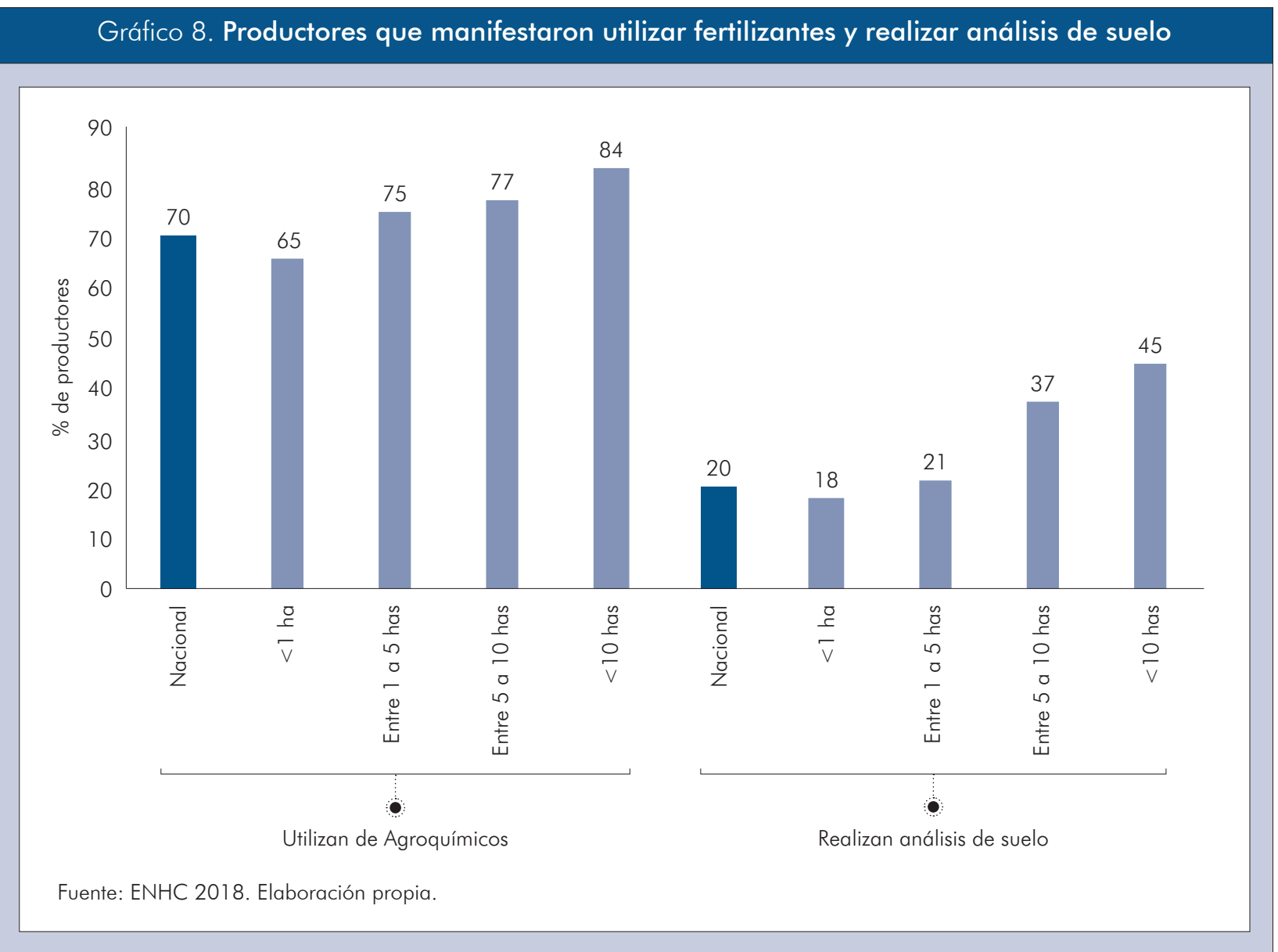

\section{INDICADORES SOBRE LA CONSERVACIÓN DE LA BIODIVERSIDAD, FLORA Y FAUNA}

Colombia está catalogado como uno de los 17 países megadiversos del mundo, lo que quiere decir que el territorio nacional posee una inmensa diversidad de vida en sus ecosistemas, incluidos los ecosistemas donde se encuentran los cultivos de café. El cuidado de estas especies, endémicas y transitorias, así como de sus ecosistemas, son responsabilidad de todas las personas que hacen parte de los diferentes eslabones de la cadena de producción de café.
Con respecto a la Fauna, en la mayoría de las viviendas cafeteras no se encuentran evidencias de tener animales silvestres cautivos o realizar cacería. Además, el $21 \%$ de los productores expresó tener comederos y bebederos para aves (ver Gráfico 9). Baker et al. (2007) muestra la estrecha relación entre las aves y los cultivos de café, la cual puede ser tan fuerte en los cultivos de sombra que es posible usar el número de aves como un indicador del estado de la vegetación, ya que estos 
Gráfico 9. Indicadores sobre la flora y fauna desde la percepción del caficultor

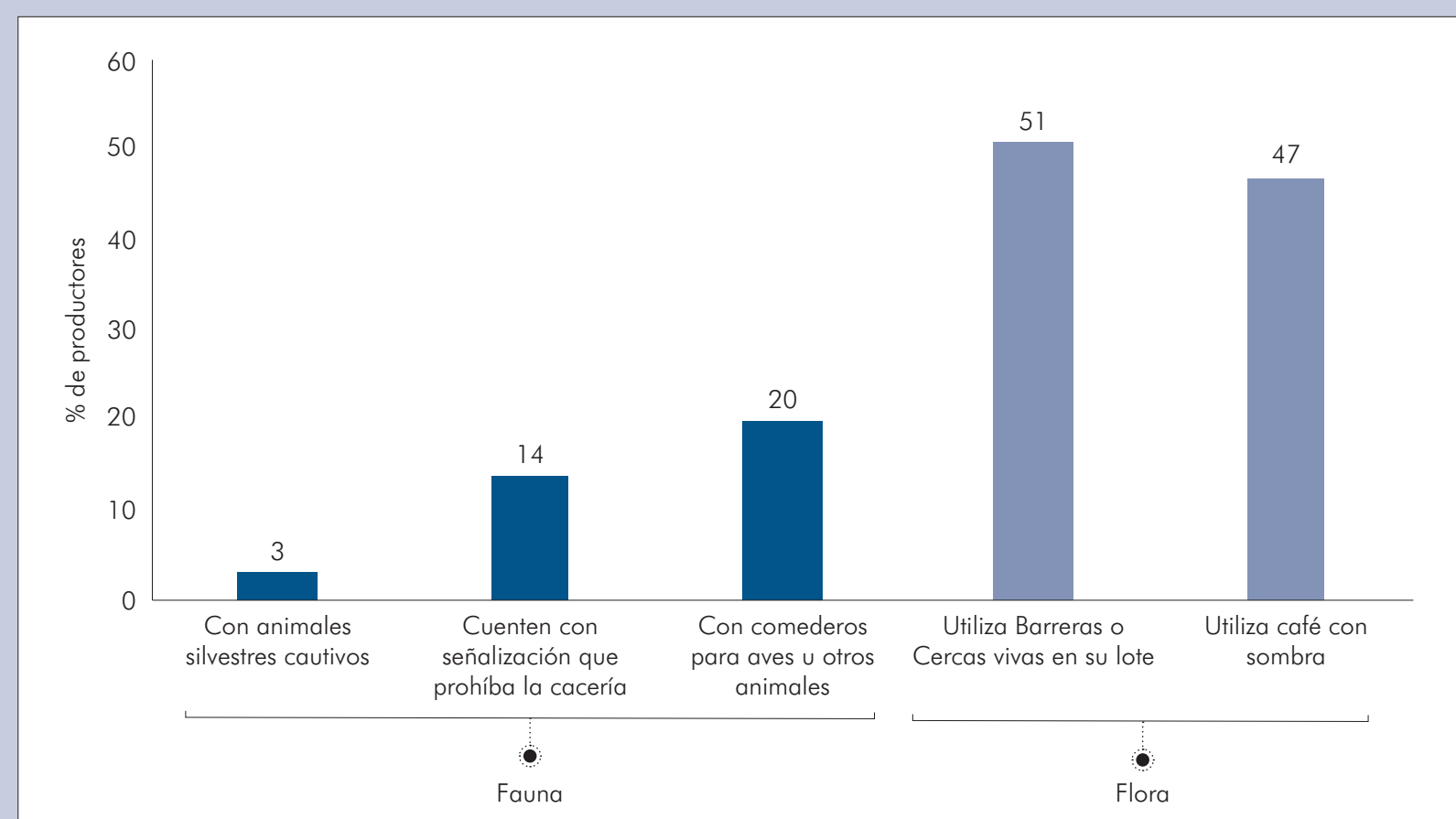

Fuente: ENHC 2018. Elaboración propia.

promueven una mayor biodiversidad debido a que las características de los cultivos de sombra son similares a las del bosque tropical.

Por el lado de la Flora, el $51 \%$ de los productores manifestó tener barreras o cercas vivas en el lote del cultivo. Además, el café tiene la posibilidad de ser un cultivo permanente con sombra ya que, si bien su altura máxima puede ser de $10 \mathrm{~m}$, se deja crecer únicamente hasta los 2,5 o 3 metros de altura, esto permite la posibilidad de asociarse con plantas que sean más altas que protegen los cafetales de las lluvias agresivas y la alta luminosidad. En ultimas, termina promoviendo la vegetación en la finca cafetera, sin olvidar, el bene- ficio económico que pueden obtener al tener otro producto agrícola. La encuesta encontró que el $47 \%$ de las fincas cafeteras tienen café con sombra, cifra cercana a lo que reportó el SICA a 2019 que se encontraba alrededor del $41 \%$, incluyendo sombra y semisombra.

\section{CONCLUSIONES}

Con base en la nueva estrategia de valor de la FNC en materia ambiental y en la caracterización presentada en este artículo, que sirve como instrumento de soporte y línea base, se logró identificar las cinco acciones ambientales más relevantes que se tienen para la agenda cafetera en Colombia para 2027. 
La primera consiste en aumentar la tenencia de activos y prácticas ecológicas que disminuyan el consumo de agua tanto en la vivienda como en el beneficio del café. A pesar de que la cobertura del acueducto en los hogares es solo del 44\%, la mayoría de los caficultores manifestó no sufrir ni escasez ni conflictos por el agua en su vivienda ni en el beneficio. En la ruralidad colombiana existen diversas fuentes de agua, por lo cual, a pesar de que el suministro de agua está asegurado, se encontró que existe un espacio importante para fomentar la tenencia de activos ecológicos como tanques de almacenamientos o dispositivos de ahorro, así como algunas prácticas como el cierre oportuno del grifo en la finca.

En segundo lugar, y como punto esencial es promover el tratamiento de las aguas residuales producto del beneficio de café. Alrededor de el $11 \%$ de los productores manifestaron que en lugar donde hacen el beneficio se preocupan por el tratamiento de las aguas residuales. Existen diferentes formas de realizar los vertimientos de manera adecua$\mathrm{da}$, teniendo en cuenta el marco legal de las autoridades ambientales, se debe generar información acerca de las prácticas recomendadas y amigables con el ecosistema.

Sumado a lo anterior, se encontró que el $70 \%$ de los productores manifestaron utilizar alguna clase de agroquímicos (fertilizante, herbicida, fungicida), sin embargo, muchos productores no utilizan los fertilizantes correctos ni las cantidades óptimas. Los planes adecuados y efectivos de fertilización requieren la realización de análisis de suelo que indiquen los productos óptimos y las cantidades ade- cuadas. No obstante, solo el $20 \%$ de los productores manifestaron haber realizado dicho estudio. En este sentido, la tercera acción a realizar es la de incentivar los análisis de suelos y fomentar mejores prácticas en el uso de fertilizantes y herbicidas. Estos, aumentan la productividad del cultivo y armonizan la relación entre el medio ambiente y la actividad humana.

De otra parte, en cuanto al manejo de residuos, alrededor del $36 \%$ de las viviendas cafeteras manifestaron en la encuesta Sisbén tener un sistema inadecuado de eliminación de excretas, y $42 \%$ afirmó utilizar las quemas como principal mecanismo de eliminación de residuos no aprovechables. Las quemas ocasionan erosión en el suelo y aumentan la posibilidad de incendios forestales. En cuanto al cultivo, la pulpa es el principal residuo sólido del beneficio, se recomienda utilizar una fosa de compostaje para que pueda ser convertida y utilizada como abono orgánico. La cuarta parte de los productores manifestaron tener la fosa de compostaje. De esta manera, la cuarta acción para implementar es la de mejorar los sistemas de disposición adecuada de residuos sólidos y orgánicos, tanto del cultivo como del hogar, mediante el mejoramiento de los sistemas de eliminación de excretas, la no realización de quemas, la creación de fosas de compostaje y la adopción de hábitos y prácticas de clasificación de residuos y reciclaje.

La ENHC mostró que la mayoría de las fincas cafeteras no tienen evidencia de poseer animales silvestres cautivos o de realizar actividades de caza, además, el 20\% manifestó 
tener comedores para aves. En cuanto a la flora, una alta proporción de caficultores demostró utilizar barreras y cercas vivas (51\%), y realizar cultivo bajo sombra (47\%), lo cual promueve la biodiversidad y favorece la productividad del cultivo. Por lo anterior, se considera que la última acción a implementar debe ser la promoción del cultivo bajo sombra, así como, la tenencia de comederos para aves y corredores de conservación. Adicionalmente, esto puede ir apoyado con la búsqueda de sellos ambientales para cafés con marcas propias, los cuales alinean intereses ambientales y económicos. 


\section{REFERENCIAS BIBLIOGRAFICAS}

Foro Economico Mundial (2021). The Global risks report 2021, 16th Edition. Insight Report. Recuperado el 27 de Mayo de 2021 de https://www.weforum.org/reports/the-global-risks-report-2021

Wallace, D (2019). El planeta inhóspito. Debate.

Contraloria general de la nación (2020). Realidad Ambiental en Colombia llena de Carencias. Recuperado el 27 de Mayo de 2021 de: https://www. contraloria.gov.co/contraloria/sala-de-prensa/ registro-de-prensa/-/asset_publisher/JLthS7u$\mathrm{mE} 1+Z /$ content/semana-com-la-realidad-ambiental-de-colombia-esta-llena-de-carencias-contraloria-general? inheritRedirect $=$ false

FAO (2018). Los contaminantes agrícolas: una grave amenaza para el agua en el planeta. Recuperado el 27 de Mayo de 2021 de: http://www.fao.org/ in-action/agronoticias/detail/es/c/1 $141955 /$

Aguilar, A. , Aguilar ,M. , Reyes, H., \& Guzmán, M. (2018). Gobernanza ambiental y pagos por servicios ambientales en América Latina. Sociedad y ambiente, (16), 7-31. Recuperado en 15 de abril de 2021, de http://www.scielo.org.mx/scielo.php? script=sci_ arttext\&pid=S2007-65762018000100007\&lng = es\&tlng $=\mathrm{es}$

Henao, F. (2020). Colombia ambiental afectada por Colombia rural. Recuperado en 15 de abril de
2021 de (https://www.agronegocios.co/analisis/ ferley-henao-ospina-2704861/colombia-ambiental-afectada-por-la-colombia-rural-3069689

DANE (2020). Cuentas nacionales año 2020, información consolida de PIB.Colombia.

ENEC (2019). Estrategia de Economia circular. Recuperado en 15 de abril de 2021 de https://www. dnp.gov.co/Crecimiento-Verde/Documents/ Comite\%20Sostenibilidad/Presentaciones/ Sesi\%C3\%B3n\%202/1_Metas_Estrategia_Nacional_Economia_circular.pdf

Cenicafe (2010). Rangos adecuados para la lluvia para el cultivo de cafe en Colombia. Avances técnicos 395. Recuperado en 15 de abril de 2021 de https:// www.cenicafe.org/es/publications/avt0395.pdf

Baker, P., Lentijo, G., Botero, J., Riaño, N., Jaramillo, A., Sadeghian, S., \& Duque, H. (2007). Café y el medio ambiente. Bibloteca de cenicafe. Recuperado en 15 de abril de 2021 de https://biblioteca.cenicafe. org/bitstream/10778/780/7/Cap\%206.\%20 Caf\%C3\%A9\%20y\%20medio\%20ambiente.pdf

Ministerio de Vivienda (2019). Informe de vivienda de calidad de agua. Recuperado en 15 de abril de 2021 de https://www.minvivienda.gov.co/sites/ default/files/documentos/informe-calidad-deagua-2019.pdf 


\begin{abstract}
ANEXOS
Resumen ciclo del cultivo de café

El ciclo del café, como bien se detalla en el libro "Juan Valdez, la estrategia detrás de la marca" (2007), se divide en 5 etapas. La primera corresponde a la siembra, la cual consiste en tomar las semillas de café, las cuales son aquellos granos que han pasado por el proceso del beneficio, y plantarlas en el cultivo para formar los cafetales. Las semillas nacen en los germinadores donde se les protege y se les otorga nutrientes, luego de dos meses, el cafeto (la pequeña planta que acaba de nacer) se siembra en los almácigos, que son bolsas llenas de tierra y materia orgánica, durante 4-6 meses. Posteriormente, se transfiere el almacigo al campo que previamente se preparó para el cultivo de café, en este punto del ciclo, a las plantas ya se les denomina cafetales.

La segunda etapa se denomina crecimiento, en ella el cultivo de café requiere atención constante, se debe desyerbar, fertilizar, controlar y evitar las posibles enfermedades y plagas, como la roya y la broca. En esta etapa el cafetal irá desarrollando poco a poco sus hojas, raíces, nudos y ramas, a este proceso se le llama desarrollo vegetativo.
\end{abstract}

Luego de dos años desde la siembra comienza la tercera etapa, la producción, cuando se recoge la primera cosecha, cuyo rendimiento es relativamente bajo, aun así, irá aumentando de manera gradual hasta los 6 u 8 años, donde alcanza su edad de máxima productividad. Posteriormente, la producción comienza a descender lenta y progresivamente hasta los 20 o 25 años, edad en la que oscila la vida de la planta. La primera parte de la etapa de producción es la floración, que ocurre luego de periodos secos ya que la planta sufre de estrés hídrico. En el café arábico la floración ocurre aproximadamente 32 semanas antes de la recolección, esta, termina siendo un indicador sobre la producción. Es en esta etapa, aproximadamente en la semana 32, cuando empiezan a darse las cerezas rojas de manera abundante.

La cuarta etapa, la cosecha, comienza cuando los recolectores extraen los granos rojos intensos y maduros. La recolección puede tardar varias semanas, además, la cosecha varía dependiendo las distintas zonas del país donde se encuentre el cultivo, así como la época del año. Luego de haber recolectado todas las cerezas rojas comienza la última etapa, la pos-cosecha. Esta etapa busca realizar el proceso del beneficio de café, se transforma el fruto del cafetal a café pergamino seco. Para lograr esto, el fruto del café se despulpa, se remueve el mucilago, se fermenta, luego se lava y se seca. El resultado del beneficio son cargas de café pergamino seco, donde el productor lo puede transportar a la cooperativa, a las compañías exportadoras, a los intermediarios o a la FNC. De aquí en adelante, comienzan todos los procesos industriales y de comercialización, como son la tostión, el empaquetado, la liofilización, sus derivados, etc. 



\title{
Caracterización socioeconómica de los cafeteros que participaron en las elecciones gremiales del 2018
}

\author{
Dirección de Investigaciones Económicas - Federación Nacional de Cafeteros de Colombia
}

\section{RESUMEN}

A partir de los registros administrativos del Sistema de Información de Hogares Cafeteros (SICH), el presente artículo realiza una caracterización socioeconómica de los votantes para así encontrar variables determinantes sobre la participación electoral. Por un lado, a partir del perfil sociodemográfico de los votantes, se encontró que las poblaciones que menos participaron fueron los jóvenes y los productores que habitan en las cabeceras. Por otro lado, por medio de un modelo logístico se logró determinar que variables como la edad, la zona de residencia, la pertenencia a una cooperativa cafetera, el área cultivada y características municipales como el riesgo electoral tienen un efecto significativo sobre la probabilidad de votar. A partir de estos resultados, se identifican las variables que pueden ser importantes de cara a las elecciones cafeteras que se llevaran a cabo en 2022, además, se visibilizan los retos que tiene el gremio para alcanzar las metas de paridad entre los líderes electos y su comunidad.

\begin{abstract}
Based on the administrative records of the Coffee Household Information System ( $\mathrm{SICH}$ ), the present article performs a socioeconomic characterization of the voters in order to find determining variables on electoral participation. On the one hand, based on the socio-demographic profile of the voters, it was found that the populations that participated the least were the youth and the producers that live in the head towns. On the other hand, by means of a logistic model it was possible to determine that variables such as age, area of residence, belonging to a coffee cooperative, cultivated area and municipal characteristics such as electoral risk have a significant effect on the probability of voting. Based on these results, the variables that could be important for the coffee elections that will take place in 2022 are identified, in addition, the article shows the challenges faced by the guild in achieving the goals of parity between elected leaders and their community.
\end{abstract}

Palabras clave: Participación electoral, Elecciones, Perfil socioeconómico, Café, Modelo probabilístico Códigos JEL: D72, Q10, J10

Key words: Electoral participation, Elections, Socioeconomic profile, Coffee, Probabilistic model

JEL Classification: D72, Q10, J10 



\title{
Caracterización socioeconómica de los cafeteros que participaron en las elecciones gremiales del 2018
}

\author{
Dirección de Investigaciones Económicas - Federación Nacional de Cafeteros de Colombia'
}

\begin{abstract}
Para citar este artículo: Federación Nacional de Cafeteros de Colombia. (2021). Caracterización socioeconómica de los cafeteros que participaron en las elecciones gremiales del 2018.
\end{abstract}

Ensayos sobre Economía Cafetera, 33(1), 75-111.

\section{INTRODUCCIÓN}

La Federación Nacional de Cafeteros (FNC) como una de las $O N G^{\prime}$ s agrícolas más grandes del mundo, enfrenta grandes retos en la tarea de mantener y ampliar su legitimidad como representante del gremio caficultor. Esta se ratifica cada cuatro años cuando los productores cafeteros votan por sus representantes en los comités de cafeteros municipales y departamentales. Estos líderes electos orientan a la administración de la FNC para administrar el Fondo Nacional del Café (FoNC) ${ }^{2}$.

La validez y la eficacia en el funcionamiento del gremio se ponen a prueba a partir de la participación de los productores en las elecciones y de la capacidad de ejecución de recursos para llevar a cabo los proyectos que responden a los intereses de la comunidad. Por esta razón, la estrategia de valor de la FNC en 2021, en el eje de gobernanza, reconoce la importancia de estas elecciones y busca promover la unidad gremial y la participación democrática. Vale la pena destacar que este ejercicio democrático es único a nivel gremial en Colombia.

La presente investigación realiza una caracterización socioeconómica de los productores que participan en las elecciones cafeteras, a partir de la construcción de perfiles para los votantes y el gobierno cafetero elegido, y la elaboración de un modelo de probabilidad. Con base en lo anterior, se identifican los determinantes socioeconómicos que pueden in-

Equipo de investigación: Méndez, J. D. (jose.mendez@cafedecolombia.com), J.M. Izquierdo (juan.izquierdo@cafedecolombia.com), Cárdenas A. (Ancardenas23@gmail.com). Los autores agradecen a José Leibovich, Claudia Córdoba, Mario Villamil y German Gutiérrez por sus valiosos comentarios y discusiones sobre las elecciones gremiales.

2 El FoNC es una cuenta parafiscal, conformada por recursos públicos, que se nutre principalmente de la contribución cafetera. Por ser la legítima representante de los cafeteros, el Gobierno colombiano ha suscrito con la FNC, desde 1940 y aproximadamente cada 10 años, un nuevo contrato para que sea quien administre el FoNC. 
fluenciar, de manera positiva, la asistencia a las urnas, y se evidencian las brechas entre los cafeteros que son elegidos en el gobierno cafetero.

La relevancia del estudio radica en el conocimiento más profundo de los votantes cafeteros, qué variables llevan a una mayor participación electoral y la identificación de metas de equidad de género, edad y tamaño del área cultivada en los líderes electos. Este ejercicio también visibiliza los retos que tiene el gremio para lograr efectuar las nuevas elecciones en 2022 con éxito.

El trabajo se organiza de la siguiente manera; la segunda sección resume la literatura relacionada con el tema y hace una breve síntesis de la historia de las elecciones cafeteras. La tercera sección describe las fuentes de datos utilizadas. En la cuarta sección, a partir del perfil socioeconómico de los votantes, la exploración de algunas variables departamentales y los resultados del modelo logístico, se presentan las variables significativas que tienen efecto sobre la participación electoral. En la quinta sección, se presenta el perfil socioeconómico de los líderes electos analizando los retos que tiene el gremio para alcanzar la paridad por características socioeconómicas. Por último, se presentan las conclusiones, las posibles implicaciones de política y los caminos a seguir de investigaciones posteriores en el tema.

\section{REVISIÓN DE LITERATURA SOBRE LA PARTICIPACIÓN ELECTORAL}

El rol de la democracia y los procesos electo- pecíficamente para el caso de América Latina, la democracia como modelo de gobierno ha traído garantías legales y constitucionales que se han traducido en mayores derechos y libertades (Espi, 2019). Dentro de este modelo, la participación ciudadana aparece como eje central para garantizar la legitimidad y desarrollo del mismo. Existen varias formas de participación ciudadana; desde una visión integral, Vergara-Lope y Hevia (2012) proponen cuatro dimensiones; electoral, cívica, asociativa y opinativa. No obstante, la única de estas dimensiones que realmente involucra a la mayoría de los ciudadanos es la electoral (Norris, 2004). Adicionalmente, para autores, como Lijphtart (1997), la democracia constituye la forma de participación más igualitaria que existe, dado que esta menos sesgada en contra de algunos grupos demográficos o sociales.

Una parte importante de este proceso democrático es la participación en las urnas. Esta puede ser explicada por la combinación de muchos factores, aspectos sociodemográficos, el grado de desarrollo económico, la regulación electoral, la credibilidad en las instituciones o la satisfacción política. En este contexto, la participación electoral aparece como un fenómeno de estudio para entender la dinámica entre el individuo y el modelo de gobierno. La literatura sobre este tema se ha concentrado en determinar los factores que explican la participación electoral ciudadana. Uno de los trabajos más destacados en este campo es Rosenstone \& Hansen (2002), en el cual se identifican las causas de la abstención en ciudadanos estadounidenses desde la perspectiva individual como también de partidos políticos. En este trabajo se destaca 
que el ingreso, la educación y la movilización política son factores que pueden explicar una mayor participación.

Del mismo modo, Barters (2000) muestra cómo la percepción sobre la eficacia política por parte de los votantes explica la variación en la participación; también, Green y Shapiro (1994) demuestran que la competencia electoral influencia la participación electoral. En el caso colombiano, la revisión de literatura elaborada por Espi (2019), identifica autores como: Losada (1984), que conceptualizó e introdujo la categoría del "clientelismo" para explicar la asistencia a las urnas; Dávila y Delgado (2002), explican cómo esto ocurre principalmente en elecciones locales, pero no en las nacionales. De esta revisión se puede confirmar la premisa básica acerca de que la participación electoral se asocia con el grado de integración en la sociedad, cuanto más fuerte es, hay más probabilidades de participar. Este concepto es el que adoptamos en este artículo.

Una limitación de esta primera parte de la literatura es que la mayor parte de los estudios son robustas reflexiones teóricas, algunos acompañados de estudios de casos, que les permite realizar inferencias sobre la participación electoral, pero su alcance es limitado pues no es posible identificar los factores que la afectan con la rigurosidad estadística necesaria. En los últimos años, esta limitación se ha reducido debido a la explosión de herramientas cuantitativas y análisis de grandes volúmenes de datos (Espi,2019). No obstante, acorde a lo descrito por Prosser y Mello (2018) estos nuevos estudios todavía se encuentran limitados dado que utilizan como fuente, encuestas comerciales que se realizan antes o después de los escrutinios, las cuales son útiles para visibilizar la intención de participación, pero tienen problemas de representatividad, sesgos por situaciones económicas - geográficas y dificultan la identificación de factores más estructurales.

Algunos trabajos que superan parcialmente los problemas expuestos por Prosser y Mellos, se han concentrado en construir perfiles socioeconómicos sobre los votantes para mostrar la relación entre las variables relevantes y la participación. Dentro de este grupo se encuentra los estudios de: Moreno (2017) para las elecciones catalanas en 2015; Guadalupe (2019) para elecciones presidenciales en México; y Charles et al. (2018) que utiliza modelos de econometría especial en las elecciones mexicanas para realizar mejores inferencias.

Específicamente para el caso colombiano, Yann \& Guavita (2019) realizaron un ejercicio de exploración de datos para analizar la participación electoral en las elecciones presidenciales, legislativas y locales de 2018. Este trabajo es diferente dado que utiliza bases empíricas, en lugar de encuestas ${ }^{3}$. Este trabajo encontró algunos resultados que pueden ser útiles para el alcance de nuestra investigación:

Específicamente se usa la información del DANE sobre Cultura Política o el Latín American Public Project (Lapop), el cual tiene un capítulo sobre Colombia a cargo de la Universidad de los Andes. 
O Las elecciones locales tienen mayor participación que las elecciones presidenciales.

O La edad es una variable importante para explicar la participación política.

O Los grupos más abstencionistas encontrados son los jóvenes y adultos de estratos 1 y 2 que habitan en grandes ciudades.

O En el caso de las presidenciales, Colombia ha tenido una participación electoral baja con respecto a otros países de la región que tienen registro automático y sin sanciones.

O Los municipios alejados de los centros urbanos y cabeceras se interesan menos por la política nacional y más por la política local.

Por último, específicamente en el tema de elecciones cafeteras, Rangel (2010) realizó un estudio basado en información recolectada por medio de entrevistas a caficultores, ex extensionistas y exlíderes en el departamento de Quindío. En este trabajo, se postula: en primer lugar; que los beneficios que otorga la FNC son bienes comunes que se reciben independientemente de la participación electoral o del involucramiento con el gremio, generando una situación de "Free Rider" ${ }^{4}$; en segundo lugar, el autor menciona que la falta de remuneración en los líderes municipales tiene efectos mixtos. Por un lado, causa que los miembros de los comités tengan una buena imagen y no estén involucrados en acusaciones de corrupción. Por otro lado, la falta de incentivos económicos o materiales genera que los caficultores no deseen participar. Por último, se ve que, aunque no haya remuneración, los cafeteros aspiran a este cargo por la legitimidad que da a las peticiones y reclamos.

El autor también discute que la alta renovación de miembros de comités municipales y departamentales $(71 \%$ y $31 \%$ en 2010 , respectivamente) no necesariamente significa un mejor proceso democrático o una innovación de propuestas. Algunos exlíderes municipales entrevistados, expresaron que no volverían a presentarse debido a la cantidad de acuerdos y peticiones que se requieren para llevar a cabo los proyectos, causando que su capacidad de gestión sea reducida. Del mismo modo, se destaca que la cantidad de líderes que se presentan impacta la participación electoral, en principio, entre más líderes se postulen, la discusión tiene mayor profundidad y evita que los votantes tomen una postura de indiferencia. Este autor concluye que la mayoría de los encuestados se interesaron en participar debido a los beneficios individuales y colectivos que reciben de parte de su comité municipal; los cuales, en general atienden a sus peticiones. Sin embargo, no identifican el votar como una manera de fortalecer al gremio o de incidir en decisiones sobre los grandes bienes públicos de la FNC.

4 En este contexto el problema de Free Rider se presenta, porque al recibir todos el mismo bien público, las personas pueden decidir no votar porque esperan que alguien más lo haga, este problema también se ve exacerbado por la homogeneidad de propuestas entre candidatos dado que no termina importando quien es electo. 
Finalmente, votar representa un costo implícito bajo, en términos de tiempo o desplazamiento, pero puede representar altas ganancias para los caficultores pequeños, en forma de nuevas tecnologías, mejor infraestructura y estabilidad económica. Por esta razón, mejorar la participación electoral, es una forma de mejorar las condiciones de vida de los miembros del sector, a la vez que se les involucra de manera más directa en las decisiones.

En este contexto, la presente investigación busca ampliar la literatura existente ${ }^{5}$ en el tema de construcción de perfiles socioeconómicos y aplicarlo para el caso colombiano, específicamente, el caso de elecciones cafeteras. Al contar con una fuente de datos confiable y de gran escala se pueden obtener resultados estadísticamente robustos; este enfoque también permite contrastar nuestros resultados con los obtenidos en el caso de las elecciones nacionales analizado por Basset, Yann y Guavita (2019), y a su vez complementar parte de los hallazgos de Rangel (2010) con información representativa para todo el país.

\section{CONTEXTO DE LAS ELECCIONES CAFETERAS}

Las elecciones cafeteras nacieron a partir de la reforma de la Ley 66 de 1942 mediante la cual, la FNC realizó elecciones cafeteras mediante un sistema de cociente electoral para escoger los líderes de los comités de cafeteros municipales ${ }^{6}$. Posteriormente, estos líderes municipales se encargaron de elegir los líderes de los comités departamentales y miembros del Congreso Cafetero, máxima instancia del gobierno cafetero. Los productores habilitados para votar tenían que estar inscritos en el gremio y contar con el documento de registro.

Más adelante en 1996, la FNC reformó el sistema electoral debido a varios factores; primero, por la actualización del sistema gremial y jurídico; segundo, para promover una mayor participación democrática; y, por último, para atender los requerimientos de la Ley agraria de 1994 y la Ley 188 de 1995, la cual propuso un nuevo marco jurídico para la legislación de recursos parafiscales. Las reformas de los 90s obligaron a que las entidades que eran financiadas mediante recursos parafiscales tuvieran un efectivo mecanismo de representación popular. Así, cada cuatro años los miembros de los comités departamentales y municipales son elegidos directamente por los caficultores cedulados ${ }^{7}$. La importancia de los líderes cafeteros elegidos radica en escuchar la base cafetera y transmitir sus intereses y necesidades a los administradores del gremio.

5 También sugerimos algunas lecturas sobre la participación electoral y democracia; Downs (1957): "An economic theory of democracy", Green, Groth \& Arrow (2013) "field experiments and the study of the voter turnout", Gerber, L. (2004) "Beyond the median: Voter preference, District heterogeneity and political representation", Gerber \& Green (2000) "The The effect of a nonpartisan get-out-the-vote drive: An experimental study of leafletting".

6 Esta reforma a la ley se realizó debido a que FNC debía tener un mecanismo de elecciones dado que, en Colombia, solo los órganos de representación popular podían establecer impuestos, en este caso, la Contribución Cafetera.

7 Según los estatutos de la FNC, para ser un productor cafetero federado se necesita estar registrado en SICA, demostrar la tenencia (no necesariamente propiedad) de la tierra, y cumplir con un área sembrada de café igual o superior a 0.5 hectáreas y tener al menos 1500 árboles plantados. El documento que garantiza que el productor es federado es la cedula cafetera. 
Bajo la normativa actual, un municipio cuenta con un comité de cafeteros si tiene al menos 400 cafeteros cedulados y una producción de café de al menos $60 \mathrm{mil}$ arrobas. Estos comités se constituyen por seis miembros principales y 6 suplentes, elegidos por los cafeteros de su zona. Las funciones de estos miembros son: primero, ser un órgano consultivo, aconsejando al gremio con temas locales; segundo, apoyar en la elaboración de proyectos, sin embargo, ellos no ejecutan los recursos del gremio ni reciben contraprestación económica alguna. Son los comités departamentales quienes tienen presupuesto propio y ejecutan proyectos coordinados con los comités municipales.

Otro aspecto relevante es que el sector cafetero ha estado al margen de la política nacional y local, los líderes cafeteros que quieran ser candidatos no pueden hacer parte de algún movimiento político o tener algún cargo público en periodos recientes a la elección.

Adicionalmente, así como en las elecciones nacionales, las cafeteras no tienen votación obligatoria, y el mecanismo de registro es automático, si cuenta con cédula obtiene el derecho a participar. Asimismo, el gremio se ha preocupado por que los dirigentes cafeteros departamentales y municipales se renueven cada cuatro años, y que exista cierta correspondencia entre las características de los productores y las de sus líderes para que los intereses se encuentren alineados.
Históricamente, las elecciones se han caracterizado por tener altas tasas de participación, recientemente, superiores al 50\%, legitimando la capacidad de la FNC por administrar el FoNC. Entre 2002 y 2018 el promedio de la participación electoral fue $62 \%$. Un hecho importante para resaltar es que el número de caficultores habilitados para votar ha aumentado considerablemente desde el 2002, ubicándose en 358.208 productores cedulados para 2018 (Ver Gráfico 1). En términos relativos, los comités departamentales que más aumentaron la cantidad de productores cedulados en este periodo fueron Cesar-Guajira, Magdalena, Huila, Tolima y Norte de Santander. También cabe resaltar que en los últimos años han entrado nuevos departamentos a la caficultura, algunos de los cuales quedan adscritos a las Oficinas Coordinadoras ${ }^{8}$.

\section{Gráfico 1. Participación electoral cafetera y censo electoral 2002-2018}

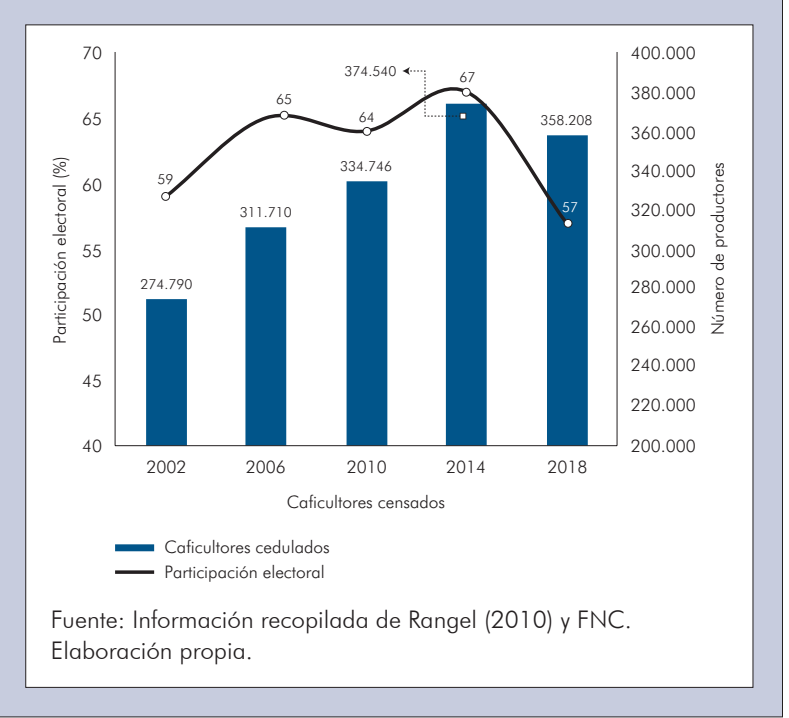

8 Para 2021, la Oficinas Coordinadora abarcan los departamentos de Meta, Casanare y Caquetá, mientras que Chocó está adscrito como parte del Comité de Antioquía. 
Por departamentos, en estas últimas cinco elecciones el promedio de la participación osciló entre el $54 \%$ y el $74 \%$ (ver Tabla 1). Los departamentos que históricamente tuvieron mayor votación promedio han sido Quindío, Caldas, Santander, Norte de Santander y Nariño. En la tabla también se puede observar como la participación electoral presenta un comportamiento heterogéneo entre departamentos como también a lo largo de los años, mostrando que este proceso electoral es dinámico.

Debido a la gran cantidad de municipios donde está presente la caficultura, la infraestructu- ra para garantizar el derecho al voto ha sido un verdadero desafío para el gremio. Dado que el $77 \%$ de los hogares cafeteros habitan en la ruralidad", la FNC ha instalado tanto mesas de votación fijas, como también mesas móviles; las cuales, recorren los municipios. Adicionalmente se han instalado mesas múltiples para que los caficultores sufraguen en municipios colindantes. Por otra parte, para garantizar la transparencia en el proceso, desde 2014 la Misión de Observación Electoral $(\mathrm{MOE})^{10}$ acompaña las elecciones cafeteras e informa a la población sobre la transparencia y eficiencia del proceso. Cabe mencionar que

\begin{tabular}{|lccccccc|}
\multicolumn{7}{c}{ Tabla 1. Participación electoral cafetera 2002-2018 } \\
\hline Departamento & 2002 & 2006 & 2010 & 2014 & 2018 & Promedio & Desviación estandar \\
& $(\%)$ & $(\%)$ & $(\%)$ & $(\%)$ & $(\%)$ & $2002-2018$ & $(2002-2018)$ \\
\hline Quindío & 62 & 85 & 80 & 78 & 67 & 74 & 8 \\
Caldas & 51 & 70 & 78 & 77 & 74 & 70 & 9 \\
Santander & 64 & 70 & 62 & 74 & 73 & 69 & 4 \\
Norte de santader & 63 & 70 & 73 & 67 & 67 & 68 & 3 \\
Nariño & 66 & 68 & 74 & 57 & 63 & 66 & 5 \\
Cesar-Guajira & 57 & 73 & 70 & 61 & 58 & 64 & 6 \\
Boyacá & 69 & 74 & 50 & 69 & 56 & 64 & 8 \\
Risaralda & 47 & 68 & 66 & 70 & 64 & 63 & 7 \\
Tolima & 58 & 60 & 65 & 77 & 53 & 63 & 7 \\
Cauca & 64 & 70 & 60 & 67 & 52 & 63 & 6 \\
Valle del Cauca & 58 & 72 & 56 & 70 & 56 & 62 & 6 \\
Antioquia & 62 & 63 & 62 & 70 & 52 & 62 & 5 \\
Nacional & 59 & 65 & 64 & 60 & 57 & 61 & 3 \\
Huila & 64 & 56 & 62 & 60 & 53 & 59 & 4 \\
Magdalena & 36 & 60 & 65 & 62 & 51 & 55 & 10 \\
Cundinamarca & 49 & 52 & 52 & 65 & 51 & 54 & 5 \\
Total & 59 & 65 & 64 & 67 & 57 & 62 & 3 \\
\hline
\end{tabular}

Fuente: Información recopilada de Rangel (2010) y FNC. Elaboración propia.

9 Federación Naciones de Cafeteros, FNC (2021).

10 La Misión de Observación Electoral es una plataforma de organizaciones de la sociedad civil que promueve el ejercicio de los derechos civiles y políticos de la ciudadanía a través de: Fomentar la participación de la sociedad civil en procesos democráticos y realizar procesos de monitoreo y observación electoral, entre otros. 
las elecciones cafeteras no cuentan con incentivos directos al sufragante como ocurre en las elecciones nacionales, pero existe un sistema de premios a los comités que tengan la mayor tasa de participación mediante bonos. Específicamente en 2018, la participación electoral en las elecciones cafeteras fue del $57 \%$, se eligieron 4.776 líderes cafeteros municipales y 179 líderes departamentales sobre un total de 16.142 candidatos. Se instalaron un total de 2.697 mesas, $12 \%$ más que en las elecciones de 2014; de éstas, 263 fueron móviles. En total, el alcance geográfico fue de 17 departamentos y 568 municipios. Además, 8.091 jurados participaron en el proceso, desde la instalación de las mesas hasta el conteo de votos.

La comparación de los resultados de las elecciones cafeteras con las elecciones locales del 2019 (gobernaciones, alcaldías, concejos y asambleas) y nacionales 2018 (legislativas y presidenciales) muestra lo siguiente: primero, en el caso de las presidenciales y legislativas, vemos que la participación en las elecciones cafeteras fue mayor en 3 p.p y 8 p.p respectivamente; segundo, con respecto a las elecciones locales, se ve que hay una participación similar a la presentada en las elecciones de concejos municipales y departamentales pero menor a la de Alcaldías. Como referencia, por la labor que desarrollan los líderes municipales cafeteros, la comparación más acertada es con las elecciones a concejos municipales y departamentales.
Este análisis comparativo de la participación en las diferentes elecciones (ver Gráfico 2) ilustra una de las ideas expuestas por Yann \& Guavita (2019), respecto a que, en Colombia, parece existir un mayor interés en las elecciones locales que en las nacionales. Los gobiernos locales tienen una relación más directa con la comunidad y por lo general conviven en un mismo espacio geográfico haciendo que la interacción entre los individuos y el gobierno local sea más fuerte. Esta sinergia también se encuentra presente en la relación que tienen los cafeteros con sus líderes y ayuda a entender el rol que ha tenido históricamente la FNC como complemento a la presencia del estado en municipios geográficamente aislados en el país. Al desagregar esta comparación a nivel departamental ${ }^{11}$, se observa cómo la participación electoral cafetera es heterogénea y presenta patrones diferentes a los observados

\section{Gráfico 2. Participación electoral cafetera vs. nacionales y locales}

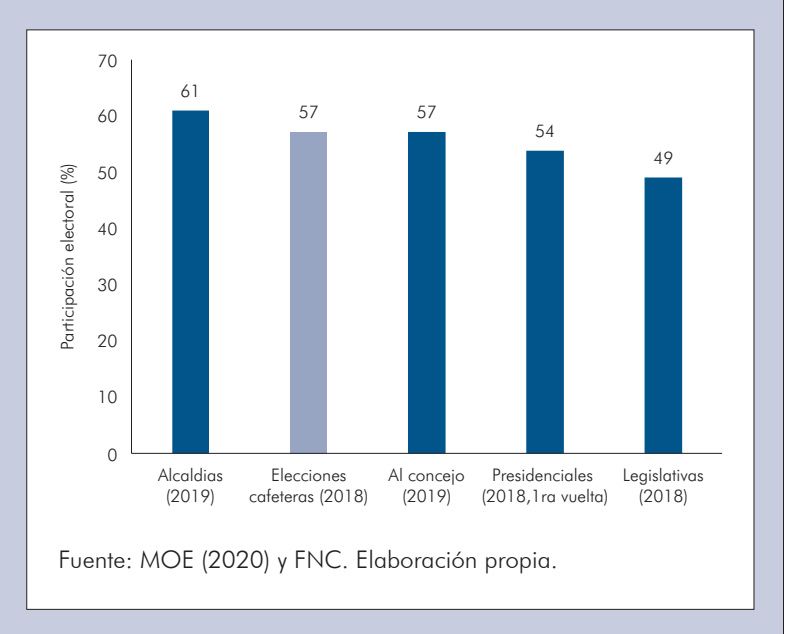


en las elecciones a concejo (ver Gráfico 3). En primer lugar, se identifica que los comités de Caldas, Santander, Norte de Santander, Quindío, Risaralda y Nariño tuvieron una participación por encima del promedio nacional.

Por otro lado, al comparar directamente respecto a las elecciones a concejo, vemos que la participación electoral de las elecciones cafeteras fue mayor por 2 p.p, teniendo en cuenta solo municipios cafeteros ${ }^{12}$. También se encontró que los departamentos con mayor votación cafetera tienen un nivel de participa- ción mayor que las registradas al concejo. Sin embargo, cabe resaltar que departamentos con alto número productores, como Huila, Tolima y Cauca presentan una participación menor con respecto al concejo. Esta relación entre la participación en elecciones cafeteras y a concejos se estudiará con profundidad en la quinta sección de este documento.

\section{Descripción de los datos}

Las estimaciones de este estudio, se realizaron a partir de los registros administrativos que

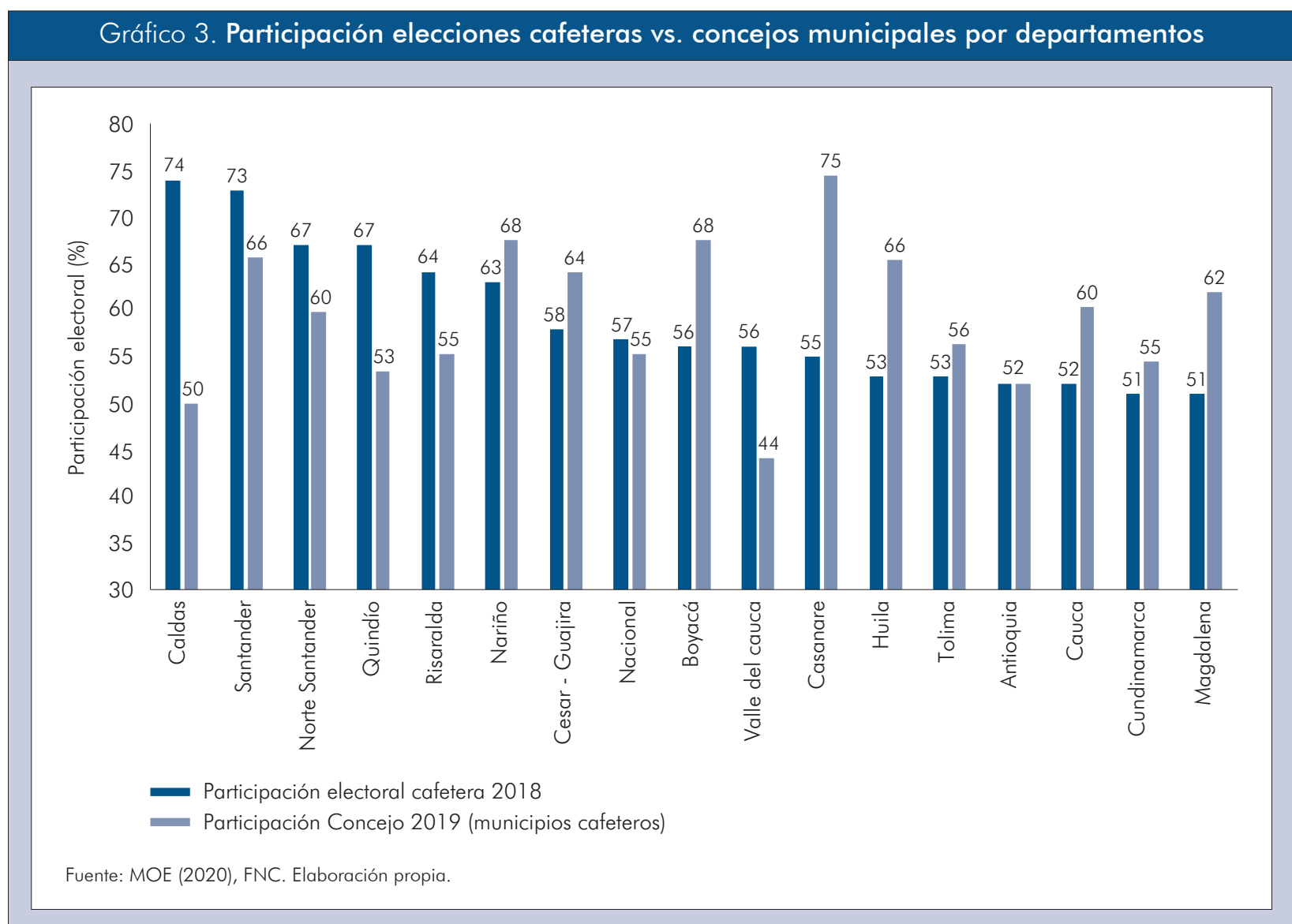

12 Con datos publicados por la MOE, se estimó la participación electoral en las elecciones a los consejos municipales en los 600 municipios cafeteros. 
hacen parte del Sistema de Información de Hogares Cafeteros (SIHC) administrado por la Federación Nacional de Cafeteros. El SIHC se nutre de varias fuentes de información internas y externas, para este análisis se consolidó una base de datos de 298,537 productores cafeteros, representativa de la población cafetera cedulada (377 mil) por departamentos y por tamaño del productor de acuerdo al área sembrada en café, lo que permite superar ampliamente, los problemas de representatividad que señalaron Prosser y Mello (2018).

Para su construcción, se cruzaron tres bases de datos que participan en el $\mathrm{SICH}$ : primero, la base de Elecciones Cafeteras 2018 consolidada por la Secretaria General de la FNC; segundo, la base de datos del Sistema de Información Cafetera (SICA) de la Gerencia Técnica de la FNC de la cual se extrae la información de variables relacionadas con la producción de café; por último, la información socioeconómica de la base Sisbén ${ }^{13}$ del Departamento Nacional de Planeación (DNP) encontrando que el $84 \%$ de los productores del censo electoral están presentes en la encuesta Sisbén. La ventaja principal de realizar este tipo de cruces de registros administrativos es reducir los problemas de representatividad que pueden llegar a tener las encuestas comerciales.

\section{DETERMINANTES DE LA PARTICIPACIÓN ELECTORAL}

A partir de la información disponible, en esta sección se pretende encontrar las variables socioeconómicas que pueden tener efecto significativo sobre la participación electoral. Se divide en tres secciones; el perfil socioeconómico de los votantes, la exploración de variables departamentales que podrían ser relevantes, y un modelo logístico que integra todas las variables observadas.

\section{Perfil socioeconómico de los votantes}

Para este estudio, el perfil socioeconómico que se construyó se divide en dos categorías.

\begin{tabular}{|c|c|c|c|}
\hline Nombre & Fuente & $\begin{array}{c}\text { Número de } \\
\text { observaciones }\end{array}$ & $\begin{array}{c}\text { Representatividad respecto } \\
\text { a población cedulada }\end{array}$ \\
\hline Infocul - SICA & Gerencia Técnica - FNC & 540.377 & $100 \%$ \\
\hline Base Elecciones Cafeteras 2018 & Secretaria General - FNC & 357.76 & $99 \%$ \\
\hline Productores cafeteros en SISBEN & Departamento Nacional de Planeación (DNP) & 445.537 & $84 \%$ \\
\hline Base Consolidada Elecciones & $\mathrm{SICH}$ (DIE) & 298.537 & \\
\hline Fuente: Elaboración propia. & & & \\
\hline
\end{tabular}

13 Base del SISBEN descargada en enero del 2020. 
La primera corresponde a la información recogida por el Sisbén donde aparecen variables relacionadas con aspectos sociodemográficos y nivel de vulnerabilidad, medido a través del puntaje Sisbén 3. La segunda categoría corresponde a variables cafeteras, las cuales corresponden a características propias de la actividad del productor de café, dentro de las cuales están el tamaño del cultivo, el tipo de tenencia del predio, o si está asociado a alguna cooperativa de caficultores.

\section{Por categorías sociodemográficas}

En cuanto a categorías sociodemográficas, se encontró en primer lugar por zona de residencia que la participación de los productores que habitan en la ruralidad dispersa es mayor en aquellos que habitan en los centros poblados y en las cabeceras municipales (ver Gráfico 4). Usualmente, se suele considerar que si las personas viven en las cabeceras entonces tienen una mayor facilidad para acceder al voto. Sin embargo, en el caso de los productores cafeteros, existen tres posibles explicaciones: primero, los productores de las cabeceras cuentan con una situación socioeconómica ${ }^{14}$ mejor $y$, por ende, no necesitan tanto apoyo del comité de cafeteros; segundo, aquellos en las caberas pueden vivir lejos de su predio cafetero ${ }^{15}$; por último, la instalación de las mesas móviles ha sido bastante efectiva para incentivar el voto en los hogares rurales.
En segundo lugar, por género, se observa que los hombres votaron en promedio 3 p.p. más que las mujeres. Específicamente, el 58\% de los hombres habilitados para votar, ejercieron su derecho al voto, mientras que en el caso de las mujeres alcanzo el 55\%. Esta diferencia también puede verse en la participación por género en las elecciones presidenciales del 2018 (1 ra vuelta), la cual fue de 2 p.p. ${ }^{16}$. Una posible explicación para esta diferencia es ilustrada por Kostelka, Blais \& Gidengil (2019), quienes usando datos del Making Electoral Democracy Work (MEDW) project ${ }^{17}$ encontraron que, aunque no hay una brecha significativa en las elecciones de primer nivel (presidenciales, parlamento), si existe una brecha en elecciones de segundo orden (regionales), explicada principalmente por falta de conocimiento o interés en estos procesos electorales por parte de las mujeres.

Asimismo, por departamentos, se observa un comportamiento bastante heterogéneo, con departamentos donde la diferencia en participación por género puede llegar a ser hasta 7.5 p.p a favor de los hombres. Específicamente, los departamentos con mayor diferencia son Magdalena, Risaralda, Valle, Antioquia, Tolima y Huila (ver Gráfico 5). Estas diferencias pueden darse por algunas condiciones estructurales o características específicas de los comités, por ejemplo, una baja participación femenina en sus líderes municipales.

14 Según el DANE, la pobreza multidimensional nacional en 2019 fue de $17,5 \%$, en cabeceras 12,3\% y en rural 34,5\%.

15 Como se mostró en FNC (2021), una alta proporción de productores cafeteros pueden vivir lejos de la ubicación del predio cafetero, no necesariamente en el mismo municipio o departamento.

16 El 54\% de los hombres en Colombia habilitados para votar ejercieron su voto, y en las mujeres fue del 52\%. (MOE,2018).

17 El MEDW incluye información de 5 países (Canadá, Francia, Alemania, España y Suiza) entre 2010 y 2015 para elecciones nacionales, regionales y supranacionales. 

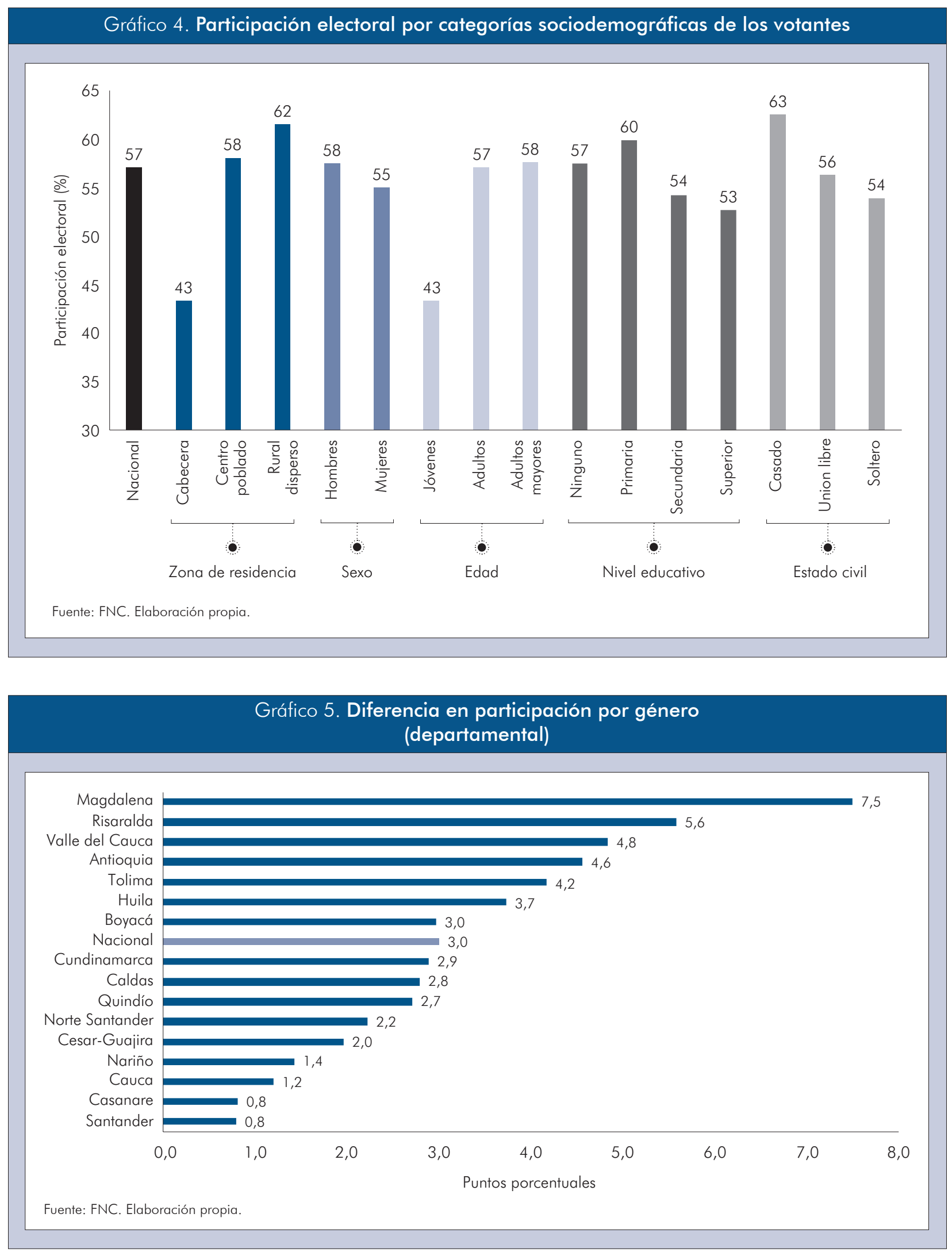
En tercer lugar, con respecto a la edad, se observa que la participación de los jóvenes productores (entre 18 y 28 años) fue 43\%, menor a la de los adultos (entre 29 y 65 años) y adultos mayores (mayores de 65 años) (ver Gráfico 4). Cabe destacar que los jóvenes representan alrededor del 3\% del Censo Electoral de 2018, lo que equivale a alrededor de 11 mil productores jóvenes; encontrando que de estos 11.000 , un poco menos de la mitad ejercieron su derecho al voto. Este comportamiento político confirma lo encontrado por Yann \& Guavita (2019), en que la abstención electoral en Colombia es mayor en los jóvenes.

En cuarto lugar, el Gráfico 4 muestra que a mayor sea el logro educativo del productor, iniciando desde primaria, menor es la participación electoral. Una posible explicación para este hallazgo es el hecho de que los jóvenes que habitan en las cabeceras presentan un mayor logro educativo, pero votan menos. La relación positiva entre educación y participación electoral se revierte sutilmente en la población cafetera, y esto parece ser producto de la interacción entre la edad y la zona de residencia. Adicionalmente, se encontró que, en promedio, los productores que viven en pareja asisten más a las urnas cafeteras que aquellos que son solteros.

Por último, el puntaje Sisbén III es un indicador global del nivel socioeconómico que tiene el hogar. El rango del puntaje es de 0 a 100, entre mayor es el puntaje, mejor es la situación socioeconómica del hogar. Se encontró que la relación entre la situación socioeconómica del hogar cafetero y la participación electoral es de una U-invertida. Los hogares más pobres y los más ricos son aquellos que menos asisten a las urnas, siendo los hogares de ingresos "medios" los que más participan (ver Gráfico 6).

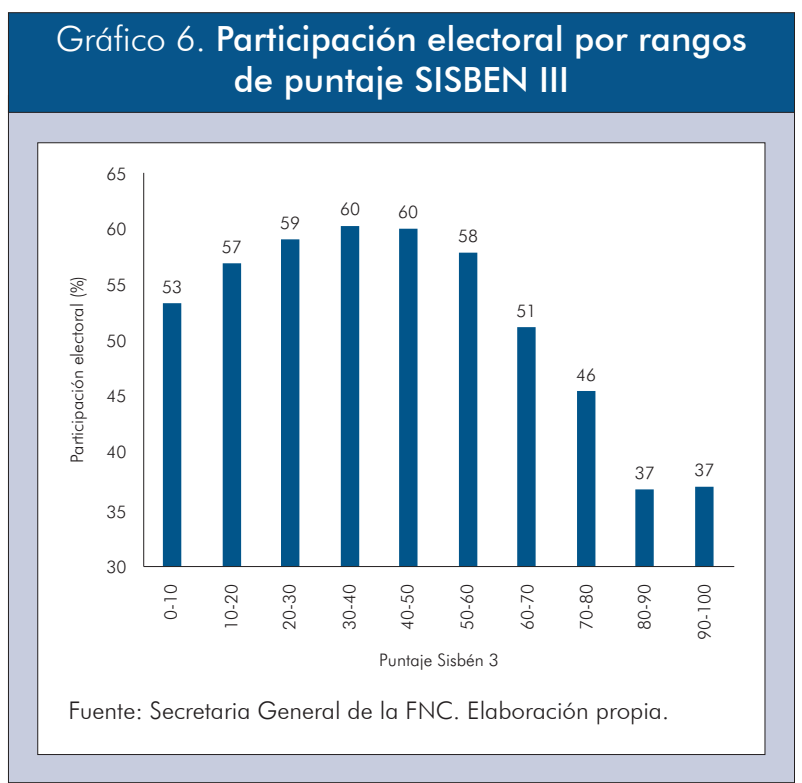

Por otra parte, como producto de este análisis se encontró que en las elecciones cafeteras no se da la tesis de Lijpahart (1997); "una baja participación electoral esconde grandes disparidades entre los grupos, y dichas disparidades suelen darse a favor de la participación de los grupos más favorecidos ". En 2018, se presentó la participación cafetera más baja en los periodos recientes, y como se observa en el Gráfico 7, la participación electoral de los hogares más vulnerables fue en promedio menor, quedando la mayor participación en los hogares de puntajes medios, pero no en los altos.

\section{Por variables del cultivo}

Como se muestra en el Gráfico 7, los productores micro $(<1 \mathrm{ha}$ ) y más grandes ( $>10 \mathrm{~h})$ ex- 
hiben una menor participación electoral, ubicándose por debajo de la media nacional. Lo anterior, corrobora la información encontrada con el puntaje del Sisbén. De nuevo, la participación electoral se concentra en los rangos medios, presentándose una distribución de $U$ invertida. $Y$ esto coincide bastante bien con lo encontrada en la información reportada en el Sisbén; la participación por tamaño del productor tiene la forma U-invertida, similar al nivel socioeconómico de los hogares medidos por el puntaje Sisbén 3.

Por tenencia del cultivo de café, los productores que son dueños de su predio participan en promedio más que aquellos que tienen su predio en comodato, arriendo o posesión. Este resultado muestra que puede existir un mayor sentido de pertenencia a la institucionalidad cafetera a medida que se es propietario de la tierra, mientras que en los otros tipos de propiedad puede ser más sencillo abandonar la caficultura y dedicarse a otras labores.

Una última variable por considerar es la pertenecía a una cooperativa cafetera. Las cooperativas son importantes actores en la institucionalidad cafetera porque a través de ellas se ejecuta la garantía de compra, uno de los principales bienes públicos de la FNC. Las cooperativas brindan a los caficultores asociados varios servicios a cambio de un aporte económico. Dentro de los servicios se encuentra la compra de café, el apoyo en créditos, venta de fertilizantes y otros insumos,

\section{Gráfico 7. Participación electoral por categorías cafeteras de los votantes}

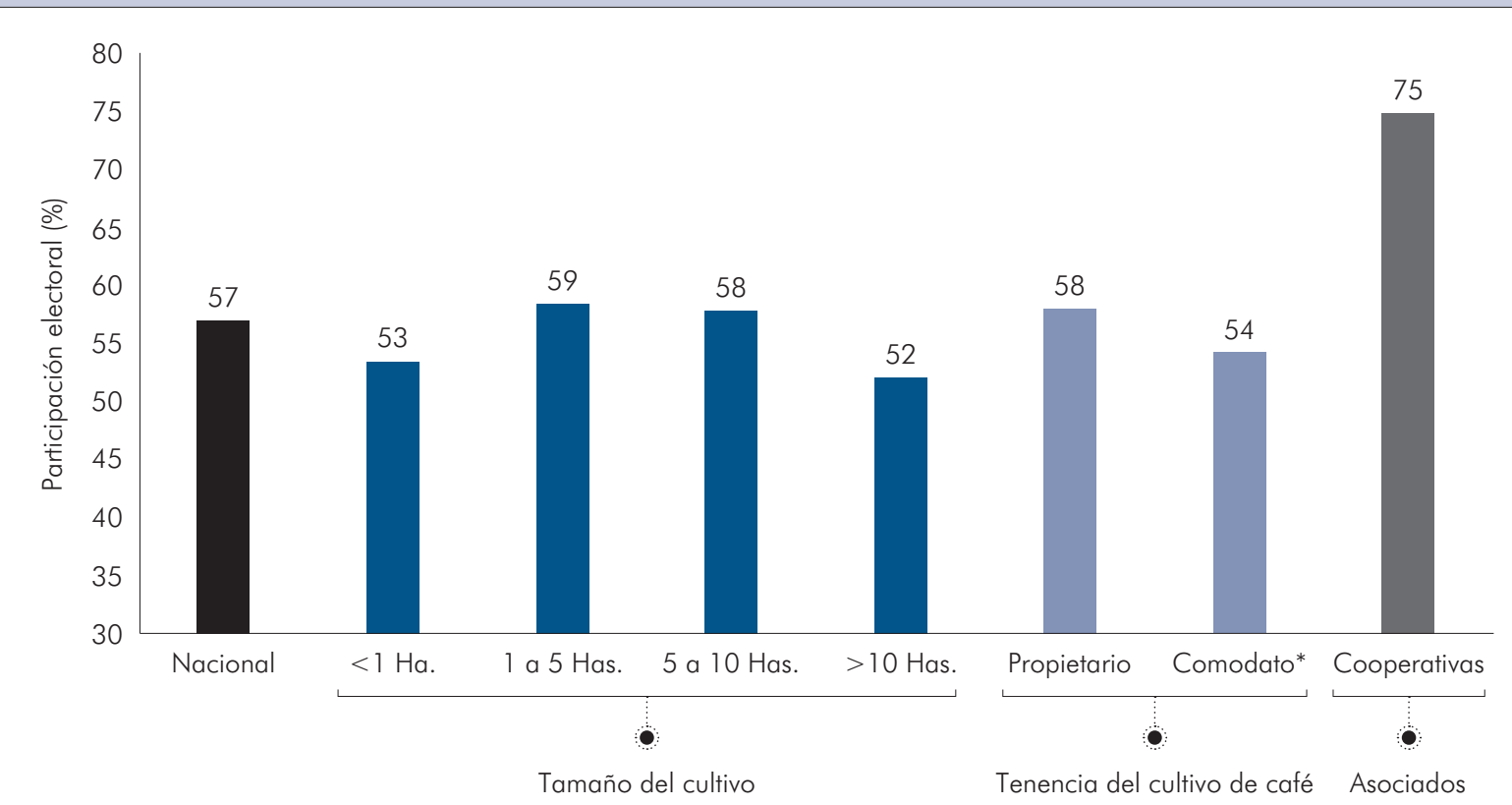

* Comodato incluye la categoría de posesión, arriendo.

Fuente: FNC. Elaboración propia. 
programas de inversión social, entre otros. En Colombia, alrededor de 77 mil productores se encuentran afiliados a alguna cooperativa de caficultores, de los cuales 66 mil cuentan con derechos gremiales, de ellos, cerca del $75 \%$ participaron en las elecciones cafeteras del 2018, 20 puntos porcentuales más que el promedio nacional. Esta cifra muestra cómo los productores miembros de cooperativas muestran tener más cercanía tienen con la institucionalidad cafetera.

\section{Otras variables relevantes que podrían ex- plicar la participación electoral}

Como se mencionó en la revisión de literatura, aparte de las características socioeconómicas, existen otros factores que inciden en la participación electoral. En el caso de las elecciones cafeteras, se analiza el rol de la competencia electoral, la inversión social de los comités y el número de productores.

En primer lugar, se encontró que entre mayor es el número de productores la participación electoral es menor (Gráfico 8). Esta relación permite clasificar los comités departamentales en tres grupos y así plantear una focalización de los esfuerzos. El primer grupo (naranja), corresponde a aquellos departamentos que tienen entre 5 mil y 30 mil productores y tuvieron una participación electoral superior al promedio nacional, lo cual favorece el grado de integración del gremio; el segundo(azules), son departamentos más pequeños, con participación electoral menor al promedio nacional, para los cuales se puede realizar un esfuerzo focalizado para aumentar la participación; y el tercero (rojos), son departamentos con la mayor cantidad de productores, la participa-

\section{Gráfico 8. Participación electoral vs. Número de productores}

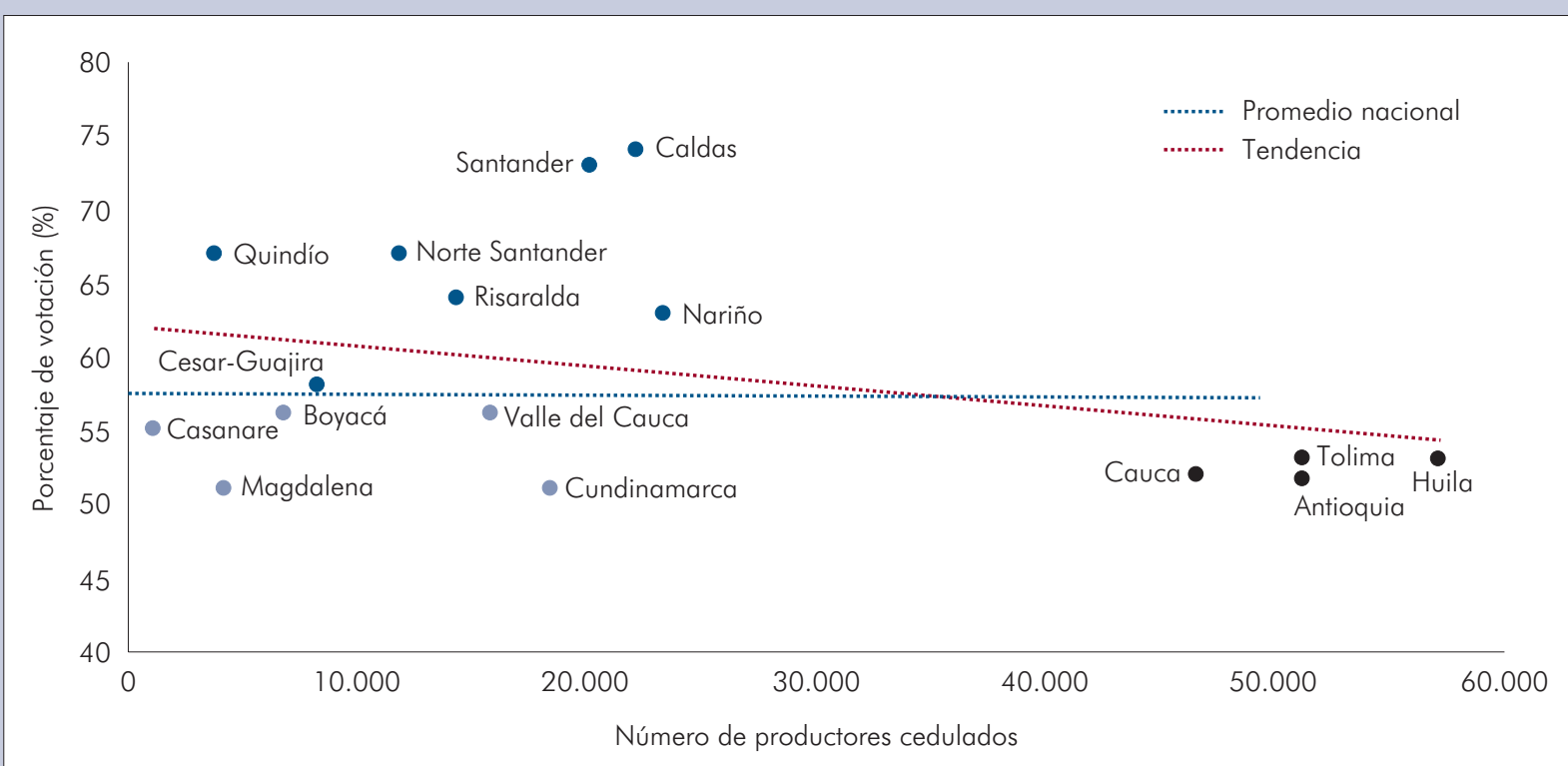

Fuente: FNC. Elaboración propia. 
ción electoral oscila entre $50 \%$ y $55 \%$, y sin duda alguna, la mayor participación electoral para el 2022 dependerá del esfuerzo del gremio para incentivar una mayor asistencia a las urnas entre los potenciales votantes.

Del mismo modo se encontró un comportamiento similar al usar como referencia el área cultivada de café en el departamento, específicamente, entre mayor sea el área cultivada del departamento, menor es la participación. Estas comparaciones contradicen la expectativa que entre mayor sea la producción o tamaño del área en café, mayor será la participación electoral. Para profundizar en este aspecto se analizó a nivel municipal la participación electoral, se formaron niveles de presencia cafetera de acuerdo con los percentiles 50 y 75 de su distribución (ver Tabla 3)

Se encontró que existen 82 municipios cafeteros que cuentan con más de 1200 productores, conteniendo a cerca del $51 \%$ de caficultores cedulados. La participación electoral en estos 82 municipios fue del $53 \%$, menor tanto al promedio nacional como también a los municipios de presencia cafetera baja y media. Por consiguiente, mayor número de productores cafeteros no implica un mayor grado de integración y participación gremial, de hecho, parece estar ocurriendo lo contrario, y eso se debe a que es más difícil promover la unidad gremial y la confianza institucional entre mayor sea el número de productores, con diferentes características y necesidades, en un municipio.

Por otra parte, Barters (2000) muestra cómo la participación electoral es explicada en buena medida por la efectividad del gobierno para llevar acciones esperadas por la comunidad. Para medir este efecto, se usó como variable proxy, la inversión social per cápita realizada por los comités departamentales entre 20152018 y se comparó con la participación electoral (ver Gráfico 9). Se encontró una tendencia positiva, mostrando una correlación leve entre una mayor inversión social y una mayor participación electoral. Por ejemplo, Caldas fue el departamento con mayor votación y mostró un alto nivel de inversión por productor; sin em-

Tabla 3. Participación electoral por presencia cafetera de acuerdo con el número de municipios

\begin{tabular}{|c|c|c|c|c|}
\hline & \multicolumn{4}{|c|}{$\begin{array}{c}\text { Presencia Cafetera } \\
\text { (ubicación de precio cafetero) }\end{array}$} \\
\hline & $\begin{array}{c}\text { Baja } \\
(<400 \text { productores })\end{array}$ & $\begin{array}{c}\text { Media } \\
\text { (entre } 400 \text { y } 1200 \text { productores) }\end{array}$ & $\begin{array}{c}\text { Alta } \\
\text { (>1200 productores) }\end{array}$ & Total \\
\hline Número de municipios & 344 & 179 & 82 & 605 \\
\hline Caficultores & 28.225 & 126.756 & 182.444 & 357.788 \\
\hline Porcentaje de café/total & 7,9 & 35,4 & 51,0 & 100 \\
\hline $\begin{array}{l}\text { Participación electoral } \\
\text { Elecciones cafeteras } 2018\end{array}$ & $57 \%$ & $58 \%$ & $53 \%$ & \\
\hline
\end{tabular}


bargo, Santander también presentó una alta participación, pero su inversión fue más baja. Todo esto demuestra que la dinámica entre los recursos invertidos y la participación gremial es compleja, con factores como el tipo de inversiones, el número de beneficiados y el mecanismo de rendición de cuentas mediando en su efecto. Debido a esto, este es un tema donde futura literatura podría profundizar.

Otro argumento presente en la literatura, planteado por Green y Shapiro (1994), es que la falta de intereses en disputa desmotiva la participación electoral. La competencia electoral convoca a la comunidad a escuchar diferentes formas y puntos de vista, además, entre más candidatos se inscriban, las discusiones se enriquecen. Los beneficios de la democracia salen a la luz cuando varios candidatos debaten entre ellos, llegando a mejores acciones y consensos. Como variable proxy de la competencia electoral, se estimó la participación entre los elegidos con respecto al número de candidatos. Entre mayor sea esta relación, mayor es la cantidad de candidatos que se presentaron. Como se observa en el Gráfico 10, en varios departamentos ocurrió que a medida que hubo mayor competencia, la participación electoral fue mayor, sin embargo, al igual que con la inversión, parece ser una relación leve.

Caldas, fue el departamento con más candidaturas y obtuvo la mayor participación electoral, siendo también uno de los departamentos que más inversión social realizó. Risaralda y Nariño también obtuvieron una cantidad importante de candidatos, y obtuvieron tasas de participación mayores al $60 \%$. Vale mencionar dos aspectos relevantes sobre la competencia electoral. Primero, se observa que existen

\section{Gráfico 9. Participación electoral vs Inversión social por productor a nivel departamental}

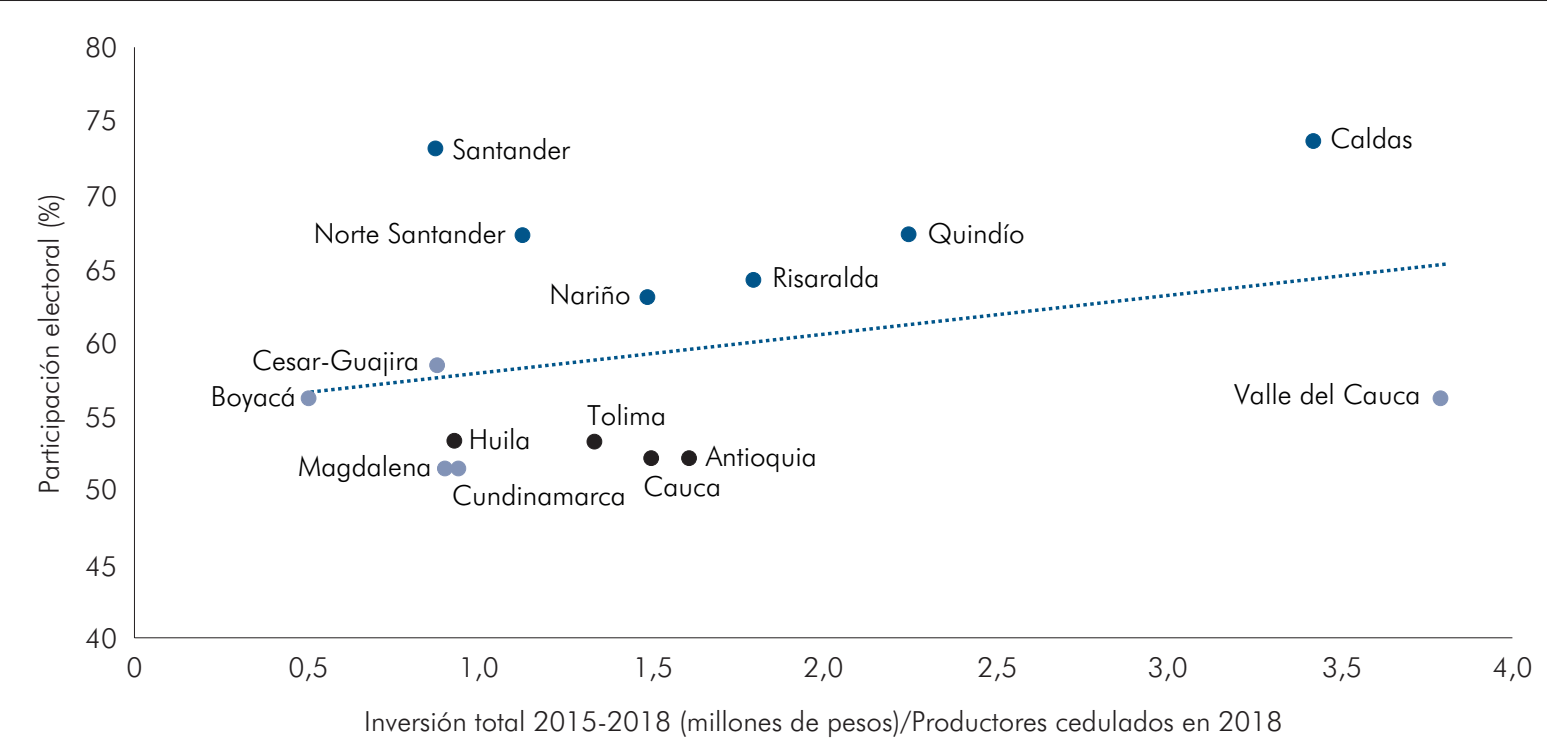

Fuente: FNC. Elaboración propia. 
Gráfico 10. Participación electoral vs competencia electoral

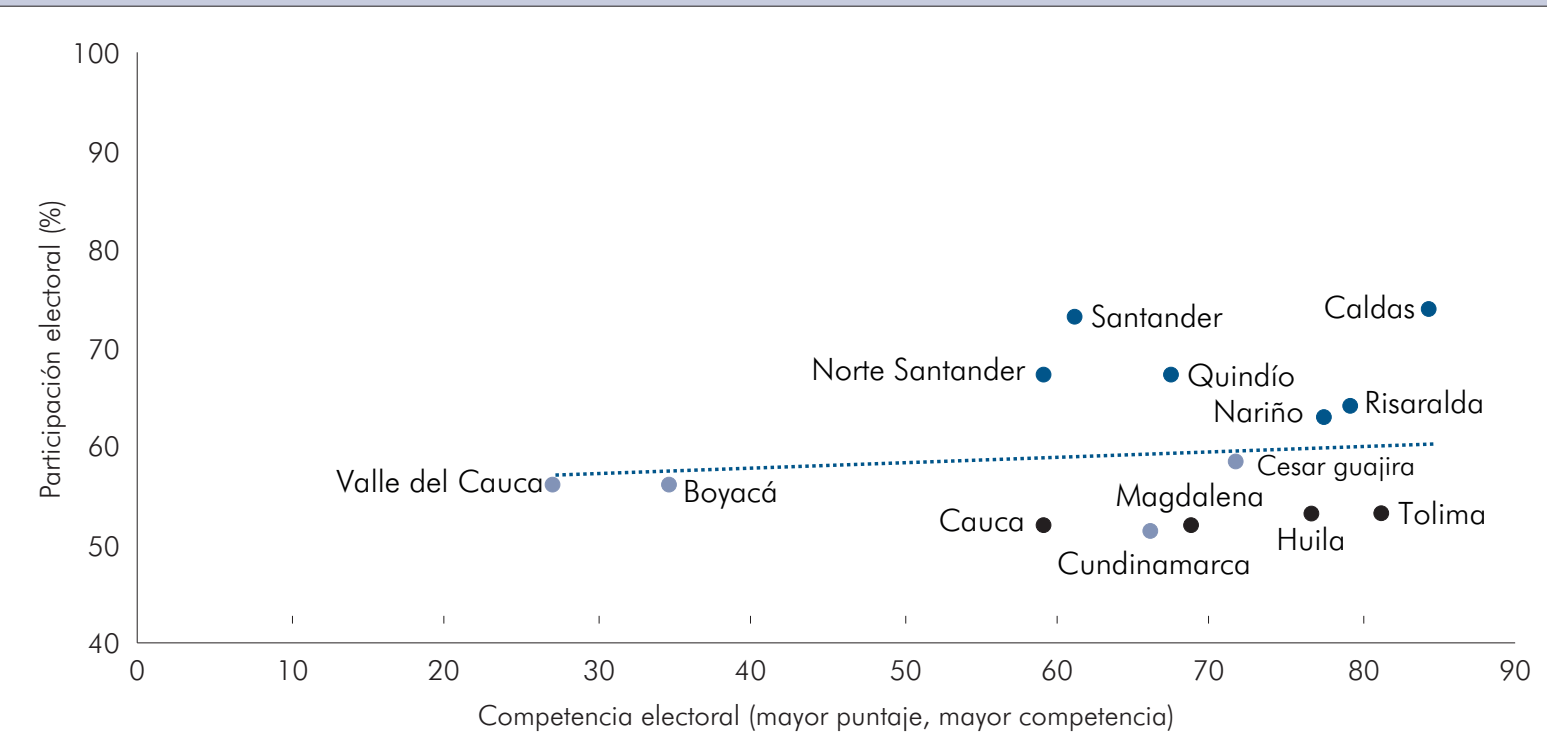

Fuente: FNC. Elaboración propia.

grandes disparidades por departamento en la cantidad de candidatos que se presentaron en las elecciones, por ejemplo, Valle del Cauca y Boyacá tuvieron una competencia más de 20 unidades menor que el resto. En segundo lugar, en los departamentos con mayor número de productores (puntos rojos) no se evidenció esta relación positiva entre la competencia electoral y la participación.

\section{Modelo de probabilidad}

El propósito de esta sección es estimar los factores que pueden llegar a ser relevantes para explicar la decisión de cada productor de vo- tar o no en las elecciones cafeteras. Dada la naturaleza de la variable que se quiere explicar (votar o no votar), la cual puede tomar solo dos valores: 0 y 1 , donde 0 es no votar y 1 es votar por lo cual, no es continua. Una primera posibilidad para estimar este tipo de regresión es usar el Modelo de Probabilidad Lineal (MPL), el cual se basa en métodos tradicionales de Mínimos Cuadrados Ordinarios (MCO) aplicados a una variable dependiente binaria. Las principales limitaciones del MPL son que el modelo puede estimar probabilidades por encima de uno (encima de 100 puntos porcentuales) y que el modelo resultante es heterocedástico ${ }^{18}$.

18 La heterocedasticidad se presenta cuando la varianza de los errores no es igual en todas las observaciones, incumpliéndose el supuesto de normalidad. En consecuencia, no se puede determinar con confiabilidad estadística si las variables sociales y económicas tienen un efecto real sobre la participación electoral. esto implica que no se cumple uno de los requisitos básicos de las hipótesis de los modelos lineales dado que la varianza del modelo está sesgada. Otra limitación de MPL es que los errores del modelo también incumplen el supuesto de normalidad. 
Una forma de sobreponerse a las limitaciones presentes al aplicar MPL es usar modelos de regresión logística (logit). Explicada de forma sencilla, la regresión logística es un modelo que en su forma básica, sólo toma valores entre 0 y 1 , representados por la función logística ${ }^{19}$ para modelar el comportamiento de una variable dependiente binaria. Dada su facilidad de uso y el hecho de que los valores estimados serán consistentes estadísticamente, en este trabajo se usará un modelo logit para identificar que variables individuales, municipales o regionales afectan la decisión de votar de los productores cafeteros en las elecciones de 2018.

Dada la metodología logit elegida, se especifica la siguiente ecuación, para describir la regresión que se busca estimar en este trabajo:

$P(Y=1 \mid x)=\Phi\left(X_{i} \beta\right), \Phi\left(X_{i} \beta\right)=\frac{e^{X_{i} \beta}}{1+e^{X_{i} \beta}}$

Donde, $Y$ es una variable que captura si el productor votó o no en las elecciones, $X_{i^{\prime}}$ es un vector que incluye todas las variables explicativas que se usaran en el modelo, $\beta$ es el vector de parámetros a estimar, y $\Phi$ corresponde a la función logística.

Para estimar el modelo descrito en (1), se usará la Base Consolidada Elecciones 2018, compuesta por 298,537 productores cafeteros y cuya construcción está descrita en la sección (3) de este documento. Esta base tiene variables que se pueden clasificar en 3 grandes categorías (ver Tabla 3): primero, variables socioeconómicas del productor como edad, sexo, nivel educativo, entre otras; segundo, variables relacionadas con el cultivo de café como tamaño del productor, propiedad de la tierra; por último, usando datos de la $M O E$, se incluyen variables a nivel municipal de la participación electoral en las elecciones al concejo y un indicador sobre riesgo electoral por fraude o violencia.

\section{Resultados}

La forma básica planteada en la ecuación (1) se estimó para cinco especificaciones diferentes, las cuales incluyen diferentes combinaciones de los conjuntos de variables descritos en la Tabla 4. Como criterio general, se buscaba que las variables nuevas que se incluían en cada especificación fueran significativas individualmente, además, aumenten la significancia y el ajuste global del modelo y que no presentarán problemas de multicolinealidad. La Tabla 5 describe con mayor detalle cada una de estas cinco especificaciones e incluye diversas pruebas o medidas de ajustes calculadas en cada modelo.

En primer lugar, el modelo 1 incluye variables socioeconómicas y una dummy de comité departamental usada para capturar características que solo cambian a ese nivel, más no a nivel individual. Sin embargo, en esta especificación, la variable de puntaje Sisbén eviden-

9 La función logística, es función matemática ampliamente usada para modelar crecimiento poblacional y propagación de enfermedades. Y está definida por la ecuación: $F(X)=\frac{1}{1+e^{-x}}$ 
ciaba problemas de multicolinealidad ${ }^{20}$; por lo que en el modelo 2, esta variable se modificó a una forma categórica. Los modelos
3 y 4 también incluyen variables productivas, con la diferencia de que el modelo 4 omite la variable de tenencia de la tierra (propie-

\begin{tabular}{|c|c|c|c|}
\hline \multicolumn{5}{|c|}{ Tabla 4. Descripción de las Variables } \\
\hline Conjunto variables & Descripción & Tipo & Agregación \\
\hline Socioeconómicas & $\begin{array}{c}\text { Incluye variables de edad, sexo, } \\
\text { estado civil, nivel educativo, zona de } \\
\text { residencia y puntaje SISBEN 3 }\end{array}$ & Variables Continuas y categóricas & Nivel Individual \\
\hline Productivas & $\begin{array}{c}\text { Tamaño del productor, tenencia de la } \\
\text { tierra, asociación a cooperativas } \\
\text { cafeteras, comité cafetero, presencia } \\
\text { cafetera en el municipio }\end{array}$ & Variables categóricas & Nivel Individual \\
\hline Electorales & $\begin{array}{c}\text { Participación electoral municipal en } \\
\text { las elecciones a concejo, municipios } \\
\text { clasificados con riesgo electoral }\end{array}$ & Variables categóricas & Nivel Municipal \\
\hline Fuente: ??? & \multicolumn{2}{|c|}{${ }^{|c|}$} & \\
\hline
\end{tabular}

\section{Tabla 5. Descripción de las especificaciones estimadas}

\begin{tabular}{|c|c|c|c|c|c|}
\hline Variables, pruebas y medidas de ajuste & Modelo (1) & Modelo (2) & Modelo (3) & Modelo (4) & Modelo (5) \\
\hline Socioeconómicas & $x$ & $x$ & $x$ & $x$ & $x$ \\
\hline Productivas & & & $x$ & $x$ & $x$ \\
\hline Dummy de Comité & $x$ & $x$ & $x$ & $x$ & $x$ \\
\hline Electorales & & & & & $x$ \\
\hline Número de Observaciones & 299.604 & 299.604 & 294.499 & 299.604 & 299.604 \\
\hline Pseudo R2 & 0,04 & 0,04 & 0,04 & 0,06 & 0,06 \\
\hline Número de Variables & 26 & 27 & 33 & 32 & 35 \\
\hline Variable presenta multicolinealidad & $x$ & & $x$ & & \\
\hline$\%$ de Obs correctamente clasificadas & $61,5 \%$ & $61,6 \%$ & $61,7 \%$ & $63,0 \%$ & $63,0 \%$ \\
\hline Test de Hosmer-Lemeshow* & $16,93(0,031)$ & $12,30(0,1382)$ & $19,09(0,014)$ & $12,26(0,056)$ & $7,16(0,2093)$ \\
\hline Área Curva ROC & 0,627 & 0,627 & 0,631 & 0,659 & 0,660 \\
\hline Criterio AIC & 390130,6 & 390213,7 & 382612,5 & 381994,6 & 381601,2 \\
\hline Criterio BIC & 390417,1 & 390510,7 & 382972,6 & 382344,7 & 381983,2 \\
\hline
\end{tabular}

* El test de Hosmer-Lemeshow es asintóticamente chi(2) y su p-valor se presenta entre paréntesis. Debido al alto número de observaciones, el test se calculó usando 10 grados de libertad en todos los modelos.

Fuente: ???

20 Para medir la multicolinealidad se usó el indicador de Factor de inflación de la varianza (VIF), descartando aquellas variables que tuvieran un VIF superior a 10. 
tario $u$ otras formas de tenencia). Por último, el modelo 5 incluye tanto las variables socioeconómicas y productivas como también las variables electorales a nivel municipal y omite la variable de presencia cafetera en el municipio.

En segundo lugar, en términos de ajuste vemos que cada modelo mejora ligeramente el porcentaje de observaciones correctamente clasificadas (productores correctamente clasificados respecto a si votaron o no), adicionalmente, también se observa que el indicador del Área debajo de la curva ROC (un área igual a 1 implica ajuste perfecto) es más alta en cada modelo. Ambos indicadores muestran que la inclusión de nuevas variables mejora el poder predictivo de la regresión y nos permite identificar con mayor precisión qué factores pueden explicar la participación en las elecciones cafeteras.

Por último, para elegir cuál de los cinco modelos es la mejor elección para este trabajo, se utilizan los criterios de información bayesiano $(\mathrm{BIC})$ y criterio de información de Akaike (AIC). Para ambos, se busca que el valor sea el más bajo entre todos los modelos; en este caso, el modelo 5 presenta tanto el AIC como el BIC más bajo. Dado esto, y debido a que también se trata del modelo con mejor poder explicativo, se eligió este modelo para presentar sus principales resultados y compararlos con las estadísticas descriptivas realizadas en la sección anterior.
Los coeficientes estimados para la regresión planteada en el modelo 5, se presentan en el anexo en las Tablas A2-A4. Iniciando por las variables socioeconómicas (ver Tabla A2), se observan efectos significativos para todas las variables incluidas, exceptuando la categoría de Educación Superior. Comparando con el perfil socioeconómico de la sección anterior también se evidencia que los signos de los coeficientes son consistentes con lo presentado anteriormente. Respecto a las variables productivas (Tabla A3), también se observan efectos significativos y con los signos esperados, destacando que el hecho de estar asociado a una cooperativa cafetera tiene un efecto fuerte sobre la probabilidad de votar.

Por otro lado, las variables electorales muestran 2 resultados interesantes. Primero, se evidencia que existe un efecto positivo de estar ubicado en un municipio que presenta altos niveles de participación electoral en otros procesos electorales respecto a municipios con baja participación. Segundo, existe un efecto negativo y significativo sobre la probabilidad de votar en las elecciones cafeteras al estar ubicado en municipios los cuales la MOE identificó en riesgo medio o alto ${ }^{21}$.

Por último, se evalúan los coeficientes de las variables de comité departamental (Ver Tabla A4). En general se observa que existen efectos significativos en muchos comités al comparar respecto a la categoría base, la cual, en este caso se trata de la Oficina Coordinadora. Este

21 Usando la clasificación de la MOE, 23.817 productores están en 25 municipios con riesgo medio, 28.517 en 25 municipios con riesgo alto y 11.810 en 16 municipios con riesgo extremo. 
resultado puede estar mostrando el efecto de variables como la competencia electoral y las inversiones sociales por productor en cada comité.

\section{Interpretación de los resultados}

Para facilitar la interpretación de los resultados del modelo logístico estimado, se calcularán los efectos marginales promedio para los resultados del modelo 5 . En este caso particular, debido a que todas las variables en el modelo 5 son categóricas, los efectos marginales se interpretan en términos de puntos porcentuales (p.p) que suman o restan a la probabilidad estimada respecto a la categoría base, controlando por el resto de las variables en el modelo.

Las Tablas 6-8 muestran los efectos marginales estimados para las variables del modelo (5). En primer lugar, respecto a las variables socioeconómicas destaca que habitar en centros poblados o en el rural disperso aumenta la probabilidad de votar respecto a habitar en cabeceras en 16 y 18 p.p respectivamente. También se observa que los Adultos y Adultos en comparación a los Jóvenes, tienen una probabilidad de votar 8 p.p mayor. Otro resultado relevante es que las mujeres votan solo 1 p.p menos que los hombres, sin embargo, como se vio anteriormente, este efecto parece ser bastante heterogéneo entre los diferentes comités cafeteros departamentales.

En segundo lugar, al analizar las variables productivas, se observan diferencias pequeñas de 3 p.p en la probabilidad de votar entre productores medianos y grandes en compara- el estar asociado a una cooperativa cafetera aumenta la probabilidad de votar, respecto a no estarlo en 22 p.p. Este resultado es particularmente importante porque muestra que, en efecto, los productores que se encuentran más estrechamente relacionados con organizaciones dentro del gremio son más propensos a votar en las elecciones cafeteras.

En términos de las variables electorales, se observa que los productores en municipios

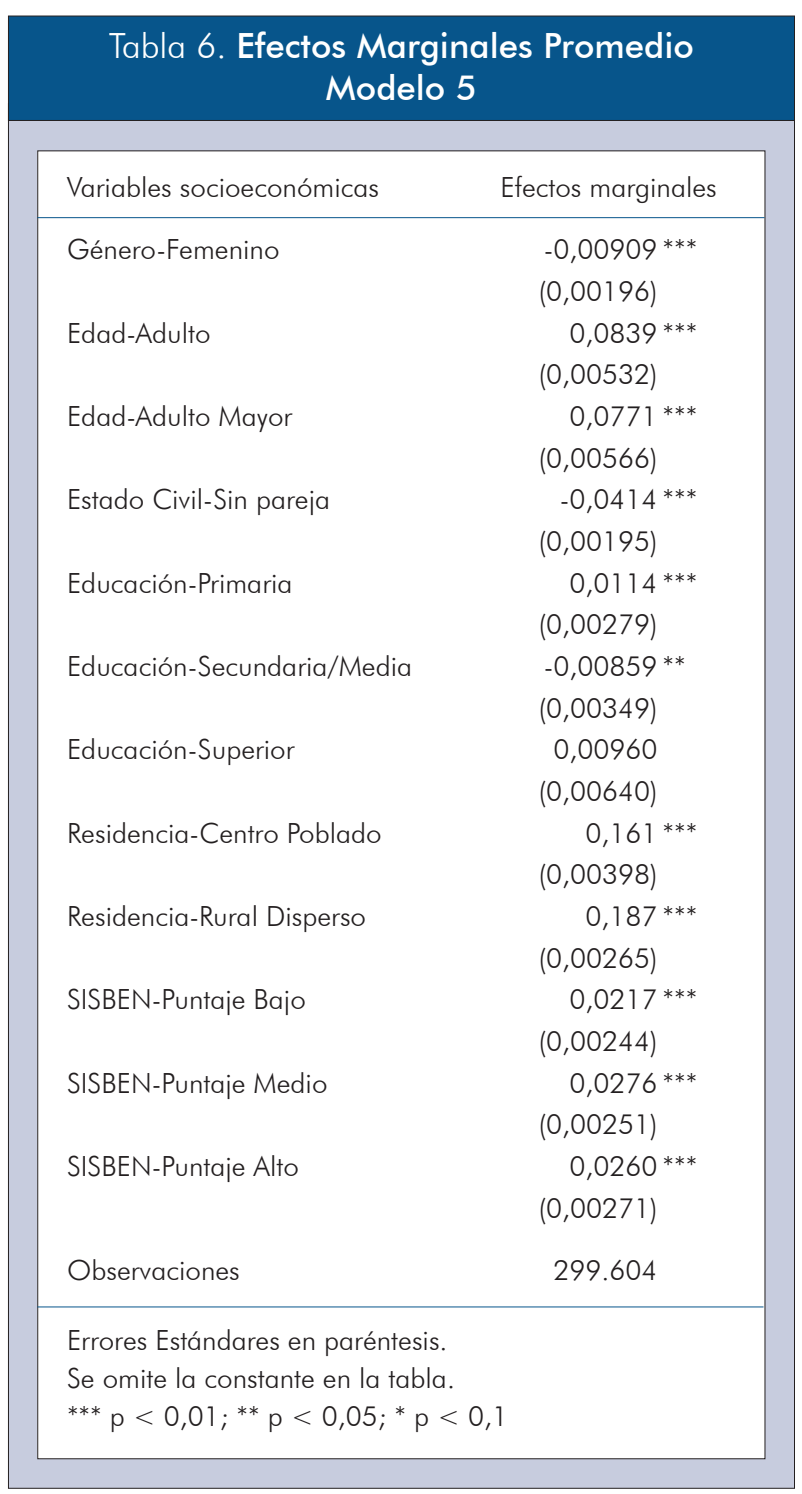


con una participación alta en las elecciones a concejo tienen una probabilidad 3 p.p mayor a los productores en municipios con participación baja. Por otro lado, la participación electoral es 5 p.p menor para productores en municipios clasificados con riesgo electoral medio en comparación a aquellos productores en municipios con riesgo bajo.

Al ver las variables por comité se observa que en los comités previamente clasificados, en la sección cuatro de este documento, en el grupo amarillo (aquellos que tienen entre 5 mil y 30 mil productores y tuvieron una par-

\begin{tabular}{|c|c|}
\hline Variables productivas y electorales & Efectos marginales \\
\hline Tamaño-Productor Mediano & $\begin{array}{c}0,0308^{\text {***}} \\
(0,00187)\end{array}$ \\
\hline Tamaño-Productor Grande & $\begin{array}{c}0,0361^{* * *} \\
(0,00548)\end{array}$ \\
\hline Asociado Cooperativa & $\begin{array}{c}0,221^{* * *} \\
(0,00258)\end{array}$ \\
\hline Participación Media Elecciones Consejo & $\begin{array}{r}0,00305 \\
(0,00252)\end{array}$ \\
\hline Participación Alta Elecciones Consejo & $\begin{array}{c}0,0310^{* * *} \\
(0,00293)\end{array}$ \\
\hline Riesgo Electoral Medio & $\begin{array}{c}-0,0591^{* * *} \\
(0,00379)\end{array}$ \\
\hline Riesgo Electoral Alto & $\begin{array}{c}-0,0203^{* * *} \\
(0,00360)\end{array}$ \\
\hline Riesgo Electoral Extremo & $\begin{array}{r}0,00359 \\
(0,00555)\end{array}$ \\
\hline Observaciones & 299.604 \\
\hline $\begin{array}{l}\text { Errores Estándares en paréntesis. } \\
\text { Se omite la constante en la tabla. } \\
{ }^{* * *} p<0,01 \text {; }^{* *} p<0,05 ;{ }^{*} p<0,1\end{array}$ & \\
\hline
\end{tabular}

22 La categoría base de este grupo de variables es oficinas coordinadoras. ticipación electoral superior al promedio nacional) muestran efectos marginales positivos respecto a la categoría base ${ }^{22}$, indicando que en efecto variables como la inversión social y

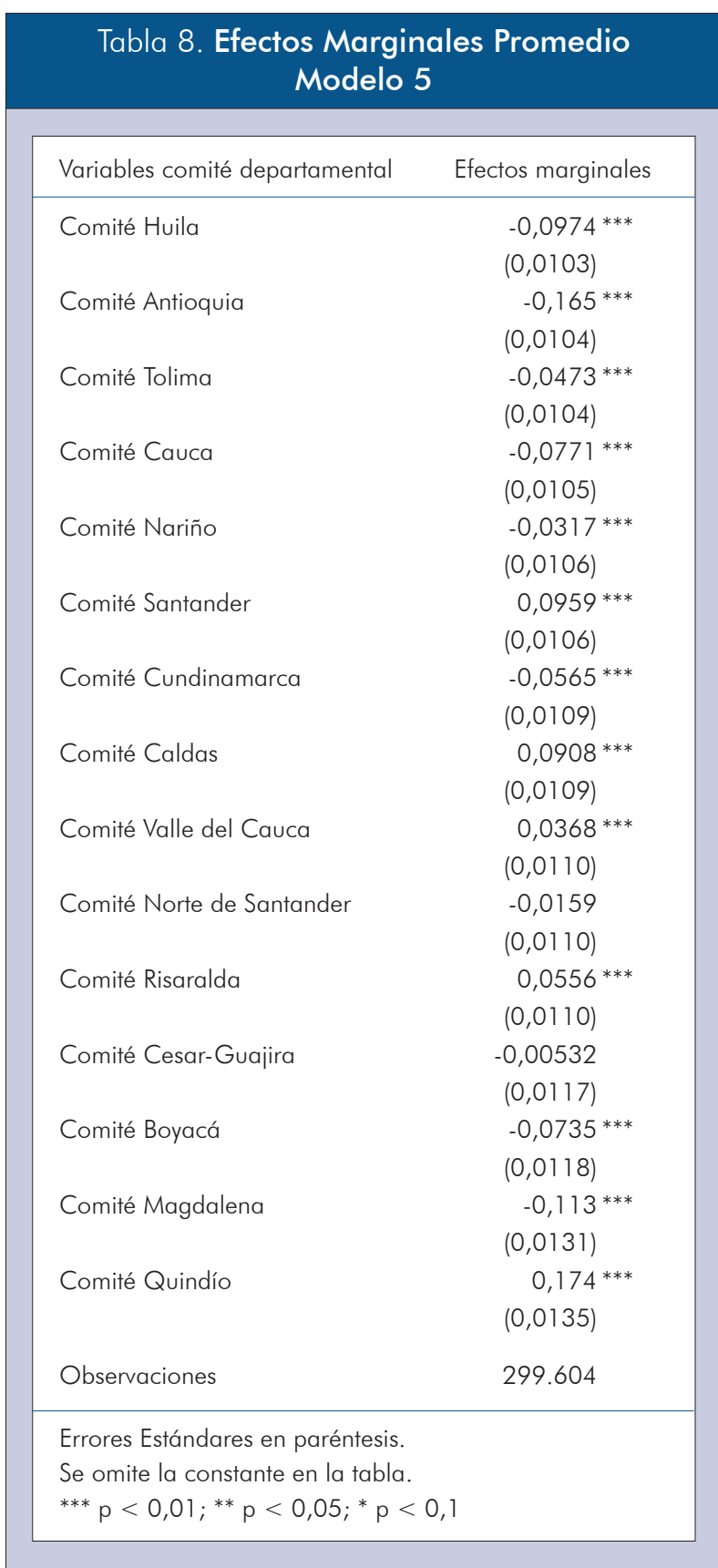


la competencia electoral afectan la decisión de los productores de involucrase en mayor medida en el proceso electoral, dado que experimentan mayores beneficios a los vistos en otros comités.

Por otro lado, uno de los resultados observados sobre el cual se puede hacer un análisis más profundo, es la brecha existente entre el voto masculino y el femenino. Esto con el objetivo de entender que factores pueden explicar esta diferencia. Siguiendo una metodología similar a la presentada por Kostelka, Blais \& Gidengil (2019), se plantea una descomposición de Blinder-Oaxaca ${ }^{23}$ para identificar que parte de la diferencia en participación electoral por género puede ser explicada por diferencias en las características (edad, nivel educativo, zona de residencia) entre hombres y mujeres (parte explicada); y que parte puede ser atribuida a variables omitidas o a la existencia de algún tipo de discriminación (parte inexplicada).
Específicamente, para este trabajo, la descomposición de Blinder-Oaxaca consiste: primero, en estimar una regresión logística para cada uno de los grupos (hombres y mujeres); segundo, aprovechando el supuesto de media cero en los residuales en las regresiones, se descomponen las diferencias en la media de participación electoral en las 2 partes previamente descritas. En una primera especificación, se incluyen las mismas variables del modelo (5), a excepción de las dummies de comité departamental. La segunda especificación calcula lo mismo, pero incluyendo estas dummies. Los resultados de esta estimación se presentan en la Tabla 9.

Esta estimación muestra dos resultados interesantes, en primer lugar, al no incluir las variables de comité, se observa que la diferencia entre la participación de hombres y mujeres puede ser explicada exclusivamente porque las mujeres no tienen las mismas ca-

Tabla 9. Descomposición Blinder-Oaxaca para brecha de género en votación

\begin{tabular}{|llllll}
\hline \multicolumn{2}{c}{ Sin variables de comité } & & & \multicolumn{2}{c}{ Con variables de comité } \\
\cline { 1 - 1 } Descomposición & Coeficiente & & Descomposición & Coeficiente \\
\hline Media hombres & $0,593^{* * *}$ & & Media Hombres & $0,593^{* * *}$ \\
Media mujeres & $0,568^{* * *}$ & & Media Mujeres & $0,568^{* * *}$ \\
Diferencia & $0,025^{* * *}$ & & Diferencia & $0,025^{* * *}$ \\
Parte explicada & $0,025^{* * *}$ & & Parte Explicada & $0,015^{* * *}$ \\
Parte ilnexplicada & 0,000 & & Parte Inexplicada & $0,010^{* * *}$ \\
\hline
\end{tabular}

Se omite el componente de interacción en la tabla

*** $p<0,01 i^{* *} p<0,05 ;^{*} p<0,1$

23 La descomposición de Blinder-Oaxaca es un método estadístico usado para explicar la diferencia en medias entre 2 grupos para identificar que parte puede ser explicada y que parte puede ser atribuida a discriminación. Un resumen detallado de la metodología se encuentra en Jann, B. (2008). 
racterísticas en las variables de control que los hombres. Al incluir las variables de comité (variables control), la parte explicada solo correspondería al $60 \%$ de la brecha, indicando que si existe una parte de la diferencia que puede ser atribuida a variables no observables como la existencia de actitudes sexistas o algún de discriminación que desincentivan a las mujeres de ejercer su voto. No obstante, se considera que vale la pena profundizar en este aspecto en estudios posteriores.

En resumen, los resultados del modelo de regresión logística parecen confirmar, en su mayoría, lo descrito en el perfil socioeconómico realizado en las secciones anteriores de este trabajo; encontrando que variables como la edad, la zona de residencia y la afiliación a cooperativas cafeteras son factores que influencian fuertemente la decisión de participar activamente en el proceso electoral cafetero.

\section{PERFIL SOCIOECONÓMICO DEL GOBIERNO CAFETERO ELEGIDO 2018-2022}

Barathe (2019), sostiene que, redistribuir el poder de forma equilibrada promueve una democracia paritaria que construye relaciones horizontales y liderazgos libres de estereotipos y prejuicios. Por esta razón, es importante que existan metas de paridad en los gobiernos y específicamente en el gobierno cafetero. Para ello, se analiza si existe una alta correspondencia por cada categoría so- ciodemográfica y productiva entre los electores y elegidos, esto se conoce como la meta de paridad $^{24}$. En el caso de la gobernanza cafetera, en este artículo se considera que se debe buscar la paridad principalmente por género, edad y tamaño del cultivo, no obstante, en el estudio se comparan todas las categorías socioeconómicas. De esta manera se incrementa la probabilidad de que los intereses de los grupos poblacionales queden bien representados.

En el Gráfico 11, se muestran las distribuciones de la población cafetera y de los líderes cafeteros municipales elegidos según categorías sociodemográficas. Primero, por zona de residencia, se esperaría que los líderes residan principalmente en la ruralidad debido a la naturaleza de la actividad cafetera, y por qué la mayor parte de la población se encuentra allí. Efectivamente, el 82,4\% de los líderes municipales residen en el sector rural disperso. Segundo, por nivel educativo, se encontró que los líderes elegidos presentan un mayor logro educativo, mostrando una prevalencia mayor en educación secundaria y superior.

Tercero, el relevo generacional es un gran desafío para la sostenibilidad del sector cafetero. En este sentido, se observa que la participación de los líderes cafeteros jóvenes es proporcionalmente baja, tanto en el censo electoral, como en los elegidos. El Gráfico 8 muestra que existe una alta correspondencia entre las dos distribuciones, donde los adul-

24 Un ejemplo de metas de paridad en Latinoamérica fue abordado por la Organización de las Naciones Unidas (ONU) en Barathe, R. (2019). 
tos toman mayor relevancia y los adultos mayores pierden algo de participación, lo cual parece razonable, dado el esfuerzo necesario para ejercer estos cargos. En conclusión, si bien parece existir paridad por edad, es evidente la baja participación de los productores jóvenes.

Por último, en cuanto al género, la meta de paridad del gremio cafetero es $72 \%$ hombres y $28 \%$ mujeres. En el caso de los líderes municipales elegidos, la meta se encuentra 4 puntos porcentuales por debajo, dado que el $76 \%$ de los líderes cafeteros municipales son hombres y el $24 \%$ son mujeres. Como se detalla en el Gráfico 10, la brecha es mayor en los líderes departamentales, donde se encuentra 12 puntos porcentuales por debajo de la meta. No obstante, vale la pena mencionar que la presencia de la mujer ha venido aumentando en la agremiación cafetera, en efecto, en el periodo anterior (2014-2018), la participación de las mujeres en los líderes cafeteros municipales era del $20 \%$.

Ampliando el análisis por género, se estimó la distribución entre candidatos y elegidos en los comités departamentales y municipa-

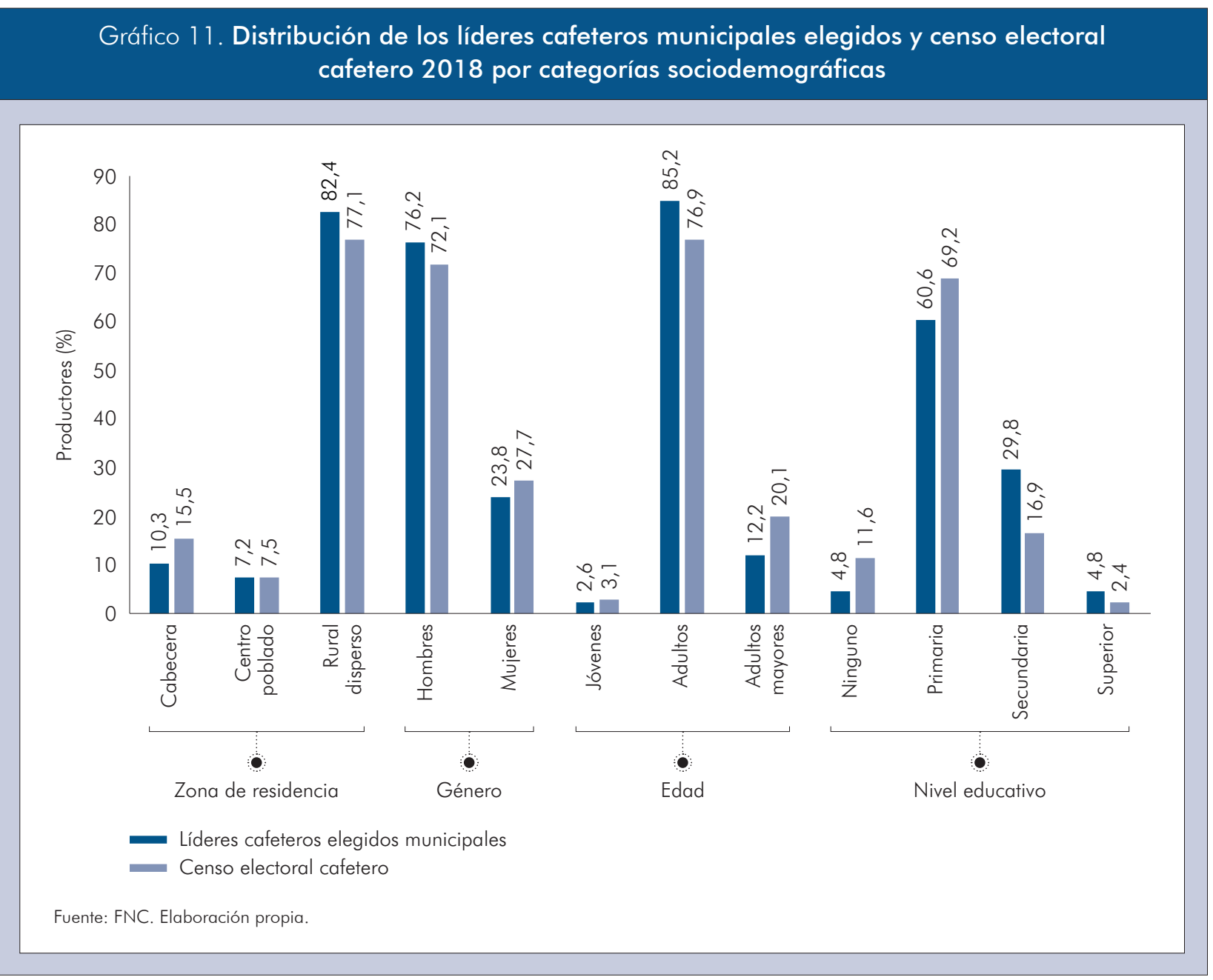


les. En términos relativos, se encontró que el productor cafetero no discrimina su voto por sexo, lo que ocurre es que las mujeres se presentan menos que los hombres. Como se muestra en el Gráfico 12, en ambos casos se encontró que la distribución de los candidatos en relación con los elegidos es casi idéntica, signo de la no preferencia del votante en las urnas por sexo. Puede concluirse que existe un espacio importante para incentivar a las mujeres a que se presenten a ser candidatas, con esto se lograría la meta de paridad del gremio.

Respecto a los líderes departamentales elegidos, se observa que estos líderes tienen un papel más activo en la institucionalidad, cuentan con autonomía presupuestal en su departamento y eligen a los miembros del comité directivo de la FNC. En el Gráfico 13 se evidencia que al igual que los líderes municipales, la correspondencia por zona se mantiene, ya que la mayoría de los líderes departamentales reside en la ruralidad. Además, el gremio reconoce la experiencia de las personas que se presentan al cargo de líder departamental, el $83,7 \%$ tiene entre 29 y 65 años. Este grupo de líderes es pequeño y en general las personas que llegan allí han tenido una larga trayectoria en la actividad productiva. Por otra parte, este grupo presenta un mejor nivel educativo, ya que la mayoría alcanzó la secundaria y una proporción importante cuenta con estudios en educación superior.

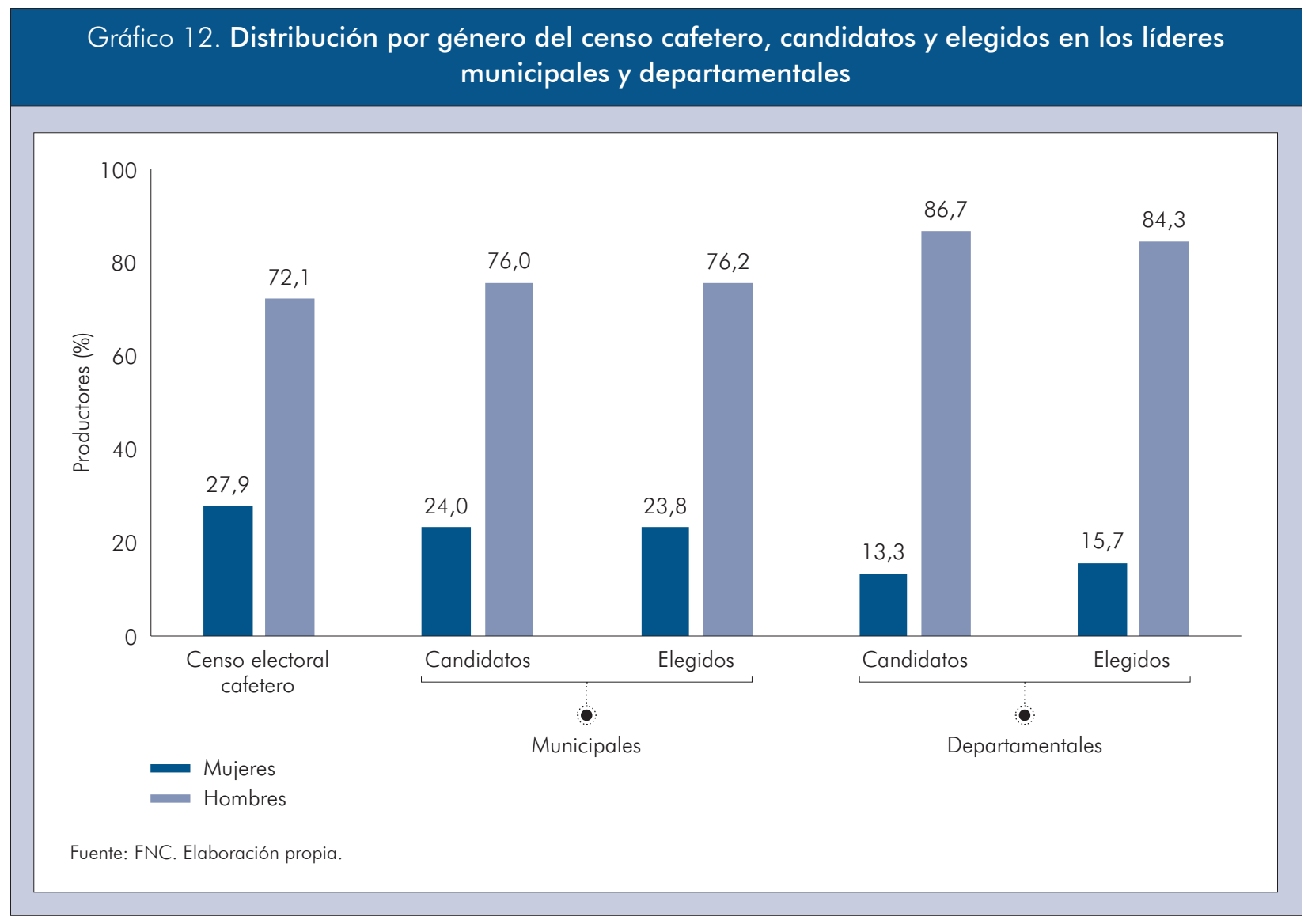




\section{Gráfico 13. Distribución de los líderes cafeteros departamentales elegidos y el censo electoral}

cafetero de 2018 por categorías sociodemográficas

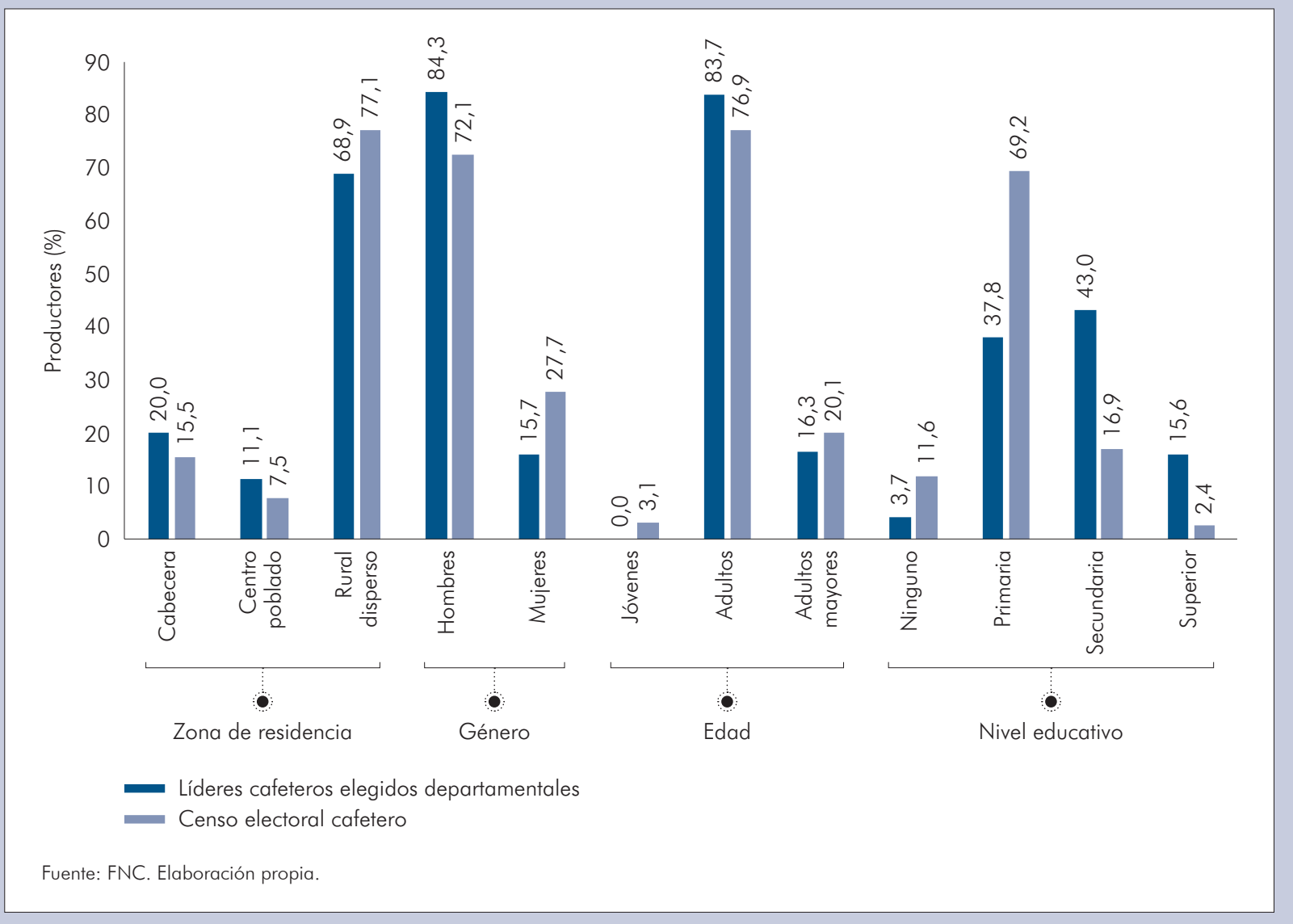

Por características del cultivo

Como se mencionó anteriormente, también es importante tener paridad por tamaño del productor, dado que, de esta manera se aumenta la probabilidad de que los intereses de la comunidad cafetera se encuentren bien representados. Como se muestra en el Gráfico 14, el 93\% de los líderes municipales elegidos tiene entre 0 a $5 \mathrm{Ha}$.; mostrando una alta correspondencia con la distribución del censo electoral, donde la mayoría de los productores también son pequeños. Producto de este análisis de distribuciones se concluye que existe una correspondencia por tamaño del productor.

En la categoría de tenencia del cultivo, se encontró que el 64,1\% de los líderes cafeteros municipales son dueños de su predio cafetero, siendo una participación mayor a la del censo electoral (54,4\%). Una implicación interesante es que los productores pueden estar votando más por aquellos que son dueños de su pre- 


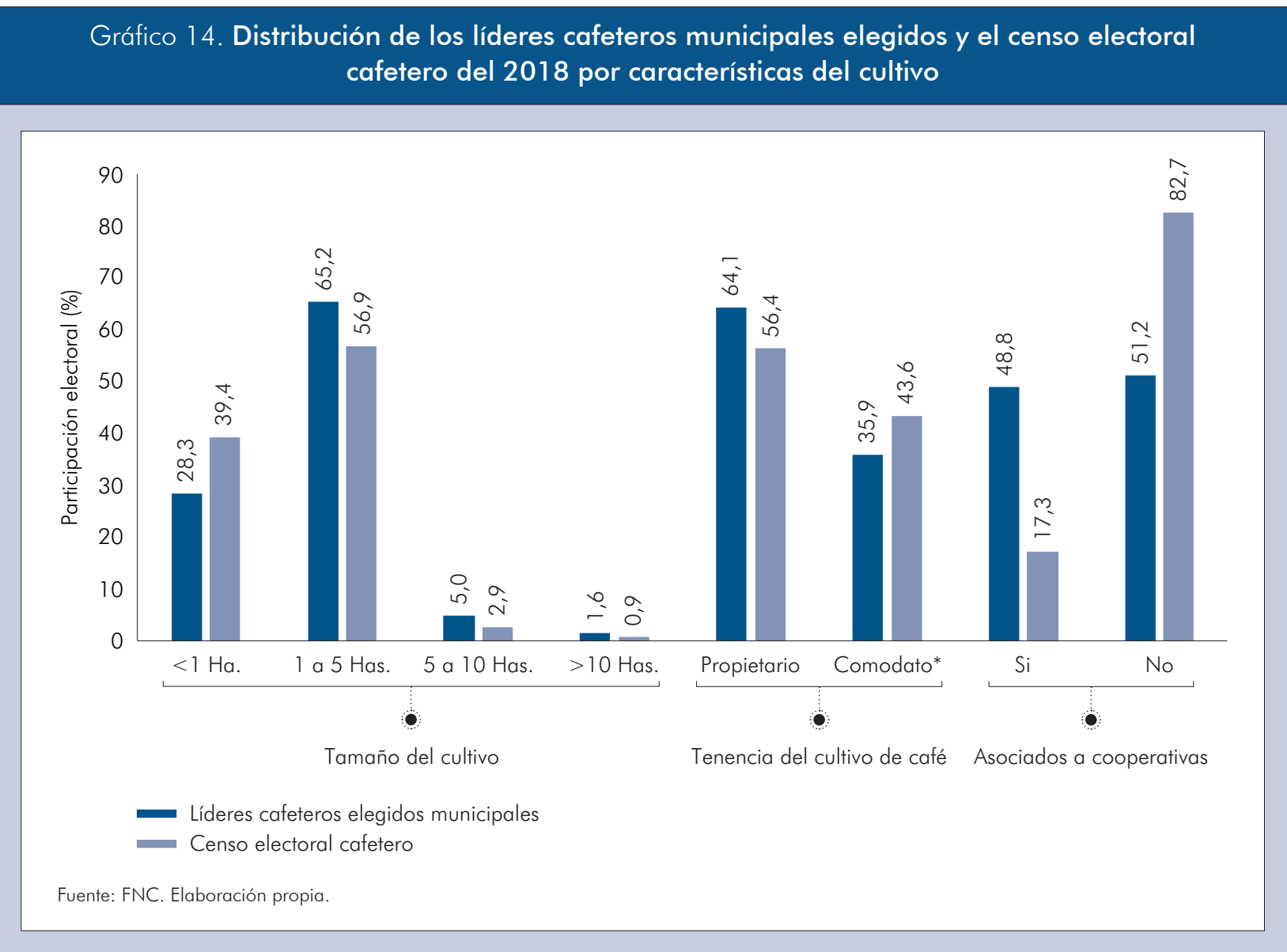

dio porque estos tienen un mayor arraigo en la comunidad y probablemente llevan más años involucrados en esta actividad productiva.

Sumado a lo anterior, se ratifica la estrecha relación que existe entre la FNC y las cooperativas (ver Gráfico 15). Mientras el 17\% del censo electoral está asociado a alguna cooperativa, esta proporción asciende al 49\% cuando se trata de los líderes cafeteros. Esto muestra, sin duda, que los líderes municipales tienen una relación estrecha con las cooperativas y esto a su vez se traduce en una tasa de participación más alta que el promedio para los productores involucrados con estas cooperativas.
Por otra parte, en cuanto a los líderes departamentales, se mantiene la correspondencia en cuanto al tamaño del cultivo, dado que $75 \%$ son pequeños caficultores (ver Gráfico 15). No obstante, también se observar cómo crece la participación en los tamaños del cultivo medianos.

Adicionalmente, se observa que el 67,6\% de los elegidos en los comités departamentales están asociados a alguna cooperativa y con esto se refuerza la idea que entre mayor es el nivel de poder, hay más participación de las cooperativas de caficultores en la dirección del gremio. 


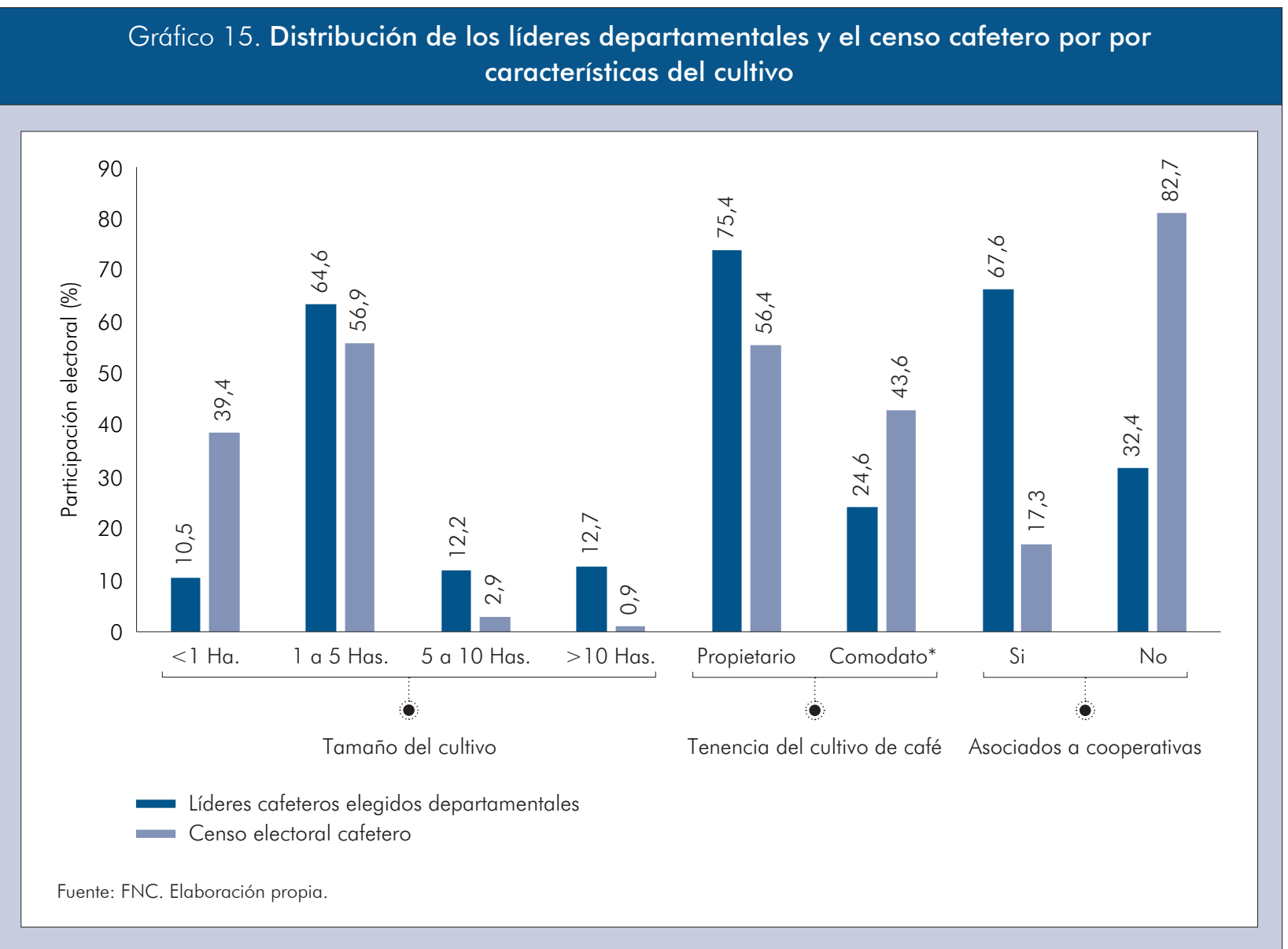

\section{CONCLUSIONES}

En este trabajo se identificaron los grupos poblaciones que tuvieron una menor participación en las elecciones cafeteras del 2018. Específicamente, aquellos que habitan en las cabeceras municipales, los jóvenes, los cafeteros que habitan en hogares en ambas colas de la distribución del puntaje Sisbén y los microfundistas $(<1 \mathrm{Ha})$. Del mismo modo, mediante un modelo logístico, se encontró que la probabilidad de participar en las elecciones aumenta si el productor se encuentra en alguna de las siguientes situaciones; habitar en la ruralidad dispersa, está asociado a alguna nicipio catalogado por riesgo electoral bajo o medio por la $\mathrm{MOE}$, y si es un productor que tiene entre 1 y $5 \mathrm{Ha}$.

También se encontró que variables como el número de caficultores por departamento, la inversión en proyectos y competencia electoral pueden explicar de manera parcial la asistencia de las urnas. No obstante, vale la pena señalar la necesidad de estudios complementarios que evalúen a fondo la dinámica de esta relación, así como también explorar el impacto sobre la participación electoral de otras variables no observables hasta el momento 
como los logros y dificultades que tienen los líderes electos en su actuar, y la efectividad de los mecanismos de rendición de cuentas.

Además, al evaluar las metas de paridad entre la comunidad y el gobierno electo se encontró una alta correspondencia por género, edad y tamaño del productor. La mayoría de los caficultores son hombres, con tamaño del cultivo pequeño y tienen entre 29 y 60 años, y en general, sus líderes municipales y departamentales comparten estas características. No obstante, hay algunos retos importantes, como lograr acercarse más a la meta de paridad por género e incentivar la mayor inclusión de los jóvenes cafeteros. Para alcanzar la meta de paridad se necesita incentivar a las mujeres a presentarse como candidatas, puesto que se encontró evidencia de que el productor no discrimina su voto por sexo. Así mismo, en este estudio también se hizo evidente el problema de relevo generacional que tiene la actividad cafetera. El problema no radica en que los productores no voten por los jóvenes candidatos, sino que en general existen pocos jóvenes dedicados a la actividad cafetera.

Por otra parte, de acuerdo con el estudio se hace evidente la necesidad de un esfuerzo de focalización para las elecciones cafeteras del 2022. Los departamentos Tolima, Cauca, Antioquia y Huila, necesitan un trabajo de atención especial para incentivar una mayor participación electoral. En estos cuatro se encuentra cerca del $58 \%$ de productores habilitados para votar y para el 2018 obtuvieron una participación electoral inferior a la nacional. De otra parte, tener presente que en 82 municipios se tienen alrededor de la mitad de los productores habilitados para votar y también obtuvieron una participación menor al promedio nacional. 


\section{REFERENCIAS BIBLIOGRAFICAS}

Barathe, R. (2019). 5 razones por las cuales la paridad es clave para las democracias de América Latina. Recuperado de https://lac.unwomen.org/es/ noticias-y-eventos/articulos/2019/1/5-razonespara-la-paridad-en-las-democracias

Charles-Leija, H., Torres García, A, y Colima Valadez, L. (2018). Características sociodemográficas del voto para diputados, 2015. Un análisis de econometría espacial, 8(17), 107-135. México: Revista El Colegio de San Luis.

Green, D., y Shapiro, I. (1994). Pathologies of rational choice theory: A critique of applications in political science. Estados Unidos: Yale University Press.

Hernández, A. E. (2019). Participación electoral en América Latina: un análisis comparado desde la simultaneidad de las elecciones, 2000-2018. Apuntes Electorales, 18(61), 11 -38.

Jann, B. (2008). The Blinder-Oaxaca decomposition for linear regression models. The Stata Journal, 8(4), 453-479.

Kostelka, F., Blais, A., \& Gidengil, E. (2019). Has the gender gap in voter turnout really disappeared? West European Politics, 42(3), 437-463.

Liiphart, A. (1997). Unequal participation: democracy's unresolved dilemma. American political science review, 91 (1), 1-14.
Merino, J. A. (2017). Análisis del perfil sociodemográfico de los votantes de Junts pel Sí.

Norris, P. (2004). Electoral engineering: Voting rules and political behavior. Reino Unido: Cambridge university press.

Orenday Tapia, M., y Tapia Tovar, E. (2018). ¿¿Qué factores intervienen en la participación de futuros ciudadanos? El caso de los estudiantes universitarios. La Democracia Cuestionada. Representación Política, Comunicación Y Democracia., 1. México: COMECSO.

Rosenstone, S. y Hansen, J. (1994) La lógica de la participación política en Política Social y participación ciudadana. México: MAC.

Stock, J. H., Watson, M. W., \& Larrión, R. S. (2012). Introducción a la Econometría.

Yann, B., \& Lina Vanessa, G. (2019). Radiografía del desencanto: La participación electoral en Colombia. Editorial Universidad del Rosario.

FNC (2021). Vulnerabilidad de los hogares cafeteros. Ensayos de economía cafetera, 34 . Federación Nacional de Cafeteros. 


\section{ANEXOS}

\section{Tabla A1. Resultados Modelo Logístico - Modelos 1 al 4}

\begin{tabular}{|c|c|c|c|c|}
\hline Variables & Modelo (1) & Modelo (2) & Modelo (3) & Modelo (4) \\
\hline \multirow[t]{2}{*}{ Género-Femenino } & $-0,0710^{* * *}$ & $-0,0708^{* * *}$ & $-0,0548^{* * *}$ & $-0,0418^{* * *}$ \\
\hline & $(0,00866)$ & $(0,00866)$ & $(0,00876)$ & $(0,00878)$ \\
\hline \multirow[t]{2}{*}{ Edad-Adulto } & $0,443^{* * *}$ & $0,444^{* * *}$ & $0,419^{* * *}$ & $0,368^{* * *}$ \\
\hline & $(0,0230)$ & $(0,0230)$ & $(0,0231)$ & $(0,0231)$ \\
\hline \multirow[t]{2}{*}{ Edad-Adulto Mayor } & $0,430^{* * *}$ & $0,433^{* * *}$ & $0,407^{* * *}$ & $0,337^{* * *}$ \\
\hline & $(0,0245)$ & $(0,0245)$ & $(0,0249)$ & $(0,0247)$ \\
\hline \multirow[t]{2}{*}{ Estado Civil-Sin pareja } & $-0,215^{* * *}$ & $-0,213^{* * *}$ & $-0,201^{* * *}$ & $-0,185^{* * *}$ \\
\hline & $(0,00853)$ & $(0,00852)$ & $(0,00861)$ & $(0,00863)$ \\
\hline \multirow[t]{2}{*}{ Educación-Primaria } & $0,0712^{* * *}$ & $0,0727^{* * *}$ & $0,0688^{* * *}$ & $0,0522^{* * *}$ \\
\hline & $(0,0123)$ & $(0,0123)$ & $(0,0124)$ & $(0,0124)$ \\
\hline \multirow[t]{2}{*}{ Educación-Secundaria/Media } & $-0,00883$ & $-0,0111$ & $-0,0193$ & $-0,0365^{* *}$ \\
\hline & $(0,0153)$ & $(0,0153)$ & $(0,0154)$ & $(0,0155)$ \\
\hline \multirow[t]{2}{*}{ Educación-Superior } & $0,125^{* * *}$ & $0,103^{* * *}$ & $0,0767^{* * *}$ & 0,0448 \\
\hline & $(0,0286)$ & $(0,0282)$ & $(0,0285)$ & $(0,0286)$ \\
\hline \multirow[t]{2}{*}{ Residencia-Centro Poblado } & $0,708^{* * *}$ & $0,717^{* * *}$ & $0,731^{* * *}$ & $0,697^{* * *}$ \\
\hline & $(0,0175)$ & $(0,0173)$ & $(0,0175)$ & $(0,0175)$ \\
\hline \multirow[t]{2}{*}{ Residencia-Rural Disperso } & $0,833^{* * *}$ & $0,848^{* * *}$ & $0,858^{* * *}$ & $0,811^{* * *}$ \\
\hline & $(0,0119)$ & $(0,0115)$ & $(0,0117)$ & $(0,0117)$ \\
\hline \multirow[t]{2}{*}{ SISBEN-Puntaje Bajo } & & $0,106^{* * *}$ & $0,103^{* * *}$ & $0,0903^{* * *}$ \\
\hline & & $(0,0107)$ & $(0,0108)$ & $(0,0109)$ \\
\hline \multirow[t]{2}{*}{ SISBEN-Puntaje Medio } & & $0,146^{* * *}$ & $0,137^{* * *}$ & $0,116^{* * *}$ \\
\hline & & $(0,0111)$ & $(0,0112)$ & $(0,0112)$ \\
\hline \multirow[t]{2}{*}{ SISBEN-Puntaje Alto } & & $0,163^{* * *}$ & $0,146^{* * *}$ & $0,110^{* * *}$ \\
\hline & & $(0,0119)$ & $(0,0121)$ & $(0,0121)$ \\
\hline \multirow[t]{2}{*}{ Tamaño-Productor Mediano } & & & $0,208^{* * *}$ & $0,137^{* * *}$ \\
\hline & & & $(0,00829)$ & $(0,00830)$ \\
\hline \multirow[t]{2}{*}{ Tamaño-Productor Grande } & & & $0,367^{* * *}$ & $0,161^{* * *}$ \\
\hline & & & $(0,0244)$ & $(0,0247)$ \\
\hline \multirow[t]{2}{*}{ Tenencia-Propietario } & & & $0,123^{* * *}$ & \\
\hline & & & $(0,0298)$ & \\
\hline \multirow[t]{2}{*}{ Tenencia-Otro Tipo } & & & $0,0567 *$ & \\
\hline & & & $(0,0300)$ & \\
\hline \multirow[t]{2}{*}{ Presencia Cafetera-Media } & & & $-0,000567$ & $-0,00611$ \\
\hline & & & $(0,0133)$ & $(0,0133)$ \\
\hline \multirow[t]{2}{*}{ Presencia Cafetera-Alta } & & & $-0,0313^{* *}$ & $-0,0293^{* *}$ \\
\hline & & & $(0,0144)$ & $(0,0145)$ \\
\hline \multirow[t]{2}{*}{ Puntaje SISBEN } & $0,0163^{* * *}$ & & & \\
\hline & $(0,00101)$ & & & \\
\hline \multirow[t]{2}{*}{ Puntaje Sisben al cuadrado } & $-0,000179^{* * *}$ & & & \\
\hline & $(1,38 \mathrm{e}-05)$ & & & \\
\hline \multirow[t]{2}{*}{ Asociado Cooperativa } & & & & $0,991^{* * *}$ \\
\hline & & & & $(0,0120)$ \\
\hline Observaciones & 299.604 & 299.604 & 294.499 & 299.604 \\
\hline
\end{tabular}

Errores Estándares en paréntesis

Se omiten de la tabla las variables de comité departamental y la constante

${ }^{* * *} p<0,01 i^{* *} p<0,05 ;^{*} p<0,1$ 


\begin{tabular}{|lc|}
\hline \multicolumn{2}{|c}{ Tabla A2. Estimación Logit para } \\
Modelo (5)
\end{tabular}

\begin{tabular}{|c|c|}
\hline Variables productivas y electorales & Modelo (5) \\
\hline \multirow[t]{2}{*}{ Tamaño-Productor Mediano } & $0,137^{* * *}$ \\
\hline & $(0,00831)$ \\
\hline \multirow[t]{2}{*}{ Tamaño-Productor Grande } & $0,161^{* * *}$ \\
\hline & $(0,0247)$ \\
\hline \multirow[t]{2}{*}{ Asociado Cooperativa } & $0,990 * * *$ \\
\hline & $(0,0120)$ \\
\hline \multirow[t]{2}{*}{ Participación Media Elecciones Consejo } & 0,0136 \\
\hline & $(0,0112)$ \\
\hline \multirow[t]{2}{*}{ Participación Alta Elecciones Consejo } & $0,139^{* * *}$ \\
\hline & $(0,0131)$ \\
\hline \multirow[t]{2}{*}{ Riesgo Electoral Medio } & $-0,261^{* * *}$ \\
\hline & $(0,0165)$ \\
\hline \multirow[t]{2}{*}{ Riesgo Electoral Alto } & $-0,0904^{* * *}$ \\
\hline & $(0,0159)$ \\
\hline \multirow[t]{2}{*}{ Riesgo Electoral Extremo } & 0,0161 \\
\hline & $(0,0249)$ \\
\hline Observaciones & 299.604 \\
\hline \multicolumn{2}{|l|}{ Errores Estándares en paréntesis. } \\
\hline \multicolumn{2}{|l|}{ Se omite la constante en la tabla. } \\
\hline \multicolumn{2}{|l|}{${ }^{* * *} p<0,01$; $^{* *} p<0,05 ;^{*} p<0,1$} \\
\hline
\end{tabular}




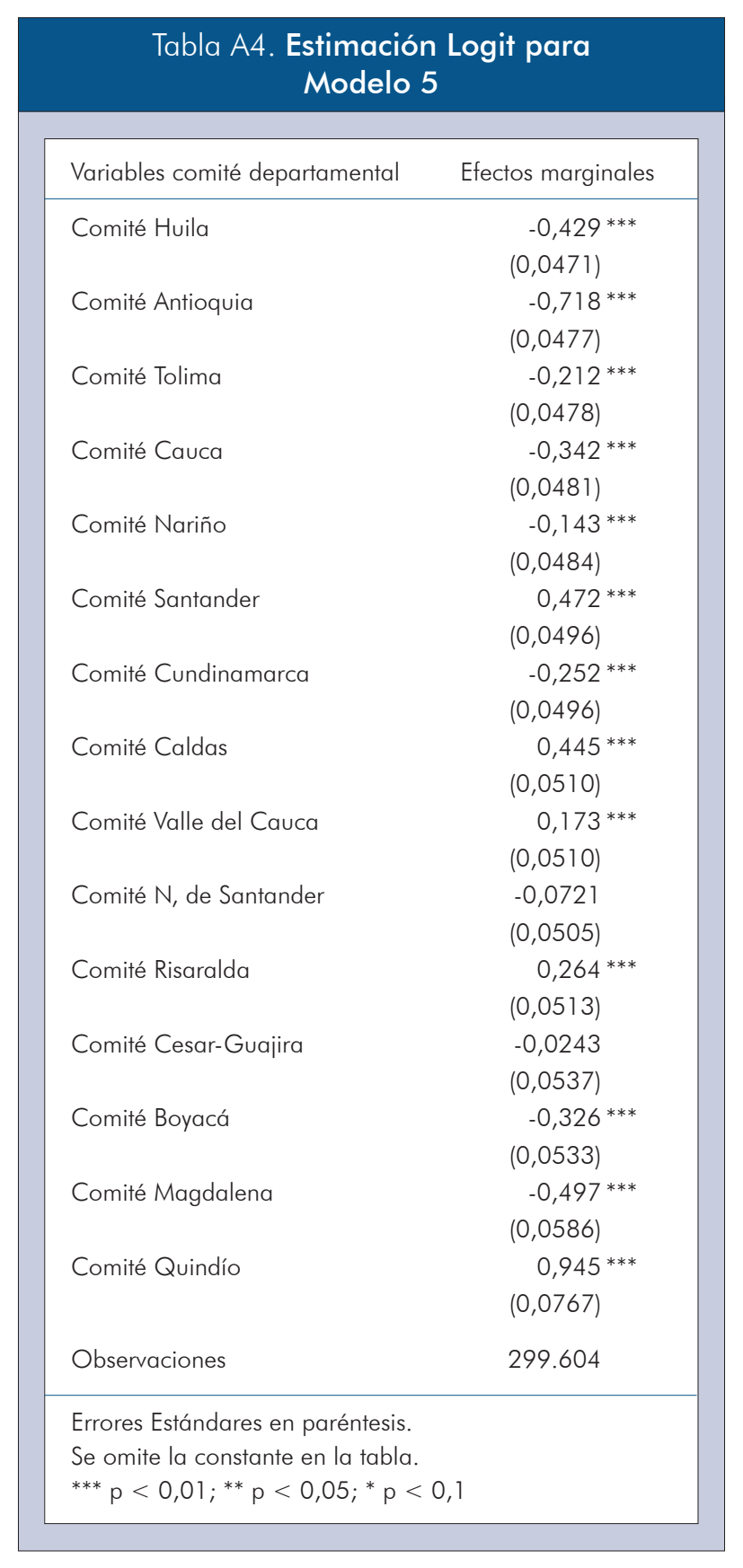





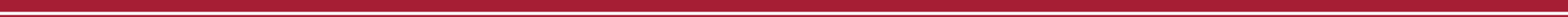

